\author{
Aus dem Fachbereich Medizin \\ der Johann Wolfgang Goethe-Universität \\ Frankfurt am Main \\ betreut am \\ Zentrum der Chirurgie \\ Klinik für Allgemein- und Viszeralchirurgie \\ Direktor: Prof. Dr. Wolf O. Bechstein
}

\title{
Ex-vivo Nachweis der Polarität zirkulierender Tumorzellen bei Patienten mit Hepatozellulärem Karzinom
}

\author{
Dissertation \\ zur Erlangung des Doktorgrades der Zahnmedizin \\ des Fachbereichs Medizin \\ der Johann Wolfgang Goethe-Universität \\ Frankfurt am Main
}

vorgelegt von

Babette Margarete Friedrich

aus Schorndorf

Frankfurt am Main, 2021 
Dekan:

Referent:

Korreferent/in:

Tag der mündlichen Prüfung:
Prof. Dr. Stefan Zeuzem

Prof. Dr. Wolf O. Bechstein

Prof. Dr. Oliver Waidmann

4. Juni 2021 
Meinen Eltern in Dankbarkeit 


\section{Inhaltsverzeichnis}

Abbildungsverzeichnis $\quad$ vii

Tabellenverzeichnis viii

Zusammenfassung $\quad$ ix

Abstract $\quad$ xi

1 Einleitung 1

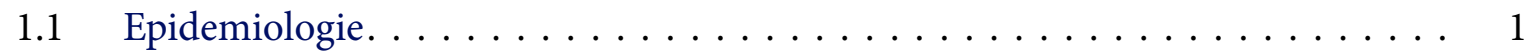

1.2 Ätiologie und Risikofaktoren . . . . . . . . . . . . . . . . . . 1

1.3 Diagnostik, Früherkennung und Prävention . . . . . . . . . . . 4

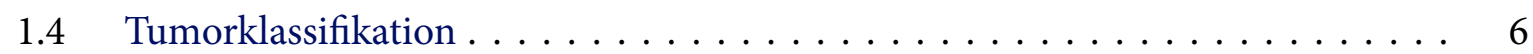

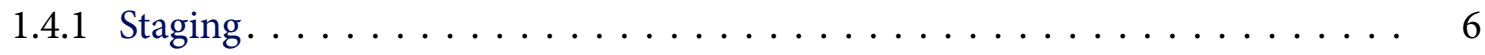

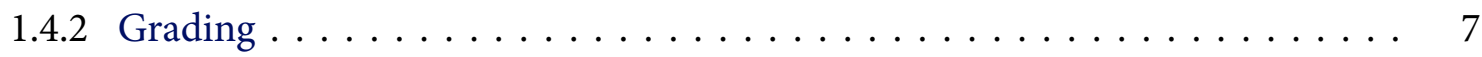

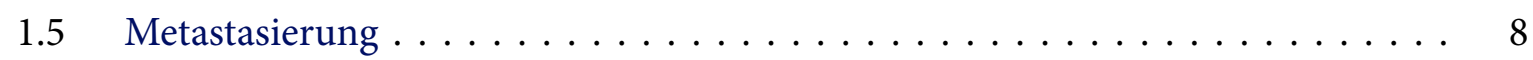

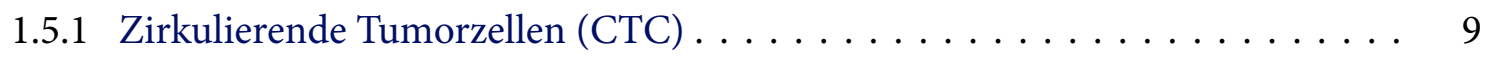

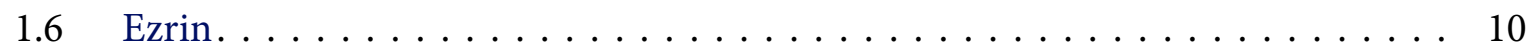

1.7 Ziel der Arbeit und Fragestellung $\ldots \ldots \ldots \ldots \ldots \ldots \ldots \ldots \ldots$

2 Patienten, Material und Methoden $\quad 13$ 
$2.1 \quad$ Patienten . . . . . . . . . . . . . . . . . . . . . . 13

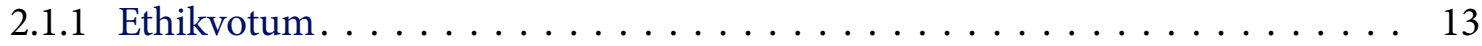

2.1.2 Patientenkollektiv. . . . . . . . . . . . . . . . . . 13

2.1 .3 Patientenproben. . . . . . . . . . . . . . . . . . . 14

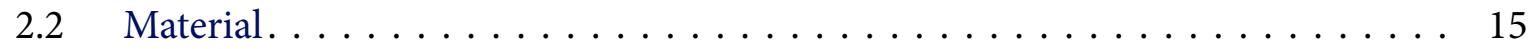

2.2.1 HepG2 Zelllinie . . . . . . . . . . . . . . . . . . . . . 15

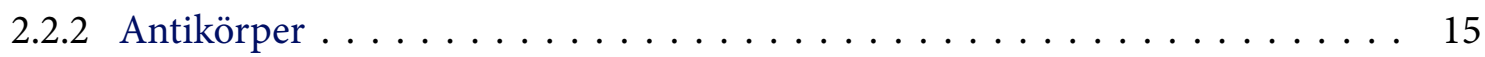

2.2 .3 Puffer und Lösungen. . . . . . . . . . . . . . . . . . . 16

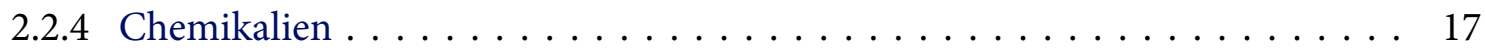

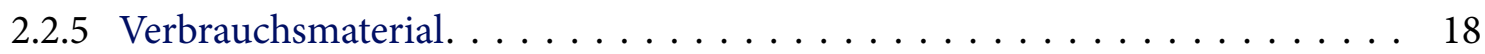

2.2 .6 Geräte . . . . . . . . . . . . . . . . . . . . . . . . . . 19

2.2 .7 Software . . . . . . . . . . . . . . . . . . . . . . . 19

2.3 Methoden ......................... 20

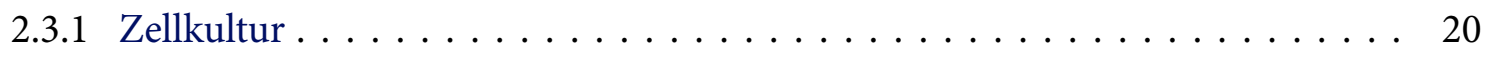

2.3.2 Isolation der CTCs mittels Oncoquick ${ }^{\circledR} \ldots \ldots \ldots \ldots \ldots \ldots \ldots$. . . . . . . 21

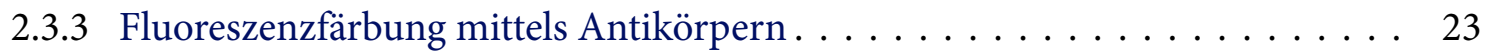

2.3.4 Detektion polarisierter CTCs mittels Fluoreszenzmikroskopie. . . . . . . . . 23

2.3.5 Spiking von Tumorzellen in Gesundblut . . . . . . . . . . . . . . . 24

2.3.6 Statistische Auswertung. . . . . . . . . . . . . . . . . . 24

3 Ergebnisse $\quad 26$

3.1 Methodenetablierung im Zellinienversuche $\ldots \ldots \ldots \ldots \ldots \ldots$

3.1.1 Protokolloptimierung im Spiking-Experiment . . . . . . . . . . . . 26

3.1.2 Nachweis der Polarisierung in HepG2 Zellinie . . . . . . . . . . . . . . . . 27

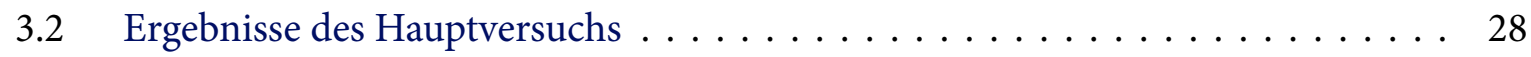

3.2 .1 Patientendaten. . . . . . . . . . . . . . . . . . . . 28

3.2.2 Detektion polarisierter CTC in Patientenproben . . . . . . . . . . . . . 32

3.2.3 Statistische Auswertung der Detektionsraten . . . . . . . . . . . . . . 35

3.2.4 Detektionsraten in Abhängigkeit von Tumorgröße und T-Stadium . . . . . . . . 37

3.2.5 Detektionsraten bei Patienten mit Fernmetastasen . . . . . . . . . . . . . 40

3.2.6 Detektionsraten in Abhängigkeit vom BCLC-Stadium . . . . . . . . . . . . . 41

3.2.7 Detektionsraten in Abhängigkeit vom Differenzierungsgrad . . . . . . . . . . 43

3.2.8 Assoziation der Detektionsraten mit der AFP-Serumkonzentration . . . . . . 45

3.2.9 NMLD-Gruppe: Sensitivität und Spezifität der Methode . . . . . . . . . . . . 47

4 Diskussion $\quad 50$ 


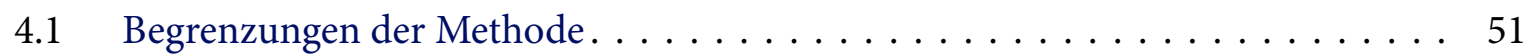

4.2 Diskussion der Ergebnisse . . . . . . . . . . . . . . . . . . . . 54

4.3 Schlussfolgerungen und Perspektiven . . . . . . . . . . . . . . . 59

$\begin{array}{ll}\text { Literaturverzeichnis } & 62\end{array}$

$\begin{array}{ll}\text { Abkürzungsverzeichnis } & 71\end{array}$

$\begin{array}{ll}\text { Danksagung } & 73\end{array}$

$\begin{array}{ll}\text { Schriftliche Erklärung } & 74\end{array}$

$\begin{array}{ll}\text { Lebenslauf } & 75\end{array}$ 


\section{Abbildungsverzeichnis}

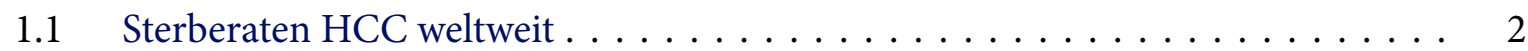

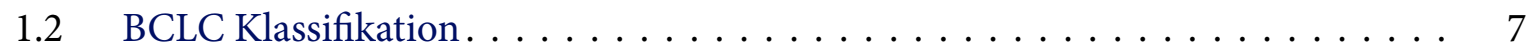

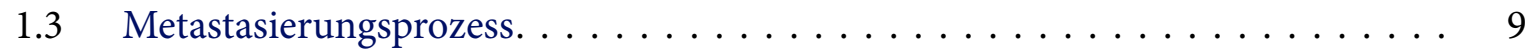

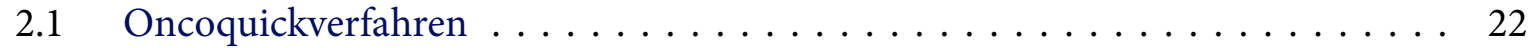

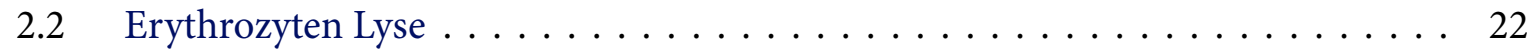

3.1 Protokolloptimierung im Spikingexperiment. . . . . . . . . . . . . . . . 26

3.2 Protokolloptimierung: Ablauf vorher vs. nachher . . . . . . . . . . . . . 27

3.3 Vergleich polarisierter vs. unpolarisierter HepG2 Zellen . . . . . . . . . . . . 27

3.4 Polarisierung in der HepG2 Zelllinie . . . . . . . . . . . . . . . . . . 28

3.5 Altersverteilung. . . . . . . . . . . . . . . . . . . . . . . . . . 29

3.6 Ätiologie des HCC . . . . . . . . . . . . . . . . . . 30

3.7 Färbeintensität Anti-Ezrin-Alexa Fluor $488^{ø} \ldots \ldots \ldots \ldots \ldots \ldots \ldots$

3.8 Exemplarische Polarisierung in einer Patientenprobe . . . . . . . . . . . 33

3.9 Exemplarische Polarisierung aller Patientenproben. . . . . . . . . . . . . . 34

3.10 Wiederfindungsraten aller CTCs/ml vs. p-CTCs/ml . . . . . . . . . . . . 35

3.11 Detektionsraten der CTCs und p-CTCs in Bezug auf das Tumorstadium des Patienten . . . . . . . . . . . . . . . . . . . . . . . . 37

3.12 Anzahl CTCs in Bezug auf das Tumorstadium. . . . . . . . . . . . . 38

3.13 Detektionsraten der CTCs und p-CTCs in Bezug auf die Tumorgröße . . . . . . 38

3.14 Anzahl CTCs in Bezug auf die Tumorgröße . . . . . . . . . . . . . . . . . . 39

3.15 Anzahl CTCs vs. p-CTCs in Bezug auf das BCLC-Stadium . . . . . . . . . . . 41

3.16 Anzahl CTCs in Bezug zum BCLC-Stadium . . . . . . . . . . . . . . . 42

3.17 Anzahl CTCs in Bezug zum Differenzierungsgrad . . . . . . . . . . . . . . 44

3.18 Anzahl CTCs in Bezug zum Differenzierungsgrad . . . . . . . . . . . . . . . . 44

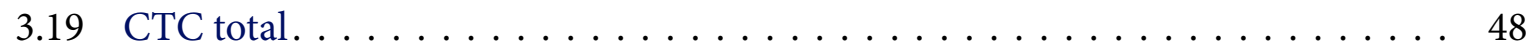

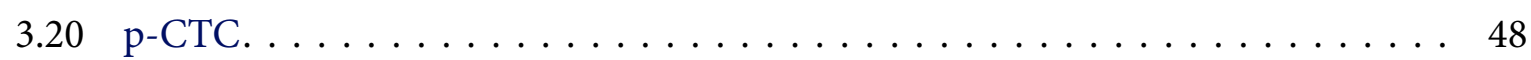




\section{Tabellenverzeichnis}

1.1 Risikofaktoren HCC . . . . . . . . . . . . . . . . . . 4

1.2 HCC Hochrisikogruppen . . . . . . . . . . . . . . 5

1.3 TNM Klassifikation . . . . . . . . . . . . . . . . . . 6

1.4 Grading .............................. 8

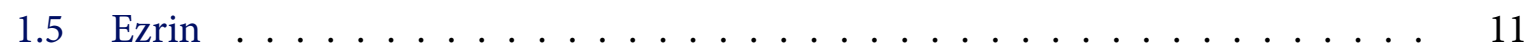

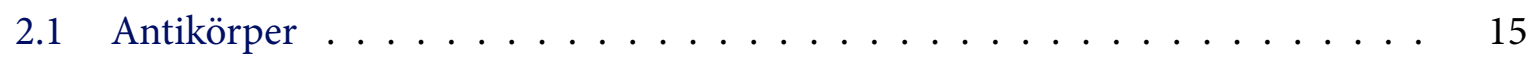

2.2 Puffer und Lösungen . . . . . . . . . . . . . . . . . . . . . 16

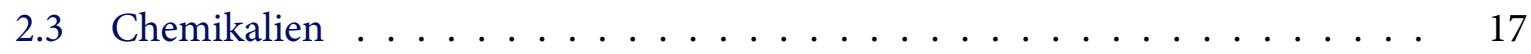

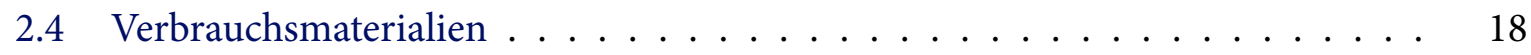

2.5 Geräte . . . . . . . . . . . . . . . . . . . . . 19

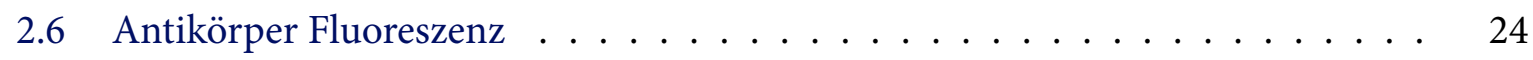

3.1 Demografische Übersicht . . . . . . . . . . . . . . . . . . 31

3.2 Übersicht HCC Patientendaten . . . . . . . . . . . . . . . . . 36

3.3 Übersicht NMLD Patientendaten . . . . . . . . . . . . . . . . 36

3.4 Übersicht spezieller Patientendaten . . . . . . . . . . . . . . . . . . . 37

3.5 Anzahl CTCs in Bezug auf die Tumorgröße . . . . . . . . . . . . . . . . 39

3.6 Anzahl CTCs in Bezug auf den M1-Status . . . . . . . . . . . . . . . . . 40

3.7 Anzahl CTCs in Bezug auf den V-Status . . . . . . . . . . . . . . . 40

3.8 Anzahl CTCs in Bezug zum BCLC-Stadium . . . . . . . . . . . . . . . 43

3.9 Anzahl CTCs in Bezug zum Differenzierungsgrad . . . . . . . . . . . . . 45

3.10 Labormesswerte . . . . . . . . . . . . . . . . . . . 46

3.11 Statistik:AFP-Werte HCC-Gruppe . . . . . . . . . . . . . . 47

3.12 Statistik:AFP-Werte NMLD-Gruppe . . . . . . . . . . . . . 47 


\section{Zusammenfassung}

Das Hepatozelluläre Karzinom (HCC) steht weltweit an dritter Stelle tumorbedingter Todesursachen. Eine kurative Therapie durch Leberresektion oder Transplantation ist nur dann Erfolg versprechend, wenn der Patient in einem frühen Stadium diagnostiziert wird, in dem noch keine Fernmetastasen oder Gefäßinvasionen vorliegen. Die Ausbildung von Mikrometastasen sind mittels Bildgebung nicht detektierbar.

Mit Hilfe der „liquid biopsy“, einem Blutanalyseverfahren, das sich auf die Detektion zirkulierender Tumorzellen (CTCs) im Patientenblut fokussiert, ist es möglich, diese Tumorzellen im Anschluss an ihre Isolation auf ihre molekularen Eigenschaften hin zu untersuchen. Im Laufe des Metastasierungsprozesses kommt es zur De- und Repolarisierung der CTCs.

In der vorliegenden Promotionsarbeit wurde ein immunologisches Verfahren zur Detektion polarisierter Tumorzellen (p-CTCs) im Blut von Patienten mit HCC entwickelt. Dazu erfolgte zunächst die Isolation der CTCs mittels Dichtegradientverfahren (Oncoquick@, Fa. Greiner bio-one) und die anschließende Immunfluoreszenzfärbung der CTCs mittels Anti-Ezrin-AlexaFluor $488^{\circledR}$ zum strukturellen Nachweis des zytoskelletalen Membranproteins Ezrin.

Anhand der Lokalisation des Ezrin innerhalb der CTCs war es möglich, die CTCs in polarisierte (p-CTC) und nicht-polarisierte Zellen (non-polarized CTC) zu unterteilen. Mit diesem Verfahren konnten in einem Zeitraum von Juni 2018 bis Januar 2019 Blutproben ( $5 \mathrm{ml} /$ Patient) von 15 Patienten mit HCC und von 10 Patienten mit einer nicht malignen Lebererkrankung (NMLD) untersucht werden.

Die häufigste Grunderkrankung war mit 30,43\% (n=7) C2 Abusus, gefolgt von der NASH mit 26\% (n=6) und DM Typ 2 mit Leberzirrhose mit 13,04\% (n=2). 10 (66,6\%) HCC-Patienten hatten eine Leberzirrhose. Bei einem Patienten war die Tumorgröße $<2 \mathrm{~cm}$, bei 7 Patienten zwischen 2-5 cm, und 7 Patienten hatten eine Tumorgröße von $>5 \mathrm{~cm}$. Die meisten Patienten hatten ein BCLC-Stadium C ( $n=7)$, gefolgt von BCLC-Stadium B $(n=4)$, und BCLC-Stadium D ( $n=3)$ und nur ein Patient hatte ein BCLC-Stadium 0.

In 14 (93,3\%) HCC-Patienten konnten CTCs 1,2 CTCs/ml (0,4-3 CTCs/ml) nachgewiesen werden. Die Falsch-Positiv-Rate lag bei 0,2 isolierte Zelle/ml (p=0,0006). P-CTC konnten in 10/14 (71\%) HCC-Patienten identifiziert werden. Die HCC-Gruppe wies mit 0,42 p-CTCs/ml signifikant mehr p-CTCs als die NMLD-Patienten $(0$-CTCs/ml, $\mathrm{p}=0,002)$.

Eine negative Korrelation fand sich zwischen der Tumorgröße, BCLC-Stadium und der Anzahl polarisierter CTCs $(\mathrm{r}=-0,029, \mathrm{p}=\mathrm{ns})$. 
Die hier vorgestellten Daten zum Nachweis der Polarisierung von CTCs in Zusammenhang mit HCC könnten zukünftig eine Rolle in der molekularen Charakterisierung von CTCs und der Diagnose des HCC darstellen. 


\section{Abstract}

Hepatocellular carcinoma (HCC) is known as one of the most common cancers in the world. Approximately 600.000 people die of it worldwide every year. As of today there is no precise method for early diagnosis and the true extend of the disease is often underestimated.

Early detachment of circulating tumor cells (CTCs) from the primary tumor play a key role in the silent progress of the tumor leading to metastasis and thereby metastasis correlated death. Throughout this process, also known as epithelial mesenchymeal transition (EMT), the CTCs establish a distinct type of polarity. Polarity is defined by the intrinsic presence of an Ezrin-rich pole.

Current studies demonstrate that the polarity of CTCs is observed in different tumor entities. It is directly involved in early attachment of the CTCs and thus affects adhesion, transmigration, and metastasis.

In this study, we characterized and enumerated the number of polar CTCs in the peripheral blood of patients with HCC for the first time. Therefore $5 \mathrm{ml}$ of EDTA blood sample was obtained from HCC patients $(n=15)$ and compared to a control cohort $(n=10)$ with non-malignant liver disease (NMLD). The blood was then stored for transport in EDTA-tubes for a maximum of 30 minutes.

Then, the CTCs were isolated using the Oncoquick ${ }^{\bowtie}$ - System (Greiner, bio-one, Frickenhausen, Germany). After isolation of the CTCs, immunostaining of the cells was performed. The CTCs were transfered on slides according to manufacturer's instructions, fixed and incubated in an antybody cocktail consisting of Ezrin Fluor $488^{\circledR}$, CD146-PE, CD45-APC, and DAPI. The slides were then analyzed on a Zeiss Axio Oberserver.Z1 microscope using a 40x objective (Carl Zeiss $\mathrm{GmbH}$, Jena).

The most common underlying disease was with 30,43\% ( $n=7)$ alcohol abuse followed by Nonalcoholic-liver disease (NASH) with 26\% $(n=6)$ and DM Typ 2+livercirrhosis in 13,04\% $(n=2)$ of the patients. 10 (66\%) of the HCC-patients were suffering from a livercirrhosis.

The tumor size varied between $<2 \mathrm{~cm}(\mathrm{n}=1), 2-5 \mathrm{~cm}(\mathrm{n}=7)$ and $<5 \mathrm{~cm}(\mathrm{n}=7)$. Most of the patients could be categorized in BCLC-Stadium C $(n=7)$ followed by BCLC-Stadium B $(n=4)$ and BCLCStadium D ( $\mathrm{n}=3)$ only one Patient was BCLC Stadium 0.

CTCs $(1,2$ CTCs/ml) were detected In $14(93,3 \%)$ HCC patients. The false positivity rate was $0,2 \mathrm{CTCs} / \mathrm{ml}$ ( $\mathrm{p}=0,0006)$. P- CTCs were found in 10/14 (71\%) HCC patients. Consequently the HCC Group shows with $0,42 \mathrm{p}$-CTCs/ml significantly more $\mathrm{p}$-CTCs then the NMLD-Group (0 $\mathrm{p}-\mathrm{CTCs} / \mathrm{ml})(\mathrm{p}=0,002)$. 
A negative correlation between the tumor size, the BCLC Stadium and the number of p-CTCs $(\mathrm{r}=-0,029, \mathrm{p}=\mathrm{ns})$ was found.

Overall Ezrin-polarized CTCs are detectable in the blood of HCC patients by the established method. The findings have provided evidence of the EMT-like phenomenon in the isolated CTCs. However, the role of an Ezrin-rich pole remains unclear.

The presented preliminary results for the detection of polarized CTCs could play a major role in the future study of molecular characterization of CTCs in the context of liver cancer and offer new ways in the diagnosis of HCC. Further studies could provide information of its importance on the clinical outcome of the patients. 


\section{Einleitung}

\subsection{Epidemiologie}

Mit weltweit jährlich etwa 841.000 Neuerkrankungen und 782.000 Todesfällen stellt das Hepatozelluläres Karzinom (HCC) die vierthäufigste tumorbedingte Todesursache und den sechsthäufigsten diagnostizierten malignen Tumor dar. ${ }^{1}$ Besonders betroffen sind dabei Nord-und Westafrika sowie Ost-und Südost-Asien.

In diesen Regionen ist das HCC die häufigste Ursache für Tumorerkrankungen. ${ }^{2}$ Während das durchschnittliche Erkrankungsalter in Industrieländern bei 65 Jahren liegt, ${ }^{2}$ sind vor allem in den genannten Regionen häufiger auch jüngere Menschen unter 45 Jahren betroffen. ${ }^{3}$ Erklären lässt sich dieser Unterschied durch eine unterschiedliche Exposition mit bekannten Risikofaktoren wie den viralen Hepatiden.

Für Deutschland liegen dazu Zahlen aus dem Jahr 2016 vor. Das HCC zeigt sich hier aktuell als eine der wenigen Krebsarten mit einer steigenden Inzidenz und Mortalität. Von jährlich 9.000 Neuerkrankungen versterben 7.500 Patienten, wobei das relative 5-Jahres-Überleben mit $14 \%$ angegeben wird. ${ }^{4}$ Das Risiko für Männer, an einem HCC zu erkranken, liegt dabei weltweit um das vier bis zehnfache über dem für Frauen, ${ }^{2}$ was auch dem deutschlandweiten Trend entspricht.

\section{2 Ätiologie und Risikofaktoren}

In 90 \% aller Fälle ist die Leberzirrhose hauptursächlich für die Entstehung eines HCC und ist damit als Präkanzerose einzustufen. Die Zirrhose entsteht auf dem Boden von Leberzellnekrosen und bindegewebigen Umbauprozessen in der Leber.

Dies kann verschiedene Ursachen haben wie die chronische Hepatitis B oder Hepatitis C Infektionen ${ }^{5}$ jahrelanger Alkoholmissbrauch, die Nichtalkoholische Fettlebererkrankung (NAFLD), ${ }^{6}$ sowie durch Vererbung erworbene Lebererkrankungen wie die hereditäre Hämochromatose, ein Alpha 1 Antitrypsinmangel, die Glykogenspeicherkrankeit Typ 1, ein Morbus Wilson oder die hereditäre Tyrosinämie. ${ }^{5}$

Zwar konnte durch präventive Maßnahmen wie die Hepatitis B Virus (HBV) Schutzimpfung eine drastische Senkung der Prävalenz von HCC in den Hochrisikoregionen wie zum Beispiel Ost-Asien erreicht werden, jedoch gibt es nach wie vor keine Immunisierung gegen das Hepatitis C Virus (HCV). ${ }^{7}$ Kritisch betrachtet werden muss, dass vor allem die ärmeren Regionen dieser 
A
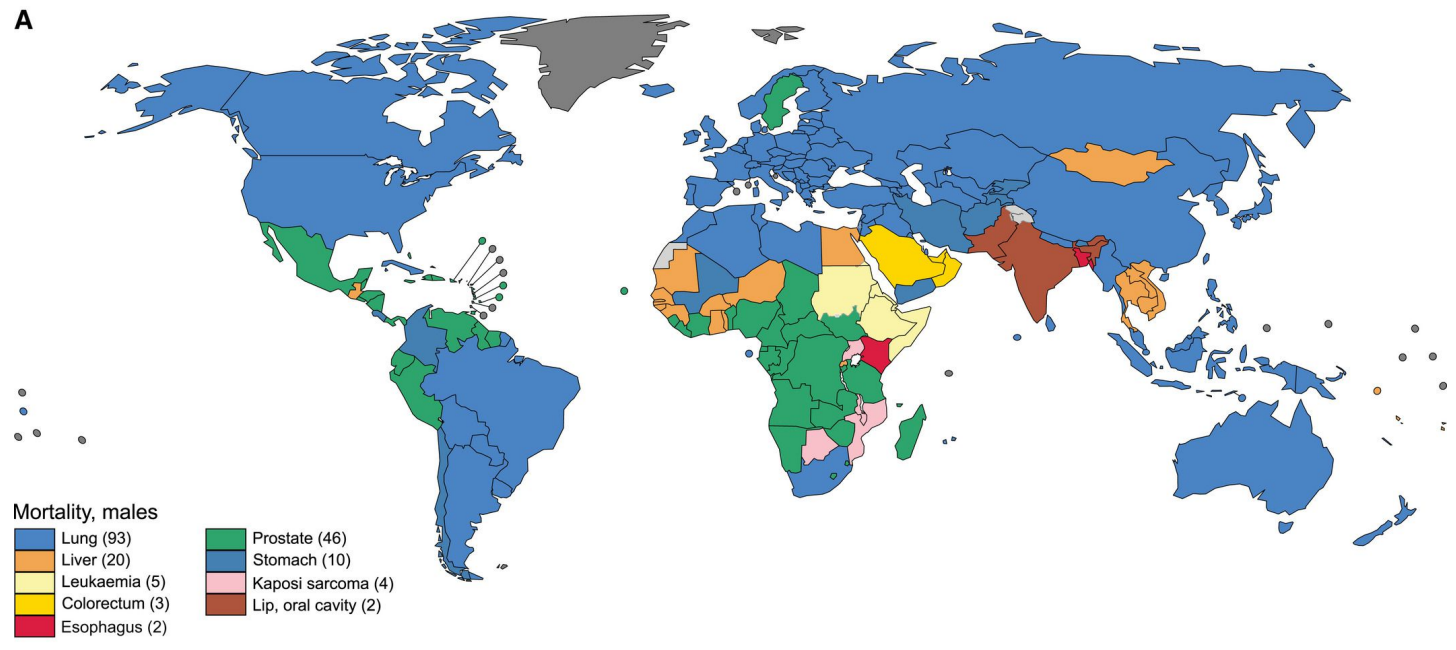

B

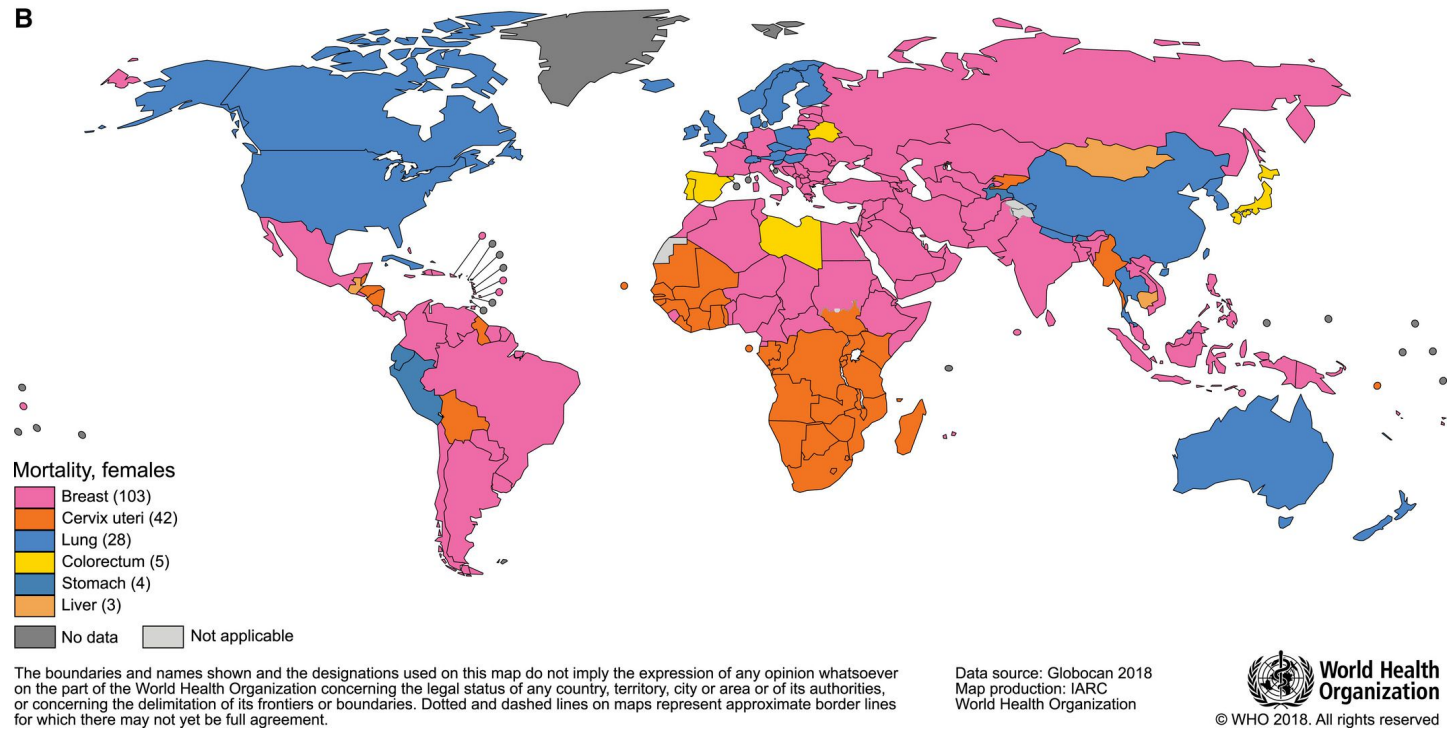

Abbildung 1.1: Die Abbildung zeigt (orange) die Länder, in denen das HCC an erster Stelle für tumorbedingte Todesursachen steht. So sterben vor allem Männer (oben) am zweithäufigsten durch das HCC, wohingegen es bei Frauen (unten) die sechsthäufigste tumorbedingte Todesursache ist. ${ }^{2}$

Welt betroffen sind. Dies ist in erster Linie auf die schlechteren Hygienebedingungen in diesen Regionen zurückzuführen, was die Prävalenz von Virusinfektionen wie z.B. HBV und HCV begünstigt. ${ }^{8}$

Damit sind die viralen Hepatiden, besonders das HCV, weltweit gesehen immer noch hauptursächlich für die Entstehung einer Leberzirrhose. ${ }^{9}$ In bis zu 50-80 \% der Fälle führt dieses parenteral übertragbare Virus zu einer chronischen Erkrankungen, als deren Spätfolge sich das Risiko an einem HCC zu erkranken auf bis zu 13,4 \% in 5 Jahren erhöht. ${ }^{10}$

Die Entstehung einer Leberzirrhose ist, wie die meisten Erkrankungen, als ein multifaktorielles Geschehen zu betrachten. So wurde nachgewiesen dass vor allen Dingen eine Kombination aus HCV und einem Alkoholkonsum von mehr als $80 \mathrm{~g}$ pro Tag oder ein moderater Alkoholkonsum bei gleichzeitigem Vorliegen einer Diabetes Mellitus Typ 2 (DM Typ 2)-Erkrankung, das Risiko an einem HCC zu erkranken um das 3,5-fache erhöht. ${ }^{11}$ 
Eine hohe Inzidenz zeigt die äthyltoxisch Leberzirrhose dabei in Europa und den USA, wohingegen Asien und Afrika hier eine eher untergeordnete Rolle für die Entstehung eines HCC, spielen. ${ }^{12}$ Dabei führt der missbräuchliche Konsum von Alkohol in circa 4-38 \% aller Fälle zu einer Erkrankungen an HCC . ${ }^{13}$

Besonders betrachtet werden sollte die nicht-alkoholische Fettlebererkrankung, da sie mit einer globalen Prävalenz von aktuell 25,2 \%, mit steigener Inzidenz, als eine der Hauptverursacher für chronische Lebererkrankungen anzusehen ist. Durch eine Fettspeicherstörung in den Leberzellen wird die Entstehung einer Fibrose, durch eine Entzündungsreaktion, begünstigt. Bereits heute ist sie in den USA eine der Hauptindikationen für die Durchführung einer Lebertransplantation. ${ }^{14,15}$

In einer aktuellen Modellstudie wurde die Prävalenz einer NAFLD für das Jahr 2030 mit einem Zuwachs von 63 \% berechnet. Dies hat zur direkten Folge dass sich auch das Risiko, dadurch an einem HCC zu erkranken, um 137 \% erhöht. ${ }^{16}$

Dieser Trend lässt sich nachvollziehen, wenn man berücksichtigt, dass die NAFLD mit dem metabolischen Syndrom assoziiert ist. Merkmale sind Übergewicht, ein DM Typ 2, Bluthochdruck und eine Hypercholesterinämie. Zunehmend mehr Menschen leiden an Übergewicht und entwickeln in Folge dessen ein metabolisches Syndrom. ${ }^{17}$ Bei $94 \%$ der Fettleibigen, definiert durch einen Body Mass Index (BMI) > 30, kann eine NAFLD nachgewiesen werden.

Ausgehend von einer NAFLD entwickeln durch entzündliches Fortschreiten der Erkrankung wiederum $25 \%$ der Patienten eine Nichtalkoholische Steatohepatitis (NASH). ${ }^{18}$ Von diesen 25 \% münden $11 \%$ in einer Leberzirrhose. Das Risiko an einem HCC zu erkranken, liegt dann bei jährlich 2,6 \%. ${ }^{19}$ Die S3-Leitlinie stuft daher auch Patienten, die bei DM Typ 2 gleichzeitig an einem metabolischen Syndrom und einer NASH erkrankt sind, als Hochrisikopatienten für HCC ein. ${ }^{20,21}$

Erwähnenswert ist auch eine Studie der Mainzer Universitätsmedizin, in der ein Zusammenhang mit dem auf einer NASH basierenden HCC-Erkrankung und der erhöhten Häufigkeit der Metastasierung aufgedeckt wurde. ${ }^{22}$

Das Aflatoxin ist ein Pilzgift und stammt aus dem Schimmelpilz Aspergillus flavus. Besonders gefährlich ist das Aflatoxin B1 (AFB1), das sich durch unsachgemäße Lagerung in Mais, Weizen, Soja oder Reis bildet. ${ }^{23}$ Dies betrifft in erster Linie Entwicklungsländer, wo eine trockene und saubere Lagerung des Getreides oft nicht möglich ist.

Es wurde nachgewiesen, dass eine tägliche Aufnahme von $10 \mu \mathrm{g}$ pro Kilogramm Körpergewicht eine karzinogene und akut hepatotoxische Wirkung zeigen. In Regionen mit hoher Aflatoxin-Kontamination der Nahrung konnten vermehrt Punktmutationen des p53Tumorsuppressorgens im HCC nachgewiesen werden. ${ }^{24}$ 
Man geht davon aus, dass 4,6-28,2 \% aller HCC-Erkrankungen weltweit auf das über die Nahrung aufgenommene Karzinogen AFB1 zurückzuführen sind. ${ }^{25}$ Eine Hochrisikogruppe stellen dabei Personen dar, die zusätzlich an einer chronischen HBV erkrankt sind. Ihr Risiko, im Laufe des Lebens an einem HCC zu erkranken, ist um das 30 -fache gesteigert. ${ }^{26}$

Zur besseren Übersicht wurden die Hauptrisikofaktoren in Tab. 1.1 zusammengefasst.

\begin{tabular}{lll}
\hline hohes Risiko & mittleres Risiko & geringes Risiko \\
\hline HCV+Zirrhose & HBV & Alpha 1 Antitrypsinmangel \\
HBV+Zirrhose & HCV & Glykogenspeicherkrankheit Typ1 \\
$\begin{array}{l}\text { Diabetes mellitus Typ 2 + NASH + NASH } \\
\text { Metabolisches Syndrom }\end{array}$ & Morbus Wilson \\
$\begin{array}{l}\text { Diabetes mellitus Typ 2 + äthyltoxi- } \\
\text { sche Leberzirrhose }\end{array}$ & äthyltoxische Zirrhose \\
& & \\
& Aflatoxine & \\
\hline
\end{tabular}

Tabelle 1.1: Ein erhöhtes Risiko, an HCC zu erkranken, zeigen vor allem Patientengruppen, die eine Komorbidität aufweisen. Das HCC lässt sich nur schwer auf einen ätiologischen Faktor zurückführen. In den meisten Fällen liegt jedoch eine Leberzirrhose zu Grunde.

\subsection{Diagnostik, Früherkennung und Prävention}

Klinisch zeigt sich das HCC lange symptomlos. Dabei variieren die oft erst spät auftretenden Symptome stark. In 91 \% der Fälle wird der Patient mit Oberbauchbeschwerden vorstellig, in einer späten Phase der Erkrankung zeigen sich Symptome einer dekompensierten Leberzirrhose mit Gelbsucht oder einer Aszites. Stellt sich der Patient mit diesen typisch onkologischen Symptomen vor, befindet sich das HCC bereits in einem fortgeschrittenen Stadium. Die 5-Jahres Überlebensrate liegt dann nur noch bei etwa 0-10\%. ${ }^{27}$

Leider werden Leberzellkarzinome oft auch nur zufällig oder im Rahmen sonographischer Screening-Untersuchungen entdeckt. Sonographisch ist es möglich, $90 \%$ der über $2 \mathrm{~cm}$ großen HCC nachzuweisen. Im Rahmen von Früherkennungsuntersuchungen der Hochrisikogruppen war es in den letzten 20 Jahren möglich, die Entdeckungsquote von ursprünglich $5 \%$ der Läsionen auf über $30 \%$ zu steigern. ${ }^{28}$ An diesen Ergebnissen orientiert sich die Empfehlung der European Association of the Study of the Liver (EASL), die eine Sonographie der Leber für die in Tab. 1.2 genannten Risikogruppen im Abstand von 6 Monaten empfiehlt. 
Hochrisikogruppen

Zirrhose, Stadium Child Pugh A oder B

Zirrhose, Stadium Child Pugh C, Patient auf Warteliste zur Lebertransplantation

Chronische HBV-Infektion ohne Zirrhose im aktiven Stadium

Chronische HBV-Infektion und positive Familienanamnese für HCC

HCV-assoziierte Zirrhose

Tabelle 1.2: Eine regelmäßige Überwachung mittels bildgebender Verfahren wird bei den gelisteten Patientengruppen empfohlen

Das Mittel der Wahl zur nicht-invasiven Diagnostik eines HCC ist mit einer Sensitivität von 100 $\%$ die kontrastmittelverstärkte Magnetresonanztomographie (MRT). Hier können selbst kleinere Knoten von 0,5-2 cm Größe entdeckt werden. Als beweisend gilt hier das typische Kontrastverhalten des Tumors mit einer führarteriellen Hypervaskularisation und den später folgenden Wash-Out Phänomen, wobei es im Bild zur Kontrastumkehr kommt. Eine Diagnosesicherheit von circa $90 \%$ ist bei einem solchen Verhalten des Tumors zu erwarten. ${ }^{29}$

Die Diagnose HCC kann nach aktuellen AASLD-Leitlinien und der S3-Leitlinie dann gestellt werden, wenn die im bildgebenden Verfahren (4-Phasen Multidetektor Computertomographie (CT) oder kontrastmittelverstärktes MRT) gezeigte Raumforderung größer als $1 \mathrm{~cm}$ ist und entsprechende Bildcharakteristika(arterielle Hyperperfusion, venöser Wash-out) aufweist. ${ }^{30}$

Der Tumormarker Alpha-Feto Protein (AFP) spielt aufgrund seiner unzureichenden Sensitivität und Spezifität bei der Diagnosesicherung nur noch eine untergeordnete Rolle und kann nicht zur primären Diagnostik eingesetzt werden. Die Expression des AFP ist dabei nicht HCC-spezifisch und kann ebenfalls bei Vorliegen anderweitiger chronischer Lebererkrankungen, beispielsweise einer Leberzirrhose, erhöht sein. ${ }^{31}$

Das AFP eignet sich daher vor allem zur Therapie- und Verlaufskontrolle nach histopathologisch gesichertem HCC. Ein Wiederanstieg des Wertes nach vorherigem Abfall lässt auf eine rezidivierende Erkrankung schließen. ${ }^{32}$

Diagnostisch relevanter als das AFP zeigt sich nach aktueller Studienlage der Entzündungsmediator Interleukin-6 (IL-6). ${ }^{33}$ Die fibrotischen Umbauprozesse der Leber stellen genau genommen einen wiederkehrenden entzündlichen Prozess dar, bestehend aus ständiger Regeneration der Hepatozyten. IL-6 wird in den Kupffer-Sternzellen der Leber gebildet und induziert die kompensatorische Proliferation der Hepatozyten.

Dieser persistierende Kreislauf aus Zellproliferation bildet die Grundlage für maligne Zellveränderungen und die Entwicklung eines HCC. ${ }^{34,35}$ Mehrere Studien bestätigen erhöhte IL-6 Werte bei Patienten mit HCC. ${ }^{36}$ In der Tumordiagnostik lässt sich bei einer Kombination aus AFP und IL-6-Serumlevel-Kontrolle die Sensitivität auf $83 \%$ und die Spezifität auf $79 \%$ steigern. ${ }^{37}$ 
Alle aufgeführten Methoden, die zu einer frühzeitigen Erkennung eines HCC führen sollen, stoßen im klinischen Alltag oftmals an ihre Grenzen. Die Entwicklung verlässlicher, voraussagender Marker sollte daher weiterhin im Zentrum wissenschaftlicher Forschung stehen.

\subsection{Tumorklassifikation}

\subsubsection{Staging}

Klassischerweise erfolgt die Therapieplanung sowie die Prognoseeinschätzung des HCC abhängig vom Tumorstadium. Dabei ist jedoch auch immer die zu Grunde liegende Leberfunktion zu berücksichtigen. Zum jetzigen Zeitpunkt gibt es daher weltweit verschiedene Staging-Systeme, die alle in unterschiedlichem Maße Tumorgröße, Anzahl der Läsionen, Koinfektionen mit HBV/ HCV sowie spezifische Serummarker berücksichtigen. Die am häufigsten verwendeten Systeme sind dabei das TNM-System, ${ }^{38}$ die Barcelona-Clinic Liver Cancer Klassifikation (BCLC), der Child Pugh-Score sowie das Okuda-System.

\section{TNM Klassifikation}

\begin{tabular}{ll}
\hline T & Tumorkategorie \\
\hline T1 & Solitärer Tumor \\
T1a & Solitärer Tumor $\leq 2 \mathrm{~cm}$ mit/ohne Gefäßinvasion \\
T1b & Solitärer Tumor $>2 \mathrm{~cm}$ ohne Gefäßinvasion \\
T2 & Tumor $>2 \mathrm{~cm}$ mit Gefäßinvasion oder multiple Tumore, keiner $>5 \mathrm{~cm}$ \\
T3 & Multiple Tumore $>5 \mathrm{~cm}$ oder Übergreifen auf eine größere Vene oder Pfortader \\
T4 & Tumoren mit Beteiligung größerer Äste der Portalvene oder Lebervene direkte In- \\
& vasion der Nachbarorgane (ausgenommen Gallenblase), auch Serosa \\
\hline N & Lymphknotenstatus \\
\hline Nx & Beurteilung regionärer Lymphknoten nicht möglich \\
N0 & Keine regionären Lymphknotenmetastasen \\
N1 & Metastasen in regionären Lymphknoten \\
\hline M & Metastasen \\
\hline M0 & Keine Fernmetastasen \\
M1 & Fernmetastasen \\
\hline
\end{tabular}

Tabelle 1.3: TNM Klassifikation ${ }^{38}$ 


\section{BCLC}

Der BCLC-Score berücksichtigt übergreifend das Tumorstadium (Tumorgröße, Anzahl der Läsionen, vaskuläre Invasion, extrahepatischer Befall), den Okuda-Score, die Leberfunktion (Child-Pugh-Stadium, portale Hypertension, Bilirubin). Ebenfalls Einfluss auf die Stadieneinteilung hat der Performance-Status des Patienten.

Die Einteilung des Patienten erfolgt nach Erhebung der beschriebenen Parameter in eines der fünf Stadien. Diese Kategorisierung ermöglicht als aktuell einziges System eine Therapiezuweisung.

Die Klassifikation hat sich etabliert und ist mit einer guten Abschätzung der Prognose verbunden. Das Scoring-System wird regelmäßig aktualisiert und dient nach der aktuellen S3-Leitlinie dem Staging und der Therapieplanung.

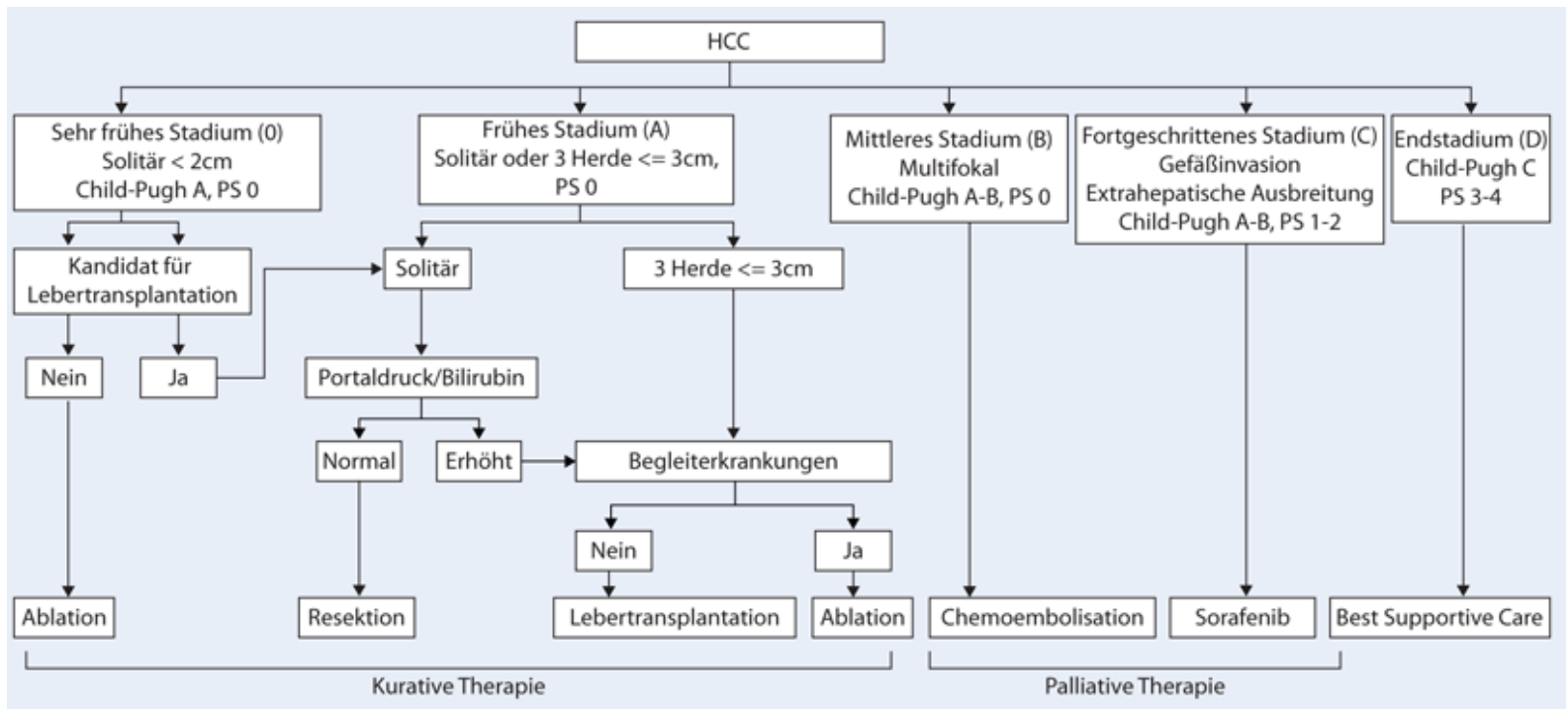

Abbildung 1.2: Abhängig von Child Pugh-Stadium sowie der Größe und Anzahl des Primärtumors wird der Patient einem BCLC-Stadium von 0-D zugeordnet. Anhand dieses Algorithmus wird eine Therapieentscheidung getroffen. Abbildung modifiziert ${ }^{39}$

\subsubsection{Grading}

Am weltweit bekanntesten ist das histopathologische, vierstufige Grading-System nach Edmondson und Steiner. Es wurde bereits 1954 entwickelt. ${ }^{40}$ Fraglich ist, ob es in der Zwischenzeit nicht einer Reevaluation des Systems bedarf. Es basiert auf unterschiedlichen zytologischen und histologischen Parametern. ${ }^{41}$ Weitere bekannte Grading Systeme sind das Grading nach World Health Organization (WHO) und das japanische Grading-System. ${ }^{42}$ 


\section{G1 hochdifferenzierter Tumor \\ G2 mittelgradig differenzierter Tumor \\ G3 gering differenzierter Tumor \\ G4 undifferenzierter/anaplastischer Tumor}

Tabelle 1.4: Histopathologische Differenzierungsgrade nach Edmondson und Steiner.

\subsection{Metastasierung}

Hauptursächlich für die Krebsmortalität ist nicht der Primärtumor an sich, sondern die daraus resultierenden Tochtergeschwülste in peripheren Organen des Körpers. Dieser höchst komplexe Vorgang der Metastasierung ist für das Voranschreiten von Karzinomen unabdingbar. Auch wenn die metastatische Kaskade im Detail noch nicht vollständig entschlüsselt ist, so gibt es mehrere Modelle, die versuchen diesen Prozess zu erklären.

Das erste Mal beschrieben wurde das Ablösen einer Tumorzelle aus dem Verband des Primärtumors von Greenburg und Hay in den 1980er Jahren. ${ }^{43}$ In späteren Untersuchungen wurde dieser Vorgang als Epitheliale mesenchymale Transition (EMT) bezeichnet. Dabei durchläuft der Primärtumor, der zunächst aus hochdifferenzierten und polarisierten Epithelialzellen besteht, eine Umwandlung, auch Phänotyptransition genannt. In Folge dessen lösen sich die Zell-Zell Kontakte auf und gleichzeitig wandelt die Zelle sich zu einer mesenchymalen Zelle um. ${ }^{44}$

Die EMT wird durch unterschiedliche Mechanismen beeinflusst. So besteht der Verdacht, dass durch die spontane Änderung des Phänotyps der Zelle ein Durchbruch durch die Basalmembran erleichtert wird, da die Zelle nicht mehr als fremd erkannt wird. Eine weitere Möglichkeit besteht in der Regulation durch verschiedene extrazelluläre Signalwege und durch Wachstumsfaktoren. Hierbei findet ein Umbauprozess des Zyktoskeletts statt oder die Aktivierung verschiedener Transkriptionsfaktoren (Snail, Slug, Twist, E12, ZEB1, ZEB2). ${ }^{45-47}$

Eine Schlüsselrolle spielt die Aktivierung der Transkriptionsfaktoren, die für den Abbau bzw. die Repression verschiedener Zelladhäsionsmoleküle verantwortlich sind (z.B. E-Cadherin). ${ }^{48}$ Das Herunterregulieren der Adhäsionsmoleküle erleichtert den Tumorzellen das Durchbrechen der Basalmembran und ermöglicht den Übergang in Blut-und Lymphgefäße (Intravasation). ${ }^{49}$

Nach einem kurzen Transport durch das Gefäßsystem findet nun peripher zum Primärtumor die Umkehr der EMT statt. Die Mesenchymale-Epitheliale-Transition (MET) läuft im Zielgewebe $\mathrm{ab}$ und beschreibt die Invasion der Tumorzellen in das periphere Gewebe (Extravasation). Dort bildet sich die Metastase aus. Eine schematische Darstellung der Abläufe kann Abb. 1.3 entnommen werden. 
Die Streuung des HCC verläuft auf Grund seiner starken Neigung zur Gefäßinvasion zum größten Teil auf hämatogenem Weg. ${ }^{50}$ Es metastasiert dabei intra- als auch extrahepatisch vor allem in Lunge, Knochen und Haut. ${ }^{51}$

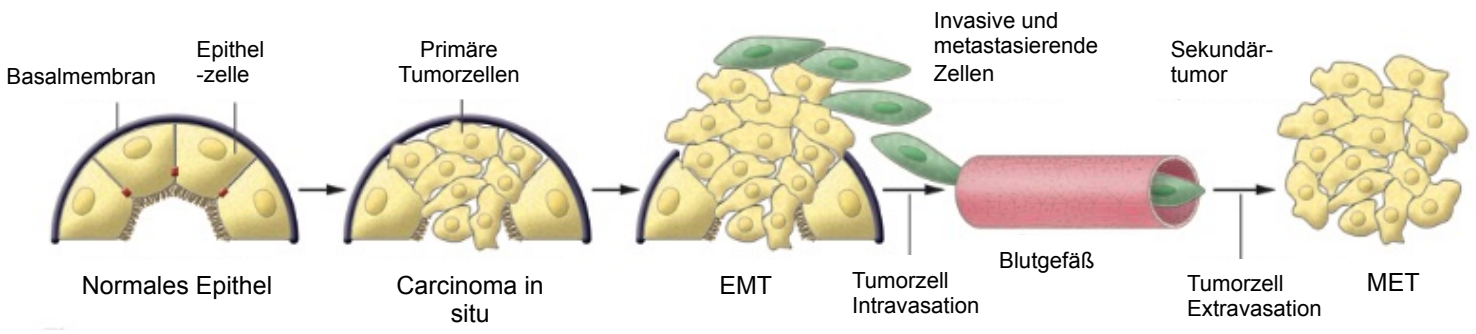

Abbildung 1.3: Der Metastasierungsprozess durchläuft mehrere Phasen. Zunächst verlieren die Epithelzellen ihre Polarität und lösen sich von der Basalmembran ab (Carcinoma in situ). Im Anschluss differenzieren sie zu mesenchymalen Zellen und durchbrechen die Basalmembran, um so in den Blutkreislauf zu gelangen. Es erfolgt der Transport in die Peripherie, wo die Tumorzellen Mikro- und Makrometastasen ausbilden und sich der Sekundärtumor bildet. ${ }^{52}$

\subsubsection{Zirkulierende Tumorzellen (CTC)}

CTCs, die sich als einzelne Krebszellen vom Primärtumor ablösen, gelangen wie in Kap. 1.5 beschrieben anschließend in das Knochenmark, das Lymphsystem und die Blutbahn. Dort können sie über einen längeren Zeitraum in einer Art Ruhezustand (Dormanz) verharren. Ausgehend von diesen CTCs bilden sich im Verlauf jedoch Lokalrezidive oder auch Fernmetastasen aus.

Es steht fest, dass mit wachsendem Tumorvolumen zunehmend mehr CTCs freigesetzt werden. ${ }^{53}$ Die Freisetzung der CTCs beginnt bei einer Tumorzellzahl von ca. einer Million, was einer Tumorgröße von ca. $1 \mathrm{~mm}$ entspricht; dabei ist eine Gefäßversorgung des Tumorgewebes Grundvoraussetzung. 54

Die Phase vor Ausbruch erster Symptomatiken oder die stille Progression des Tumors ist besonders tückisch. Zu diesem Zeitpunkt scheint der Patient in den bisherigen diagnostischen Verfahren oftmals fälschlicherweise tumorfrei. Da eine Früherkennung für die günstige Prognose bei Krebsleiden aber in höchstem Maße relevant ist, besteht ein großes Interesse daran, valide Detektionsmethoden für den Nachweis von CTCs zu entwickeln.

Ziel ist es, die Prognose des Patienten abzuschätzen oder eine Therapieüberwachung in Echtzeit durchführen zu können. ${ }^{55}$ Durch die Analyse, wie schnell die CTCs zunehmen, lassen sich Rückschlüsse auf die Wachstumsgeschwindigkeit des Tumors ziehen.

Im Jahr 1869 berichtete der Arzt Thomas Ashworth das erste Mal über sich im Blut befindliche, zirkulierende Tumorzellen. ${ }^{56}$ Erst knapp 100 Jahre später war es möglich, diese Tumorzellen zunächst durch Filtration ${ }^{57}$ und Sedimentation ${ }^{58}$ im Blut zu detektieren. Die Methode, der heute die meiste Aufmerksamkeit zukommt, die Immunomagnetische Separation der CTC, wurde erst im Jahr 1998 entwickelt. ${ }^{59}$ Die Entwicklungen der letzten Jahre lassen hoffen, dass die Detektion 
zirkulierender Tumorzellen ("liquid biopsy") einen Fortschritt in der personalisierten Medizin bringt.

Diese minimalinvasive Biopsiemethode hat viele Vorteile gegenüber der herkömmlichen Gewebebiopsie. Die Durchführbarkeit bzw. die Zugänglichkeit zu Patientenblut ist deutlich einfacher, die Wiederholbarkeit der Untersuchung schneller und kosteneffizienter durchzuführen. ${ }^{60,} 61$

Durch den Nachweis und Isolation der CTCs im Blut ist es außerdem möglich, molekulare Veränderungen oder auch Mutationen patientenbezogen nachzuweisen. ${ }^{62,63}$ Daraus kann eine individuelle Therapie abgeleitet werden. Insbesondere bei Patienten mit Mammakarzinom ist die Methodik bereits gut untersucht und zeigt ihren Nutzen in der Verlaufsdiagnostik. Ebenfalls profitieren bereits Patienten mit Kolon- ${ }^{64}$ und Prostatakarzinom. ${ }^{65}$

Bei der Detektion und Isolation stößt man jedoch auf vielerlei Problematiken. Das Hauptproblem stellt dabei die Konzentration der CTCs im Blut dar, die mit einer CTC pro $10^{6}-10^{7}$ Leukozyten sehr gering ist. Daher liegt besonderes Augenmerk auf der Entwicklung geeigneter Methoden zur Anreicherung und Detektion der CTC. ${ }^{60}$

Basierend auf ihren physikalischen Eigenschaften werden die Tumorzellen nach ihrer Dichte, Größe, Verformbarkeit oder ihrer Membraneigenschaften aussortiert. Ebenfalls möglich ist ein Isolation an Hand der biologischen Merkmale. Die immunomagnetische Anreicherung steht mit dem Cell-Search ${ }^{\oplus}$-System (Jannsen Diagnostic,LLC, Raritan) dabei aktuell im Mittelpunkt. ${ }^{66}$ Dieses System wird momentan als einziges von der US Food and Drug Administration (FDA) zur Isolation und Anreicherung von CTCs anerkannt. Aus einer Vollblutprobe (7,5ml) lassen sich CTCs standardisiert und reproduzierbar nachweisen.

Die Detektion erfolgt im Anschluss an die Anreicherung proteinbasiert (Immunfluoreszenzfärbung, Durchflusszytometrie) oder mRNA-basiert über die Reverse transcriptase polymerase chain reaction (RT-PCR).

In Deutschland ist die „liquid biopsy“ aktuell durch die European Medicines Agency (EMA) für die Therapiewahl beim nichtkleinzelligen Karzinom der Lunge zugelassen, soweit nicht ausreichend Material für eine Gewebebiopsie zur Verfügung steht. ${ }^{67}$

\subsection{Ezrin}

Das zytoskeletale Membranprotein Ezrin ist Teil der Ezrin-Radixin-Moesin (ERM)-Proteinfamilie und wird hauptsächlich von Epithelzellen exprimiert. Es akkumuliert unterhalb der Plasmamembran, dabei interagiert das C-terminale Ende mit F-Actin und bindet mit seiner $\mathrm{N}$ terminalen Domäne an die Plasmamembran.

Die Bindeaffinität von Ezrin wird dabei über den Prozess der Phosphorylierung reguliert. Dabei spielt der Second Messanger $\mathrm{PIP}_{2}$ eine regulierende Rolle. Er phosphoryliert einen spezifi- 
schen Threoninrest am C-terminalen Ende. $\mathrm{PIP}_{2}$ erhöht dadurch die Affinität von Ezrin zu den Oberflächenadhäsionsmolekülen CD44 und ICAM1-/2. ${ }^{68}$ Ezrin sorgt dabei für den Verlust an E-Cadherin, dies hat die Überregulation von CD44 zur Folge. ${ }^{69}$ CD 44 ist nachweislich an der Entstehung von Tumoren beteiligt. ${ }^{70}$ Gleichzeitig beeinflusst Ezrin die Lokalisationsveränderung von ICAM, wodurch dieses zu einem Pol der Zelle wandert. ${ }^{68}$ Weitere Eigenschaften des Proteins sind in Tab. 1.5 aufgeführt.

\begin{tabular}{ll}
\hline Synonyme & Cytovillin, Villin-2 \\
Gen Lokalisation & $6 \mathrm{q} 25.2-\mathrm{q} 26$ \\
mRNA & $3155 \mathrm{bp}$ \\
Größe & $81 \mathrm{kDA}$ \\
Aminosäuren & 586 \\
\hline
\end{tabular}

Tabelle 1.5: Eigenschaften Ezrin

Zusammenfassend reguliert Ezrin das Zellüberleben, die Zelladhäsion, die Zellmigration als auch die Zellinvasion über verschiedene, noch nicht vollständig geklärte Mechanismen und Signalwege. Auf Grund dieser Eigenschaften wird davon ausgegangenen, dass Ezrin eine Rolle in der Entstehung und Fortentwicklung von Krebs spielt. Mehrere Untersuchungen bestätigen, dass Ezrin eine Schlüsselrolle bei der Metastasierung von Tumoren spielt. ${ }^{71-76}$ Es ist in neuesten Untersuchungen gelungen, Ezrin in CTCs erfolgreich nachzuweisen. ${ }^{77,78}$

\subsection{Ziel der Arbeit und Fragestellung}

Aufgrund der starken Durchblutung der Leber metastasiert das HCC vorzugsweise auf hämatogenem Weg. Daher ist die Detektion von CTCs im Blut dieser Patientengruppe ein wichtiges, künftiges diagnostisches Mittel. CTCs sind bereits, durch die Erosion des wachsenden Tumors bedingt, im frühen Stadium der Karzinogenese nachweisbar.

Bisher sind eine Vielzahl von Methoden entwickelt worden, unter anderem die ex vivo und in vivo Flow cytometry, die RT-PCR, das Fluorescence-activated cell sorting (FACS), das Magneticactivated cell sorting (MACS), Mikrofluidik-Chips, sowie weitere Methoden, die in Abhängigkeit von der Zellgröße die Tumorzellen herausfiltern. Am weitesten verbreitet ist dabei aktuell die Methode der immunomagnetischen Anreicherung (Cell Search $\left.{ }^{\circledast}\right)$.

In Kombination mit Zellanreicherung und Isolationstechniken weisen diese Methoden die Konzentrationen der CTCs nach. Sie haben ebenfalls einen klaren prognostischen Aussagewert. Die Detektion von CTCs kann im Laufe eines Behandlungszyklus zur Verlaufskontrolle dienen und den Therapieablauf entscheidend beeinflussen. 
Dabei spielt vor allem die minimalinvasive Blutprobenentnahme „liquid biopsy“ eine zentrale Rolle. Sie ist im Gegensatz zu aufwendigen Gewebebiopsien einfach in den klinischen Alltag zu integrieren und kann gleichzeitig beliebig oft wiederholt werden. Ebenfalls denkbar wäre ein Einsatz dieser Methodik im Rahmen eines Vorsorgeprogramms für die genannten Risikogruppen.

In der vorliegenden Untersuchung soll nach Isolation der CTCs mit Hilfe des Oncoquick ${ }^{\circledast}$ Verfahrens das polare Expressionsmuster eines intrazellulär befindlichen Proteins (Ezrin) nachgewiesen werden. Die Isolationsmethode der CTCs wurde in der Arbeitsgruppe bereits etabliert.

Ein Ziel dieser Arbeit ist es daher, zunächst CTCs mit der etablierten Methode zu detektieren. In einem weiteren Schritt erfolgt die Etablierung der Methode zum Nachweis des Proteins Ezrin in CTCs von Patienten mit hepatozellulärem Karzinom.

Die Hauptfragestellung dieser Arbeit lautet:

„Ist ein Konzentrationsunterschied von CTCs mit und ohne Polarisierung unter dem Patientenkollektiv mit HCC und der Kontrollgruppe feststellbar?“

Da die Arbeit explorativer Natur ist, sind zusätzlich noch zwei weitere Fragestellungen zu beantworten:

1. Ergibt sich ein Zusammenhang aus den Detektionsraten mit der Einteilung des HCCs nach Tumorgröße, dem Differenzierungsgrad, dem BCLC-Stadium, der AFP- und IL-6 Konzentration?

2. Gibt es Unterschiede zwischen Patienten mit HCC und der Kontrollgruppe bezüglich biometrischer Daten und Laborwerten? 


\section{Patienten, Material und Methoden}

\subsection{Patienten}

\subsubsection{Ethikvotum}

Die Studie wurde gemäß Ethikantrag vom 08.08.2016 (Nr. 321/16) mit Zustimmung durch die Ethikkommission der Johann-Wolfgang-Goethe Universität Frankfurt durchgeführt. Den eingeschlossenen Patienten wurde vor Blutentnahme eine Einverständniserklärung vorgelegt.

Nach ausführlicher mündlicher und schriftlicher Information über den Inhalt und das Ziel der Studie durch einen ärztlichen Mitarbeiter des Universitätsklinikums Frankfurt am Main sowie nach ausreichender Bedenkzeit wurde die Einverständniserklärung durch den Patienten schriftlich erteilt.

Darin erklärte der Patient sich dazu bereit, sein Blut für wissenschaftliche Zwecke zur Verfügung zu stellen und wurde zeitgleich über mögliche Risiken bei der Blutentnahme aufgeklärt. In Bezug auf den Datenschutz wurden die Patienten darüber aufgeklärt, dass die Patientenidentität pseudo-anonymisiert wird und die wahre Identität nur autorisierten Studienärzten bekannt wird.

\subsubsection{Patientenkollektiv}

Die im Rahmen dieser Pilotstudie verwendeten Blutproben stammen von Patienten aus der Klinik für Allgemein- und Viszeralchirurgie des Universitätsklinikums der Johann-WolfgangGoethe Universität Frankfurt. Im Zeitraum von Juni 2018 bis Januar 2019 wurden konsekutiv 25 Patienten eingeschlossen.

Dabei handelt es sich um Patienten, die entweder eine Leberteilresektion erhielten oder aber auf Grund des fortgeschrittenen Stadiums eines HCC über die onkologische Ambulanz zur Beratung und Planung einer Alternativtherapie (Transarterielle Chemo-Embolisation (TACE), Mikrowellen-Ablation (MWA), Sorafenib-Therapie) vorstellig wurden. Diese Patientengruppe wird im weiteren Verlauf als HCC-Gruppe bezeichnet. Als Vergleichsgruppe dienten zehn Patienten mit benigner Lebererkrankung. Diese Patientengruppe wird im weiteren Verlauf als Non malignant liver disease (NMLD)-Gruppe bezeichnet. 


\section{Einschlusskriterien}

- Zustimmungsfähigkeit

- Alter $>18$ Jahre

- Patient mit radiologisch oder pathologisch gesichertem Befund eines Hepatozellulären Karzinoms

- Verfügbare Befunde aus Laboruntersuchungen, Röntgen-, Pathologie- und klinischen Untersuchungen

\section{Ausschlusskriterien}

- Lebermetastasen bei vorliegendem Zweitmalignom

- Humane Immundefizienz Virus (HIV)

- $\mathrm{HBV}$

- $\mathrm{HCV}$

Da mit frischem Blut gearbeitet wurde mussten HIV,HBV und HCV Patienten, auf Grund der Sicherheitsregulationen im Labor, von der Untersuchung ausgeschlossen werden.

\subsubsection{Patientenproben}

Die Blutentnahme von $5 \mathrm{ml}$ EDTA-Blut und 4,9 ml Serum-Blut erfolgte im Rahmen medizinisch indizierter präoperativer beziehungsweise präinterventioneller Maßnahmen, sodass für die Patienten keine zusätzliche psychische oder physische Belastung entstand. Dadurch war es auch möglich, alle weiteren benötigten Blutparameter den im normalen Behandlungsumfang durchgeführten Laboruntersuchungen zu entnehmen.

- Albumin

- Bilirubin

- INR

- Alkalische Phosphatase

- Interleukin 6

- AFP

Präoperativ erfolgte die Entnahme unmittelbar vor OP-Beginn aus dem zentralen Venenverweilkatheter. Im Rahmen der onkologischen Sprechstunde erfolgte die venöse Blutentnahme 
via Butterfly aus einer oberflächlichen Armvene. Die Serumproben wurden im Anschluss an das Zentrallabor des Johann-Wolfgang-Goethe Universitätsklinikums geschickt und auf den Tumormarker AFP und das Zytokin IL-6 hin untersucht. Die Verarbeitung der EDTA Proben erfolgte innerhalb eines Zeitraums von maximal 60 Minuten im Forschungslabor der Allgemein- und Viszeralchirurgie des Universitätsklinikums Frankfurt, wobei die EDTA-Röhrchen beim Transport unterhalb einer Temperatur von $20^{\circ} \mathrm{C}$ gelagert wurden.

\subsection{Material}

\subsubsection{HepG2 Zelllinie}

Die verwendete humane hepatozelluläre Karzinom-Zelllinie stammt aus dem Lebergewebe eines 15-jährigen Kaukasiers. Die Zellen wachsen in einlagiger Zellschicht. Erworben wurde die Zelllinie von CLS Cell Line Service GmbH (Heidelberg).

\subsubsection{Antikörper}

\begin{tabular}{llll}
\hline Name & Hersteller/Firmensitz & Herkunft & Konzentration \\
\hline Antihuman CD 146 PE & Biolegend/San Diego (USA) & Maus & $200 \mu \mathrm{g} / \mathrm{ml}$ \\
Antihuman CD 45 APC & Thermofisher/ Waltham (USA) & Maus & $5 \mu \mathrm{l} /$ Test \\
Alexa-Fluor 488 & abcam/Cambridge (UK) & Kaninchen & $100 \mu \mathrm{l} \mathrm{bei} \mathrm{0,5} \mathrm{g/ml}$ \\
ProLong Gold Antifade & Life technologies/ Eugene (USA) & & \\
Mountant with DAPI & & & \\
\hline
\end{tabular}

Tabelle 2.1: Antikörper 


\subsubsection{Puffer und Lösungen}

\begin{tabular}{|c|c|}
\hline Puffer/ Lösung & Zusammensetzung \\
\hline \multirow[t]{2}{*}{$4 \%$ Formaldehyd methanolfrei } & $10 \mathrm{ml}$ Formaldehyd methanolfrei \\
\hline & $30 \mathrm{ml} \mathrm{PBS}$ \\
\hline \multirow[t]{3}{*}{ Blocking Solution } & $1 \mathrm{ml} \mathrm{FCS}$ \\
\hline & $0,5 \mathrm{~g}$ BSA \\
\hline & $50 \mathrm{ml} \mathrm{PBS}$ \\
\hline \multirow[t]{2}{*}{ FACS Buffer 0,5 \% } & $500 \mathrm{ml} \mathrm{PBS}$ \\
\hline & $2,5 \mathrm{~g} \mathrm{BSA}$ \\
\hline \multirow[t]{2}{*}{ Permeabilisierungs Buffer } & $500 \mathrm{ml} \mathrm{PBS}$ \\
\hline & $100 \mu \mathrm{l}$ Triton X-100 \\
\hline \multirow[t]{4}{*}{ RBC Lysis Solution } & $8,02 \mathrm{~g} \mathrm{NH}_{4} \mathrm{Cl}_{2}$ \\
\hline & $0,84 \mathrm{~g} \mathrm{NaHCO}_{3}$ \\
\hline & $0,37 \mathrm{~g}$ EDTA \\
\hline & $100 \mathrm{ml}$ Aquadest \\
\hline \multirow[t]{2}{*}{ Tween Buffer 0,01 \% } & $500 \mathrm{ml} \mathrm{PBS}$ \\
\hline & $50 \mu \mathrm{l}$ Tween \\
\hline
\end{tabular}

Tabelle 2.2: Puffer und Lösungen 


\subsubsection{Chemikalien}

\begin{tabular}{ll}
\hline Name & Hersteller / Firmensitz \\
\hline Accutase & Siga-Aldrich / St. Louis, MO,USA \\
Aceton & J.T. Baker / Center Valley, PA, USA \\
Antifade Mountant mit DAPI & Thermo Scientific / Waltham, MA, USA \\
Bovine Serum Albumin (BSA) & Sigma-Aldrich / St. Louis, MO, USA \\
Destilliertes Wasser & Fresenius Kabi / Bad Homburg v.d. Höhe \\
Ethanol & Sigma-Aldrich / St. Louis, MO, USA \\
$16 \%$ Formaldehyd methanolfrei & Thermo Scientific / Rockford, IL, USA \\
Dulbeccos Phosphate Buffered Saline (PBS) & Gibco/Invitrogen / Karlsruhe \\
Trypanblau & Gibco/Invitrogen / Karlsruhe \\
Triton X 100 & Sigma-Aldrich / St. Louis, MO, USA \\
FCS & Gibco/Invitrogen / Karlsruhe \\
Tween 20 & Sigma-Aldrich / St. Louis, MO, USA \\
\hline
\end{tabular}

Tabelle 2.3: Chemikalien 


\subsubsection{Verbrauchsmaterial}

\begin{tabular}{ll}
\hline Name & Hersteller / Firmensitz \\
\hline C-Chips & NanoEnTek / Seoul, Korea \\
Eppendorf Cups lichtdicht & Eppendorf / Hamburg \\
Greine Centrifuge Tubes & Greiner bio-one / Frickenhausen \\
Kryobox & Thermo Scientific / Wilmington, DE, USA \\
Kryotubes & Starlab / Hamburg \\
Microscope Cover Slips & Glaswarenfabrik Karl Hecht GmbH \\
& Sondheim v.d. Rhön \\
Microscope Slides Superfrost Plus & Thermo Scientific / Braunschweig \\
Pasteurpipette & Sarstedt / Nümbrecht \\
Pipette Micro One & Starlab / Hamburg \\
Pipette Tips Tip One & Starlab / Hamburg \\
Pipettor Pipettus & Hirschmann- Laborgeräte / Eberstadt \\
Serological Pipette & Sigma-Aldrich / St. Louis, MO, USA \\
S- Monovetten 4,9 ml K3 EDTA & Sarsted / Nümbrecht \\
Zellkulturflaschen & Sarsted / Nümbrecht \\
\hline
\end{tabular}

Tabelle 2.4: Verbrauchsmaterialien 


\subsubsection{Geräte}

\begin{tabular}{lll}
\hline Gerät & Name & Hersteller / Firmensitz \\
\hline $\begin{array}{l}\text { Automatisierter } \\
\text { Färbeautomat }\end{array}$ & Mirastainer & VWR International / Radnor, PA, USA \\
Brutschrank & Hera Cell & Hereaus/ Hanau \\
Cell Imaging System & Evos XL Core & Thermo Scientific / Waltham, MA, USA \\
Eismaschine & Scotsman & Scotsman/ Milan, Italy \\
Elektronen Mikroskop & & Carl Zeiss Microscopy GmbH / Jena \\
Fluoreszenzmikroskop & Zeiss Axio & Carl Zeiss Microscopy GmbH / Jena \\
& Observer.Z1 & \\
Lichtmikroskop & & VWR International / Radnor, PA, USA \\
Moist Chamber & Strain Tray & Sigma-Aldrich / St.Louis, MO, USA \\
Sterile Werkbank & Antair BSK6 & Mc Labor oHG / Albstadt \\
Vortex & Vortex Mixer & Velp Scientifica / Usmate, Italy \\
Waage & TB-124A & Denver Instrument / Göttingen \\
Zentrifuge & Rotana AP & Hettich / Tuttlingen \\
Zentrifuge & Heraeus Mul- & Thermo Scientific / Waltham, MA, USA \\
tifuge X3 FR & \\
Zentrifuge & Picofuge II & Thermo Scientific / Waltham, MA, USA \\
\hline
\end{tabular}

Tabelle 2.5: Geräte

\subsubsection{Software}

Die strukturierte Datenerhebung erfolgte unter Zuhilfenahme des Microsoft Office Programms Excel. Die Grundlage für die patientenbezogene Datenerhebung bildet die elektronische Patientenakte (NICE/Orbis). 


\subsection{Methoden}

\subsubsection{Zellkultur}

\section{Kultivierung und Lagerung der Zelllinie}

Die HepG2 Zellen wurden unter sterilen Bedingungen kultiviert und verwahrt. Dies erfolgte stets in einer sterilen Sicherheitsarbeitsbank. Im Inkubator herrschte eine konstante Temperatur von $37^{\circ} \mathrm{C}$ mit wassergesättigter Atmosphäre bei einem $\mathrm{CO}_{2}-$ Gehalt von $5 \%$.

\section{Auftauen der Zellen}

Zur Rekultivierung der konservierten Zellen wurden diese bei $37^{\circ} \mathrm{C}$ aufgetaut und rasch in 20 $\mathrm{ml}$ Zellmedium resuspendiert. Nach Zentrifugation bei $1500 \mathrm{rpm}$ für $5 \mathrm{~min}$ bei $4{ }^{\circ} \mathrm{C}$ wurde das Zellpellet mit $15 \mathrm{ml}$ Medium versetzt und in eine neue Zellkulturflasche gegeben, die dann im Brutschrank inkubiert wurde.

\section{Subkultivierung der Zellen}

Die Passagierung der Zellen in eine neue Zellkulturflasche (Sarstedt; Nümbrecht) erfolgte nachdem eine Konfluenz von 80 \% erreicht war. Hierfür wurden die am Boden der Zellkulturflaschen adhärenten Zellen nach Entfernung des alten Mediums mit $10 \mathrm{ml} \mathrm{PBS} \mathrm{(ohne} \mathrm{Ca}^{2+}$ und $\mathrm{Mg}^{2+}$ ) gewaschen und mit Hilfe von $10 \mathrm{ml}$ Accutase gelöst. Angepasst an die Zellteilungsrate wurden die gelösten Zellen mit dem zugehörigen Zellmedium resuspendiert und in eine neue Kulturflasche ausgesät.

\section{Kryokonservierung}

Zur Langzeitlagerung der Zellen wurden diese disloziert und anschließend bei $1500 \mathrm{rpm}$ für 5 min bei $4{ }^{\circ} \mathrm{C}$ zentrifugiert. Das Zellpellet wurde dann in Einfriermedium resuspendiert (70\% Zellmedium, 20 \% FBS, 10 \%DMSO) und jeweils $1 \mathrm{ml}$ der Zellsuspension in Cryotubes überführt. Mit Hilfe einer speziellen Einfrierbox, die für eine schonende graduelle Abkühlung von $-1^{\circ} \mathrm{C}$ pro Minute sorgte, wurden die Zellen über Nacht bei $-80^{\circ} \mathrm{C}$ eingefroren. Am Folgetag erfolgte die Überführung der Cryotubes in flüssigen Stickstoff $\left(-196^{\circ} \mathrm{C}\right)$. 


\section{Bestimmung der Zellzahl}

Um standardisierte Bedingungen bei der Durchführung der Vorversuche zu gewährleisten, wurden die ausgesäten HepG2 Zellen mithilfe eines C-Chips (Neubauer-Zählkammer, C-Chip, Fa. NanoEnTek, Seoul, Korea) gezählt. Dazu wurden die C-Chips mit ca. $20 \mu \mathrm{l}$ der bei der Zellgewinnung erhaltenen Zellsuspension (10 $\mu \mathrm{l}$ Trypanblau $+10 \mu \mathrm{l}$ Zellsuspension) befüllt. Dies geschah durch Ansetzen der Pipettenspitze an der Kante der Zählkammer, wobei die Suspension durch Kapillarkräfte zwischen Deckglas und Kammer gesaugt wurde.

Die Zählkammer konnte nun unter das Lichtmikroskop (Fa. VWR International, Radnor, PA, USA) gelegt werden, welches bei 20 -facher Vergrößerung so eingestellt wurde, dass die Einteilungslinien der Kammer sichtbar wurden. Anschließend wurden vier der großen Quadrate der Neubauer-Kammer ausgezählt. Die genaue Zellzahl konnte anschließend berechnet werden, wobei ausschließlich die vitalen Zellen gezählt wurden. Diese sind anhand ihrer hellen Farbe von den toten, blau gefärbten Zellen zu differenzieren.

\subsubsection{Isolation der CTCs mittels Oncoquick ${ }^{\circledast}$}

Die Isolation und Anreicherung der CTC basierte auf dem Oncoquick - Dichtegradientensystem (Fa. Greiner bio-one, Frickenhausen). Das Funktionsprinzip dieser Isolationsmethode wird in Abb. 2.1 schematisch dargestellt.

Die zu untersuchenden Blutproben wurden unmittelbar nach der Blutentnahme (siehe 2.1.3) im Labor analysiert. Entsprechend des Standard-Protokolls wurden die Oncoquick Tubes bei $1500 \mathrm{~g} 5 \mathrm{~min}$ bei $4{ }^{\circ} \mathrm{C}$ zentrifugiert und anschließend die EDTA-Blutproben gemeinsam mit dem Oncoquick Tube für 15 min auf Eis gelagert. Das Blut (5 ml) wurde vorsichtig aus dem EDTA-Röhrchen (Fa. Sarsted, Nümbrecht) in ein neues $50 \mathrm{ml}$ Tube umpipettiert und mit ca 10 $\mathrm{ml}$ PBS (ohne $\mathrm{Ca}^{2+}$ und $\mathrm{Mg}^{2+}$ ) auf $15 \mathrm{ml}$ aufgeschüttet und verdünnt.

Das vorgekühlte und verdünnte Blut wurde daraufhin langsam auf den porösen Filter pipettiert und bei $1600 \mathrm{~g} 20 \mathrm{~min}$ bei $4{ }^{\circ} \mathrm{C}$ zentrifugiert. Der Überstand wurde mit einer vorher bereits angefeuchteten Pipette (Fa. Sigma-Aldrich, St. Louis, USA) in ein mit FACS-Buffer ausgewaschenes neues $50 \mathrm{ml}$ Tube gegeben und bis auf $50 \mathrm{ml}$ mit FACS-Buffer aufgefüllt. Nach fünfmaligem Schwenken erfolgten die Waschschritte. 


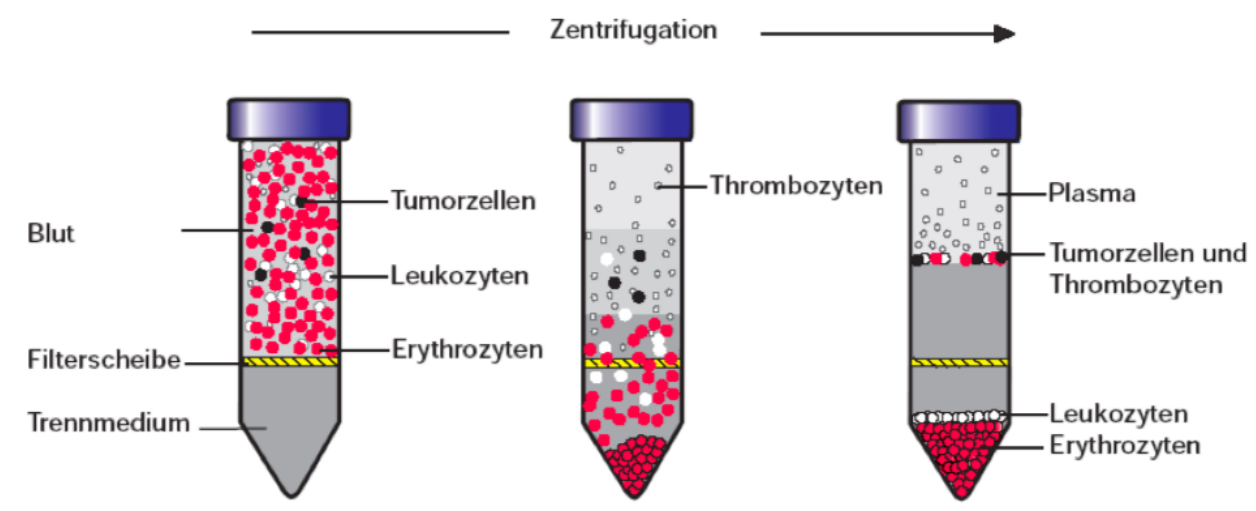

Abbildung 2.1: In Folge mehrfacher Zentrifugations- und Waschschritte reichern sich die im Blut befindlichen Zellen entsprechend ihrer Dichte entlang eines Dichtegradienten an. Ein spezielles Trennmedium und eine eingebaute poröse Trennscheibe tragen dazu bei, die enthaltenen Zellanteile entsprechend ihrer Dichte aufzutrennen. Dabei reichern sich die Zellen mit geringerer Dichte oberhalb der porösen Barriere an; diese Fraktion enthält unter anderem die CTCs. Abbildung modifiziert nach Gebrauchsanleitung Oncoquick Greiner Bio One International GmbH

Die Zellen wurden hierfür $10 \mathrm{~min}$ bei $200 \mathrm{~g}$ und $4{ }^{\circ} \mathrm{C}$ zentrifugiert. Der Überstand von $45 \mathrm{ml}$ wurde vorsichtig abpipettiert und $5 \mathrm{ml}$ auf dem Tubenboden belassen. Es erfolgte ein erneutes Resuspendieren des Zellpellets mithilfe des Vortex Mixers (Fa. Velp Scientifica, Usmate, Italy). Der Waschschritt wurde nach erneutem Aufschütten von FACS-Buffer auf $50 \mathrm{ml}$ wiederholt.

Ein Lyseschritt wurde notwendig, wenn sich am Tubenboden ein kreisrunder roter Punkt, bestehend aus Erythrozyten, gebildet hatte (siehe Abb. 2.2). Hierfür wurde dem $5 \mathrm{ml}$ Überstand 5 $\mathrm{ml}$ Red Blood Cell (RBC) Lysis Buffer zugegeben und bei $37^{\circ} \mathrm{C}$ für 5 min im Brutschrank (Fa. Hereaus, Hanau) inkubiert. Daran schloss sich ein erneuter Waschschritt wie bereits beschrieben an. Abschließend wurde der Überstand dekantiert und für 3 min umgedreht auf einer sterilen Unterlage stehen gelassen. Das Tube wurde erneut umgedreht und bei geschlossenem Deckel noch einmal für 2 min stehen gelassen.

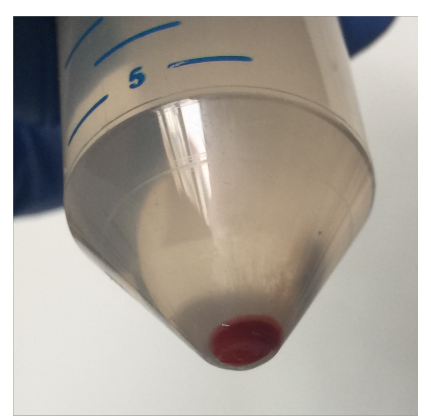

Abbildung 2.2: Eine Lyse wurde notwendig, wenn sich nach zweimaliger Zentrifugation ein dunkelroter Punkt (Erythrozyten) am Tubenboden gezeigt hat. 


\subsubsection{Fluoreszenzfärbung mittels Antikörpern}

Das abgesetzte Zellpellet wurde in der übrigen Flüssigkeit durch auf- und abpippetieren resuspendiert und $40 \mu \mathrm{l}$ der Suspension auf einen positiv geladenen adhäsiven Glasobjektträger (Fa.Glaswarenfabrik Karl Hecht GmbH, Sondheim v.d. Rhön) aufgebracht. Die Lufttrocknung der Probe erfolgte über Nacht. Am nächsten Tag erfolgte die Fixierung der Zellen für 10 min mit $100 \mu \mathrm{l} 4 \%$ methanolfreiem Formaldehyd (Fa. Thermo Scientific, Rockford, Il, USA).

Zu Beginn des Fixierungsprozesses wurde die Probe mit einem hydrophoben Pen umkreist. Anschließend wurde die Probe im vollautomatisierten Färbeautomaten Mirastainer (Fa. VWR International, Radnor, PA, USA) zweimal fünf Minuten in PBS und einmal drei Minuten in Tween20 (Fa. Sigma-Aldrich, St. Louis, MO, USA) gewaschen.

Die Probe wurde in einem ersten Schritt mit einem Antikörpercocktail aus $10 \mu \mathrm{l}$ CD146-PE und $10 \mu \mathrm{l}$ CD45-APC versehen. Nach einstündiger Inkubation bei RT in der Moist Chamber (Fa. Sigma-Aldrich, St. Louis, MO, USA) wurden die Proben 2 min in PBS gewaschen. Es folgte die Permabilisation der Probe durch Aufbringen von $100 \mu$ l 0,05 \% Triton X- 100 (Fa. Sigma-Aldrich, St. Louis, MO, USA), welches 10 Minuten in der Moist Chamber inkubiert wurde.

Nach kurzem Abschütten wurde die Blocking Solution (PBS, 1 \% BSA, 2 \% FCS) für 30 min auf die Probe gegeben. Zuletzt wurde die Blocking Solution entfernt und 1,5 $\mu$ Anti-Ezrin-Alexa Fluor 488 auf die Probe gegeben.

Die Inkubation erfolgte entweder über Nacht im Kühlschrank oder zwei Stunden bei Raumtemperatur im Dunkeln. Die Probe wurde im Mirastainer für zweimal fünf Minuten in PBS und einmal drei Minuten in Tween-20 gewaschen und danach wurden $10 \mu \mathrm{l}$ DAPI-Antifading Solution (Fa. Thermo Scientific, Waltham, MA, USA) aufgebracht. Danach wurde die Probe mit einem Deckglas versiegelt.

\subsubsection{Detektion polarisierter CTCs mittels Fluoreszenzmikroskopie}

Die fluoreszenzmikroskopische Analyse der Proben erfolgte mit dem Zeiss Axio Observer.Z1 Mikroskop unter Verwendung der in Tabelle 2.6 aufgeführten Einstellungen bei 40-facher Vergrößerung in einem abgedunkelten Raum. Die Auswertung erfolgte mit Hilfe der Axio Vision Software 4.7 und wurde zudem fotografisch dokumentiert. 


\begin{tabular}{llll}
\hline Antikörper & Fluorophor & EX/EM (nm) & Belichtungszeit (ms) \\
\hline CD 45 & APC & $488-561$ & 80 \\
CD 146 & PE & $488-561$ & 180 \\
Alexa Fluor Anti Ezrin 488 & FITC & $490-525$ & 120 \\
DAPI & DAPI & $340-488$ & 2000 \\
\hline
\end{tabular}

Tabelle 2.6: Fluoreszenzverhalten der Antikörper

Zur Identifikation der gesuchten polarisierten CTCs wurden Färbung, Zellmorphologie sowie Zellgröße, Gestalt und Zellkerngröße berücksichtigt.

Zellen, die folgende Kriterien erfüllten, wurden als polarisierte CTCs identifiziert:

- Positiv für CD146-PE und Alexa Fluor Anti Ezrin $488^{\circledR}$

- Negativ für CD45-APC

- Zellgröße $>30 \mu \mathrm{m}$

- Zellkern vollständig intakt

- Polarisierung vorhanden

\subsubsection{Spiking von Tumorzellen in Gesundblut}

Für die Durchführung des Spiking-Experiments wurde EDTA-Blut eines gesunden, nicht an einem Tumor leidenden Spenders via Butterfly aus der oberflächlichen Armvene entnommen. Das Blut wurde bei Raumtemperatur gelagert und innerhalb von einer Stunde verarbeitet.

Das Spenderblut wurde in $3 \times 4 \mathrm{ml}$ Ansätze aufgeteilt. Dabei wurden $2 \times 4 \mathrm{ml}$ der Probe mit je 200 HepG2 Zellen versetzt (vgl. 2.3.1). Eine der Proben diente als Negativkontrolle und wurde daher nicht mit Tumorzellen versehen.

In allen Ansätzen erfolgte die Isolierung der Tumorzellen mittels der Oncoquick Methode wie in 2.3.2 beschrieben. Lediglich der Färbeprozess der Proben wurde zur gleichzeitigen Optimierung der Methode auf zwei unterschiedliche Arten durchgeführt. Die Unterschiede dieser Färbemethoden sind in Abb. 3.2 dargestellt.

\subsubsection{Statistische Auswertung}

Für die statistische Auswertung und die grafische Visualisierung der Daten wurde die Software GraphPad Prism Version 8.0.0 für Mac OS X, Graph Pad Software, San Diego, CA, USA genutzt. 
Auf Ebene der deskriptiven Statistik wurden Anzahlen, Mittelwerte mit Standardabweichung (Stabw.), Prozentsätze, Mediane, Bereiche (maximaler-minimaler Wert) und Normalverteilungen berechnet und dargestellt.

Um über passende Lage- und Streumaße zu entscheiden, wurde zuvor für jede Variable ein Shapiro-Wilk-Test auf Normalverteilung durchgeführt.

Um statistisch signifikante Unterschiede zwischen zwei Variablen zu ermitteln, wurden auf Grund der geringen Fallzahl $(\mathrm{n}=25)$ und meist Nicht-Normalverteilung der Parameter nichtparametrische Tests eingesetzt. Für unabhängige Stichproben kam der Mann-Whitney-U-Test zum Einsatz.

Das Signifikanzniveau betrug über alle durchgeführten Tests $\alpha=0,05$. 


\section{Ergebnisse}

\subsection{Methodenetablierung im Zellinienversuche}

\subsubsection{Protokolloptimierung im Spiking-Experiment}

Der in 2.3.3 beschriebene Färbeprozess wurde im Laufe der Arbeit in seiner Reihenfolge und im Ablauf modifiziert, um eine bessere Färbung der membranständigen Antigene gegen CD45 und CD146 zu erreichen.

Die Änderungen des Prozesses sind in Abb. 3.2 dargestellt. Es stellte sich heraus, dass eine deutlichere und scharf abgrenzbare Membranfärbung der Leukozyten dann möglich wurde, wenn man den Permeabilisierungsprozess erst im Anschluss an das Aufbringen der CD45- und CD146Antikörper durchführte. In Folge dessen war ein visueller Unterschied zwischen intrazellulär Ezrin-gefärbten CTCs und extrazellulär gefärbten Leukozyten mit einer höheren Genauigkeit feststellbar.
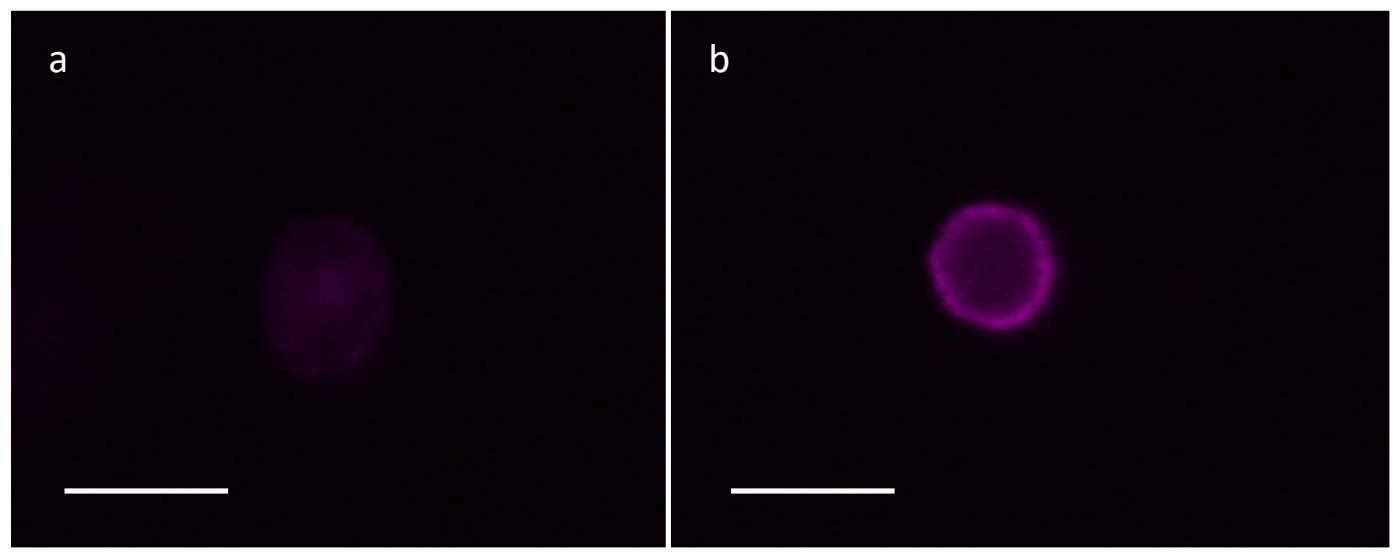

Abbildung 3.1: Bild a zeigt die undeutliche Färbung vorher. Bild b zeigt die deutliche scharf abgrenzbare Membranfärbung der Leukozyten nach der Protokolloptimierung. Maßstabbalken $=50 \mu \mathrm{m}$. 40-fache Vergrößerung. 


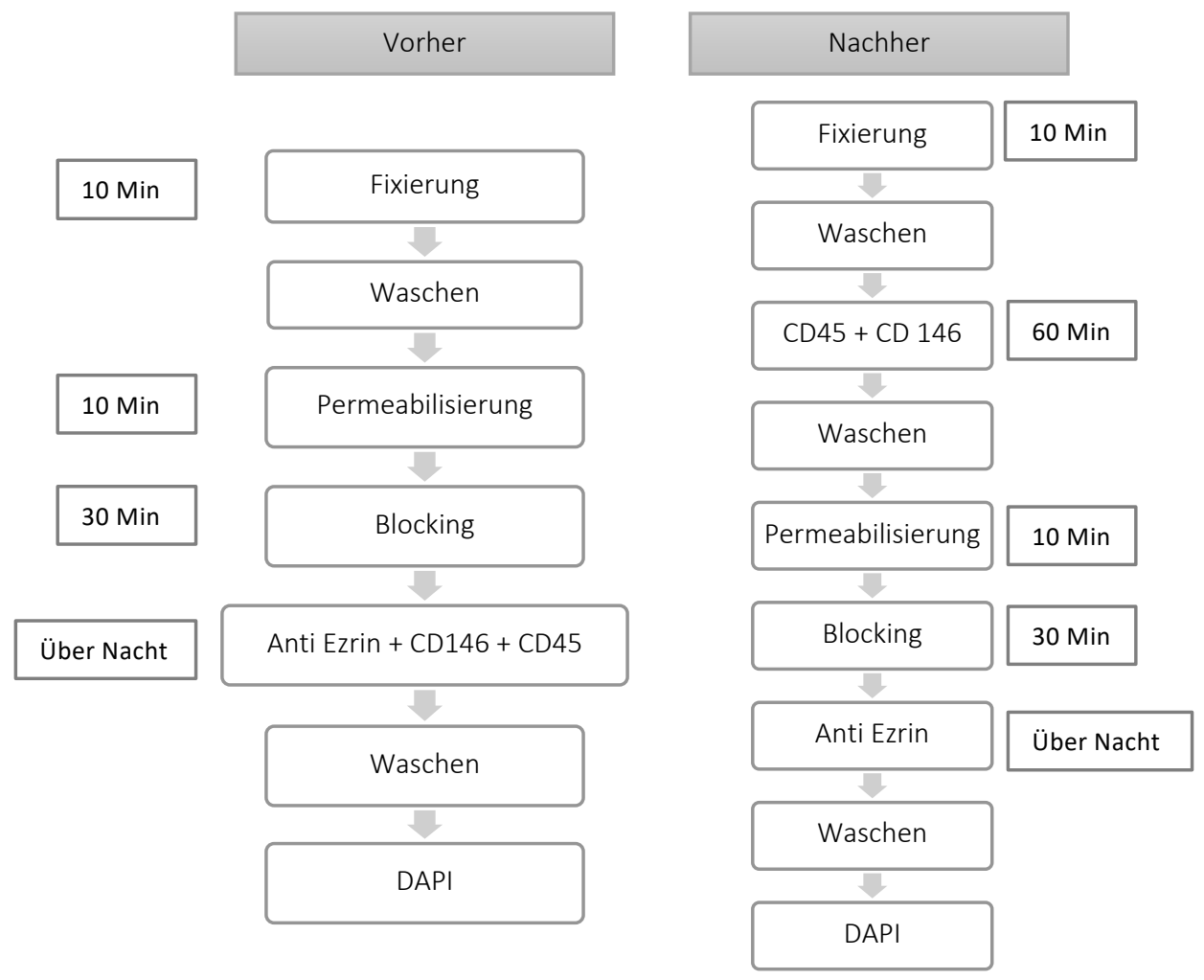

Abbildung 3.2: Darstellung der Änderungen im Färbeprotokoll

\subsubsection{Nachweis der Polarisierung in HepG2 Zellinie}

Polarisierte vs. nicht polarisierte Färbung

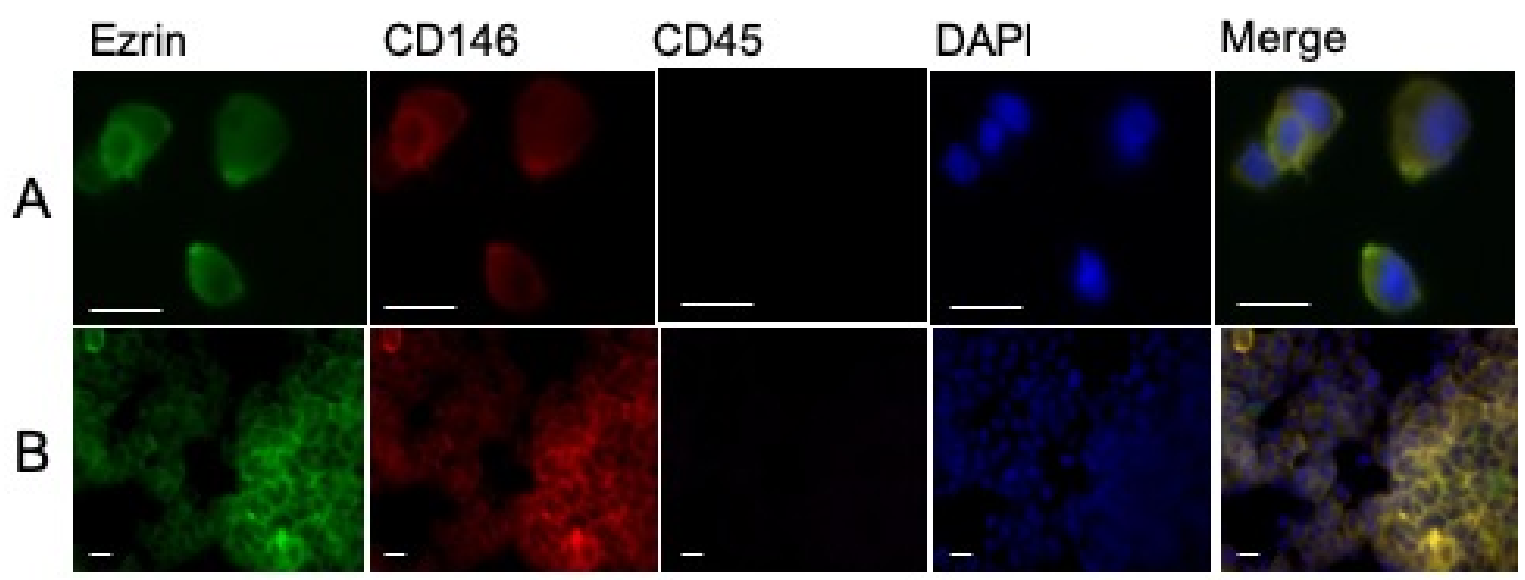

Abbildung 3.3: A) Beispiel für polarisierte HepG2 Zellen. B) Beispiel unpolarisierter HepG2 Zellen. Anti Ezrin Färbung (grün), CD 146 (rot), CD 45/ Leukozyten (violett), DAPI/ Zellkernfärbung (blau) und Überlagerungsbilder (Merge) der einzelnen Fluoreszenzkanäle. Maßstabbalken $=50 \mu \mathrm{m}$. 40-fache Vergrößerung. 

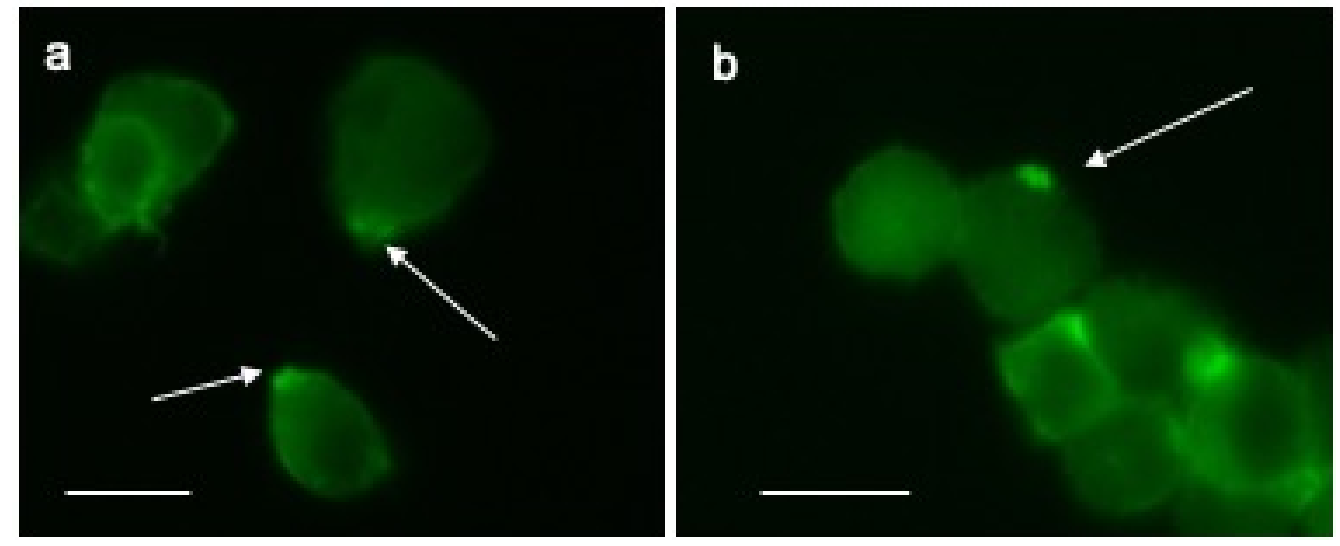

Abbildung 3.4: Tumorzelllinie HepG2 mit Alexa Fluor Anti Ezrin 488/ FITC Färbung. Die Pfeile zeigen auf die Polarisierung des Ezrin am apikalen Pol der Zelle. Maßstabbalken $=50 \mu \mathrm{m} .40$-fache Vergrößerung.

\subsection{Ergebnisse des Hauptversuchs}

Insgesamt wurden 25 Blutproben (jeweils $5 \mathrm{ml}$ ) von insgesamt 25 Patienten bestehend aus einem Kollektiv mit HCC-Patienten $(\mathrm{n}=15)$ und einem Kollektiv Patienten mit nicht-maligner Lebererkrankungen $(n=10)$, entnommen. Die Probenentnahme erfolgte aus dem ZVK. Ausnahme bildete das Patientenkollektiv aus OA1-OA3. Diese Patienten wurden im Universitätsklinikum Frankfurt am Main ausschließlich zur Beratung vorstellig und haben sich keiner chirurgischen Therapie unterzogen. Grund dafür war das bereits sehr weit fortgeschrittene Stadium der Erkankung (BCLC C und D).

Alle Patientenproben des HCC-Kollektivs wurden histopathologisch begutachtet.Eine Ausnahme bildete auch hier das Patientenkollektiv OA1, OA2 und OA3. Es erfolgte eine Klassifikation nach dem TNM-System ${ }^{38}$ und Grading durch das Pathologische Institut des Universätsklinikums Frankfurt. Die Probenentnahme und Untersuchung erstreckte sich über den Zeitraum von Mai bis Dezember 2018. Weitere Ergebnisse des Patientenkollektivs sind Tab. 3.1 zu entnehmen.

\subsubsection{Patientendaten}

\section{Geschlecht}

Die 25 entnommenen Patientenproben stammten zu 48\% ( $n=12)$ von männlichen Patienten und zu 52\% ( $n=13)$ von weiblichen Patienten. Dabei waren 16\% $(n=4)$ aller Proben von männlichen Patienten, die an einer nicht malignen Veränderung der Leber litten, und 24\% $(n=6)$ aller Proben von weiblichen Patienten der besagten NMLD-Gruppe. 


\section{Alter}

Das mittlere Alter aller Patienten zum Zeitpunkt der Blutentnahme betrug 63,1 Jahre (Stabw. \pm 10,7). Dabei lag das mittlere Alter der HCC-Patienten bei 66,6 Jahren (Stabw. \pm 7,9) und das mittlere Alter der NMLD-Gruppe bei 57,9 Jahren (Stabw. \pm 12,5) .

Trotz einer niedrigen Fallzahl von $n=25$ ließ sich in der Gesamtverteilung des Alters der Patienten graphisch eine Normalverteilung vermuten (s. Abb 3.5).

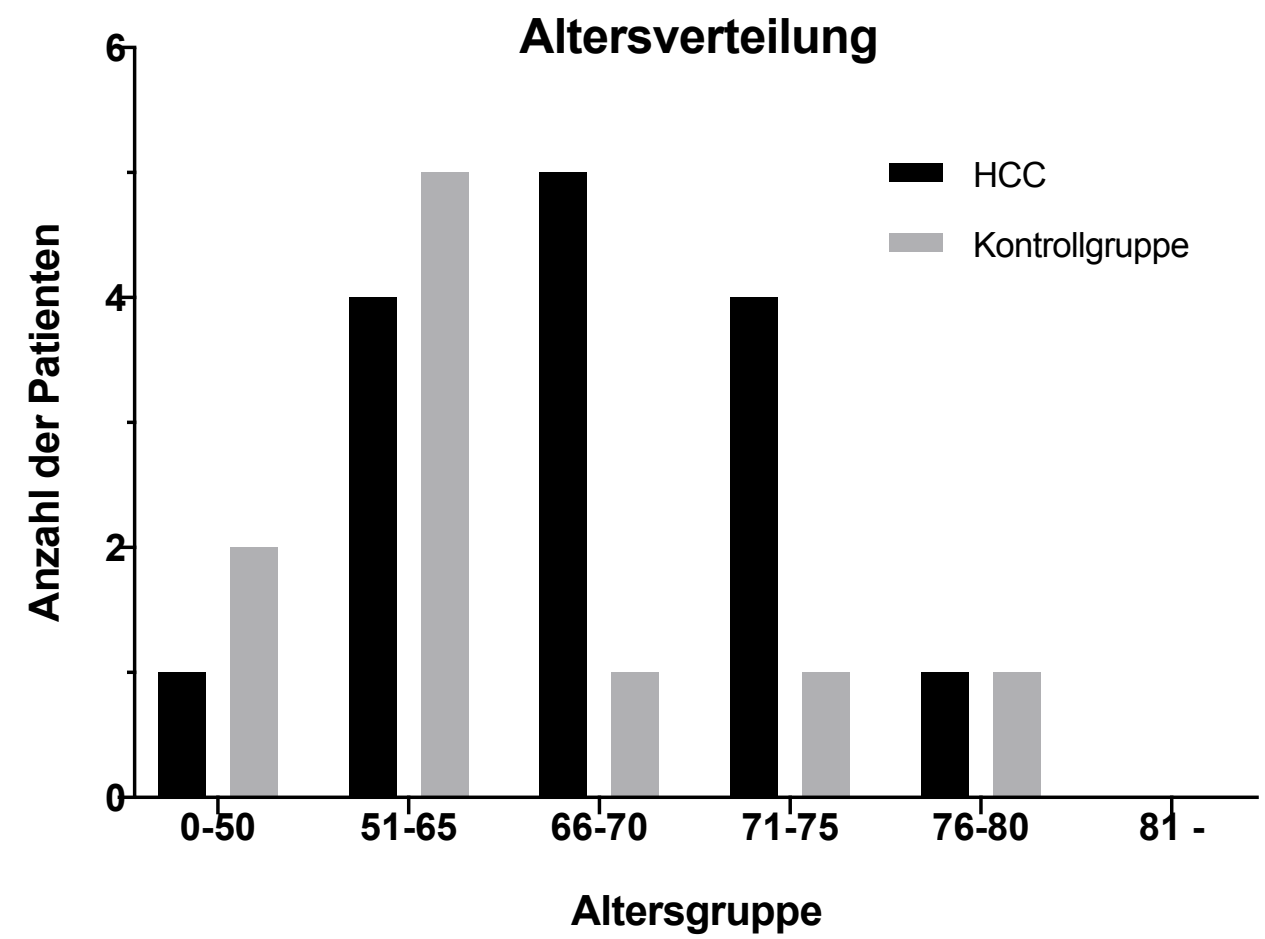

Abbildung 3.5: Altersverteilung der untersuchten Patienten 


\section{Zugrunde liegende Lebererkrankung}

Die auslösenden Erkrankungen verteilten sich wie in Abb. 3.6 dargestellt. Dabei war die häufigste Grunderkrankung mit 30,43\% $(n=7)$ die Leberzirrhose, gefolgt von Alkoholmissbrauch mit 26\% $(n=6)$ und der NASH mit ebenfalls 26\% $(n=6)$ am Gesamtanteil der HCC-Gruppe. Mit 13,04\% $(\mathrm{n}=3)$ war der DM Typ 2 auslösend.

Die Mischformen spielten ebenfalls eine Rolle. Bei 33,3\% ( $n=5)$ der Patienten war die Kombination aus Alkoholmissbrauch und einer Leberzirrhose auslösend. 13,3\% $(n=2)$ wiesen eine Mischform aus äthylotoxisch bedingter Leberzirrhose und einem DM Typ 2 auf. Ein Patient litt bei Vorliegen einer NASH gleichzeitg auch an einem DM Typ 2. Lediglich bei einem Patienten war der Auslöser unbekannter Ursache.

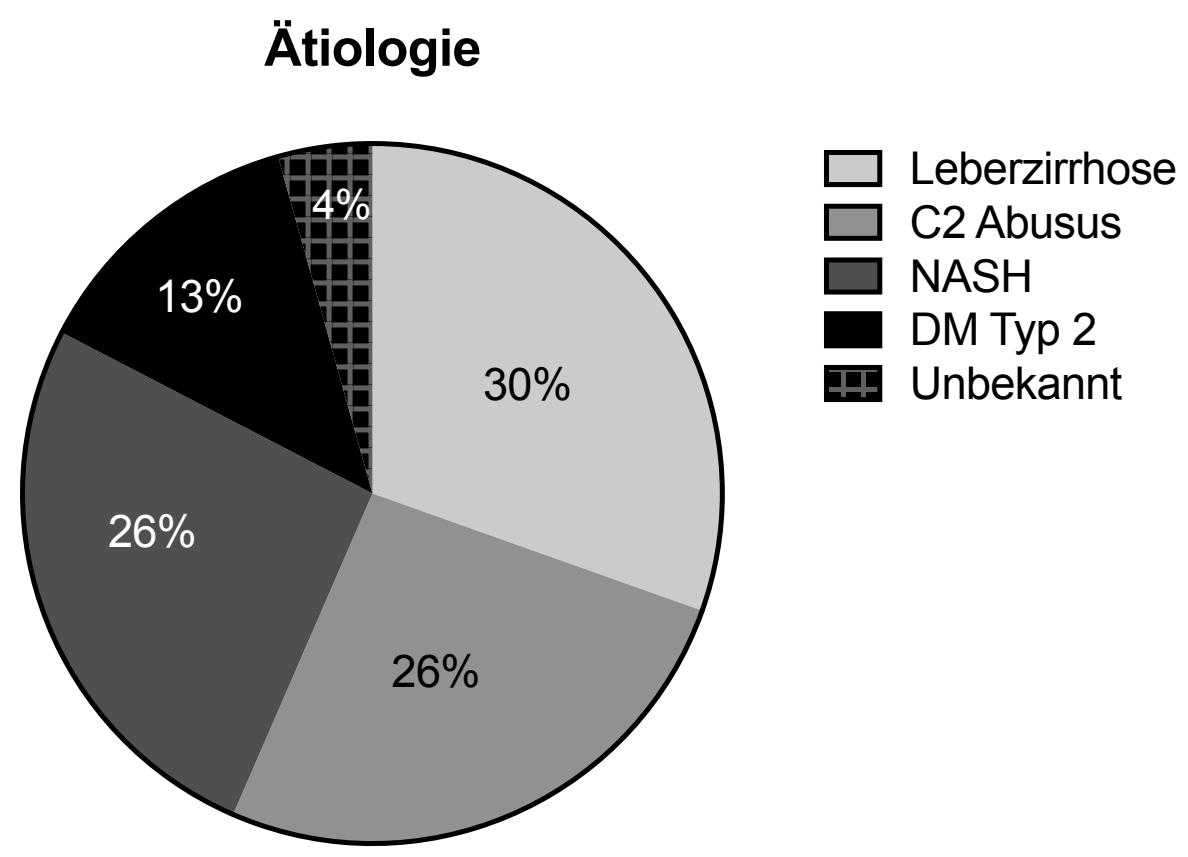

Abbildung 3.6: Ätiologie der HCC-Erkrankung 


\begin{tabular}{|c|c|c|}
\hline Variablen & & Werte \\
\hline Alter (Jahre) & & $66,6(49-80)$ \\
\hline \multirow[t]{2}{*}{ Geschlecht } & männlich & $8(53,3)$ \\
\hline & weiblich & $7(46,7)$ \\
\hline \multirow[t]{5}{*}{ Ätiologie } & Leberzirrhose & $7(30,43)$ \\
\hline & C2 Abusus & $6(26)$ \\
\hline & NASH & $6(26)$ \\
\hline & Diabetes Typ 2 & $3(13)$ \\
\hline & unbekannt & $1(6,6)$ \\
\hline \multirow[t]{4}{*}{ Grading (Edmondson\&Steiner) } & G1 & $0(0)$ \\
\hline & G2 & $11(73,3)$ \\
\hline & G3 & $2(13,3)$ \\
\hline & unbekannt & $2(13,3)$ \\
\hline \multirow[t]{3}{*}{ Tumorgröße $(\mathrm{cm})$} & $<2$ & $1(6,6)$ \\
\hline & $2-5$ & $7(46,7)$ \\
\hline & $>5$ & $7(46,7)$ \\
\hline \multirow[t]{5}{*}{ Laborwerte } & Albumin $[\mathrm{g} / \mathrm{dl}]$ & $3,967(3-4,6)$ \\
\hline & Alkalische Phosphatase [U/l] & $161,6(79-428)$ \\
\hline & Total Bilirubin [mg/dl] & $3,793(0,3-44,8)$ \\
\hline & Alpha Fetoprotein $[\mu \mathrm{g} / \mathrm{l}]$ & $481,9(2,6-4329)$ \\
\hline & IL-6 [ng/ml] & $8,936(1,5-25,7)$ \\
\hline \multirow[t]{5}{*}{ BCLC } & 0 & $1(6,6)$ \\
\hline & $\mathrm{A}$ & $0(0)$ \\
\hline & $\mathrm{B}$ & $4(26,6)$ \\
\hline & $\mathrm{C}$ & $7(46,6)$ \\
\hline & $\mathrm{D}$ & $3(20)$ \\
\hline Portalvenenthrombose (V-Status) & & $3(20)$ \\
\hline
\end{tabular}

Tabelle 3.1: Die Angaben in der Tabelle beziehen sich auf die HCC-Gruppe. Variablen werden mit Mittelwert (Spannweite) oder Anzahl (\%) angegeben. NASH=Non Alcoholic Steatohepatitis, BCLC=BarcelonaClinic-Liver-Cancer 


\subsubsection{Detektion polarisierter CTC in Patientenproben}

\section{Färbeintensität}

Bei der Erhebung der Anzahl polarisierter CTC wurde ein Scoring vorgenommen. Dieses Scoring wurde von 2 Untersuchern (Doktorandin und Laborbetreuerin) unabhängig voneinander bestätigt. Dabei wurde die Färbeintensität des Anti-Ezrin-Alexa Fluor 488 in drei Kategorien aufgeteilt und in der weiteren Auswertung wie folgt übernommen:

- Schwache Färbung [+]

- Moderate Färbung [++]

- Starke Färbung $[+++]$

Eine repräsentative Darstellung der Färbeintensitäten finden sich in Abb. 3.7.
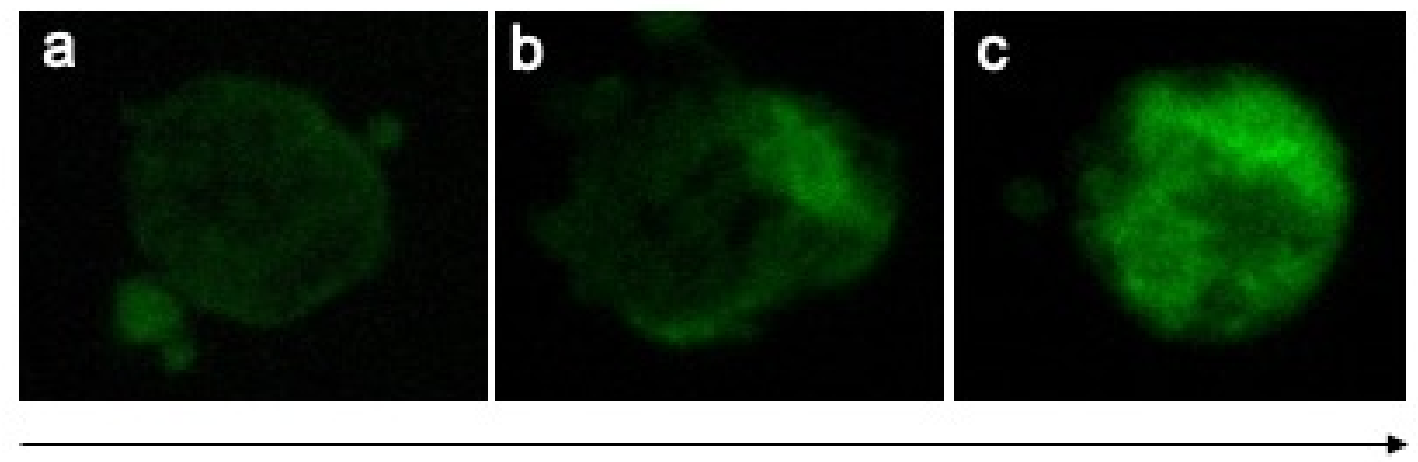

Abbildung 3.7: Darstellung der Färbeintensität von Anti-Ezrin-Alexa Fluor 488 in den Tumorzellen. a) schwache Färbung $[+]$ b) moderate Färbung $[++]$ c) starke Färbung $[+++]$

\section{Patientenproben}

Abb. 3.8 zeigt beispielhaft die Färbung polarisierter CTCs in Patientenproben im Vergleich zur Färbung einer ebenfalls in Patientproben detektieren nicht polarisierten CTC. Im weiteren Verlauf werden Zellen wie in (a) gezeigt als polarisierte CTC bezeichnet und Zellen wie in (b) dargestellt als CTC ohne Polarisierung. 

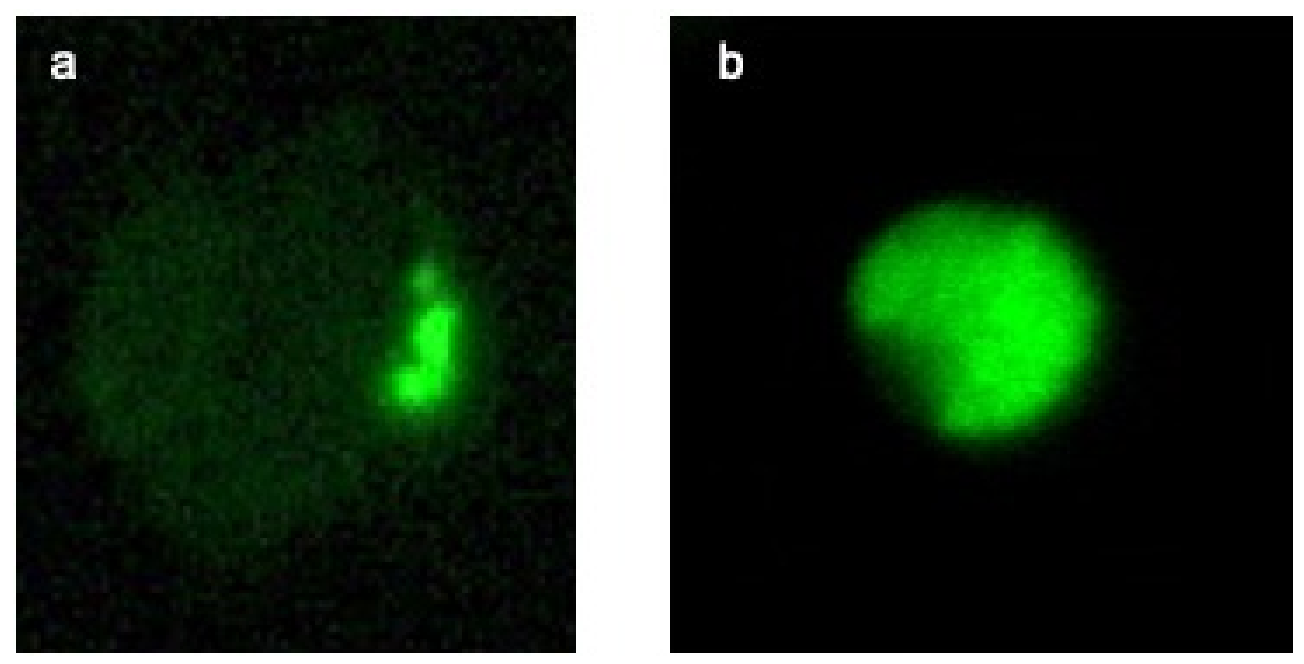

Abbildung 3.8: Anti-Ezrin-Alexa Fluor 488 / FITC positiv, 40-fache Vergrößerung: a) Polarisierte Tumorzelle aus Patientenprobe S75 b) nicht polarisierte Tumorzelle mit starker [+++] intrazellulärer Anti-Ezrin Färbung aus Patientenprobe E2.

Weitere Beispiele polarisierter CTCs finden sich in Abb. 3.9. In Vorarbeiten der Arbeitsgruppe wurden mit Hilfe der Durchflusszytometrie CD146 (Melanoma cell adhesion molecule (MCAM)) mit einer Sensitivität von 99\% in HepG2-Zellen als tumorspezifischer Marker identifiziert. Daher dient die gezeigte positive Färbung der isolierten Tumorzellen mit CD146 auch in dieser Untersuchung dem Ausschluss einer Falsch-Positivität. Eine weitere Negativkontrolle erfolgt durch den leukozytenspezifischen Marker CD45. So kann ausgeschlossen werden, dass es sich bei der detektierten Zelle um einen Leukozyten handelt. 


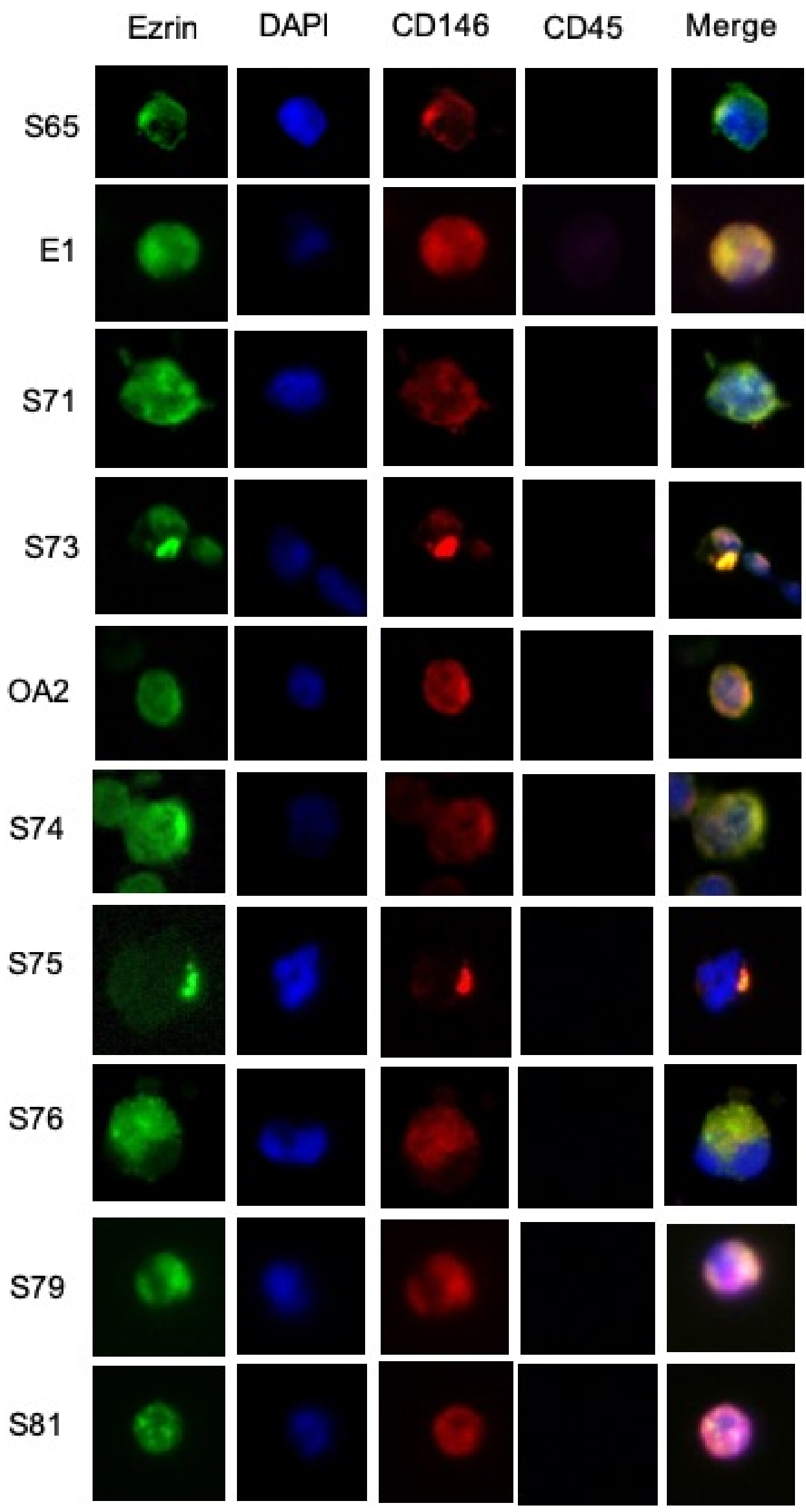

Abbildung 3.9: Beispielhafte Darstellung polarisierter CTC der einzelnen Patientenproben. Anti-Ezrin (grün), Zellkernfärbung DAPI (blau), CD146 (rot), Leukozyten / CD45 (violett), Überlagerungsbilder (Merge) Zellen 40-fache Vergrößerung. 


\subsubsection{Statistische Auswertung der Detektionsraten}

In 14 der 15 HCC-Patienten $(93,3 \&)$ konnten CTCs $(1,2$ CTCs/ml) detektiert werden. Insgesamt konnten in 10 von 15 (66,6\%) HCC-Patienten p-CTCs nachgewiesen werden. In den positiven Blutproben ließen sich zwischen minimal einer und maximal sechs p-CTC detektieren. Damit wurden im Mittel 0,42 p-CTC pro Milliliter Blutprobe nachgewiesen.

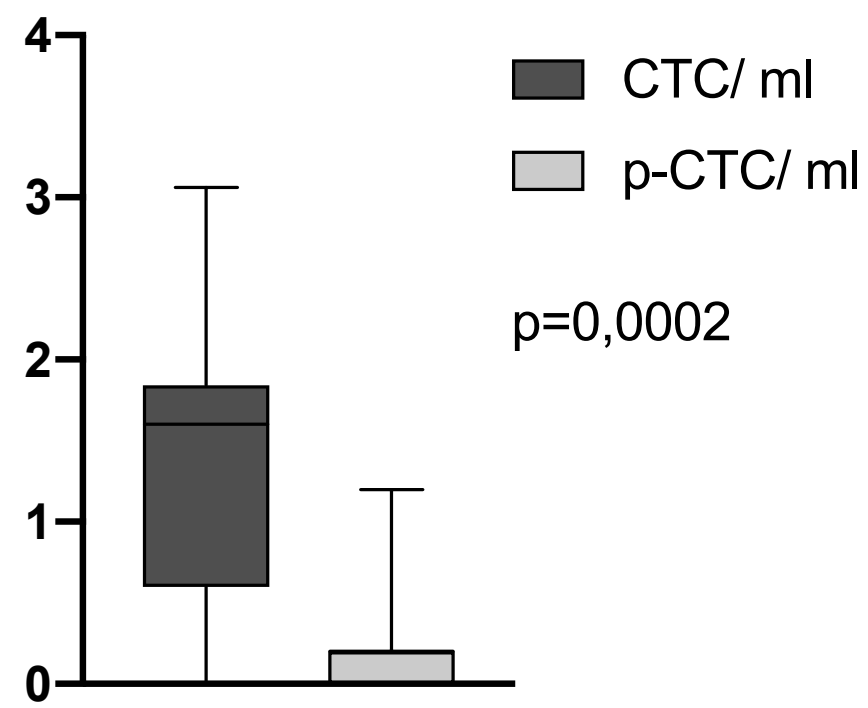

Abbildung 3.10: Wiederfindungsraten aller CTCs/ml vs. p-CTCs/ml in der Gruppe der HCC-Patienten 


\begin{tabular}{lcccccccc}
\hline Patienten \# & Alter & pT & pN & pM & V & R & CTC total & polar CTC \\
\hline S65 & 68 & T2 & Nx & M0 & 0 & 0 & 15 & 4 \\
E1 & 68 & T4 & N1 & M0 & 0 & 0 & 9 & 0 \\
S71 & 65 & T1b & Nx & M0 & 0 & 0 & 4 & 1 \\
S72 & 72 & T3 & Nx & M0 & 1 & 1 & 9 & 0 \\
S73 & 68 & T1b & Nx & M0 & & & 3 & 1 \\
OA1 & 71 & & & M0 & & & 3 & 0 \\
OA2 & 63 & & & M0 & & & 2 & 1 \\
S74 & 72 & T1a & Nx & M0 & 0 & 0 & 2 & 1 \\
OA3 & 69 & & & M0 & & & 0 & 0 \\
S75 & 55 & T1b & Nx & M0 & 0 & 0 & 9 & 4 \\
S76 & 49 & T3 & Nx & M0 & 1 & 1 & 3 & 1 \\
S77 & 57 & T3 & No & M0 & 1 & 0 & 8 & 1 \\
S79 & 74 & T1a & Nx & M0 & 0 & 0 & 12 & 1 \\
S81 & 67 & T1b & Nx & M0 & 0 & 0 & 8 & 6 \\
S83 & 80 & T3 & Nx & M0 & 0 & 0 & 9 & 0 \\
\hline & & & & & & & \\
\hline
\end{tabular}

Tabelle 3.2: Übersicht der Anzahl CTC total vs. p-CTC in der HCC-Gruppe.

\begin{tabular}{lllcc}
\hline Patienten \# & Alter & Diagnose & CTC total & polar CTC \\
\hline S66 & 77 & Regeneratknoten & 0 & 0 \\
S67 & 54 & Caroli-Syndrom & 0 & 0 \\
S68 & 74 & Leberzyste & 0 & 0 \\
S78 & 53 & Hepatolithiasis & 3 & 0 \\
S80 & 61 & dysontogenetische Leberzyste & 5 & 0 \\
S82 & 34 & Echinokkokus Zyste & 0 & 0 \\
OA4 & 55 & Leberzirrhose & 1 & 0 \\
OA5 & 47 & Leberzirrhose & 2 & 0 \\
OA6 & 61 & Leberzirrhose & 0 & 0 \\
OA7 & 66 & Leberzirrhose & 0 & 0 \\
\hline
\end{tabular}

Tabelle 3.3: Übersicht der Anzahl CTC total vs. p-CTC in der NMLD-Gruppe. 


\begin{tabular}{lccccccccc}
\hline Patienten \# & Alter & BCLC & pT & pN & pM & V & R & CTC total & polar CTC \\
\hline S65 & 68 & B & T2 & Nx & M0 & 0 & 0 & 15 & 4 \\
S71 & 65 & B & 1b & Nx & M0 & 0 & 0 & 4 & 1 \\
S73 & 68 & C & 1b & Nx & M1 & & & 3 & 1 \\
OA2 & 63 & C & & & & & & 2 & 1 \\
S74 & 72 & 0 & $1 \mathrm{a}$ & Nx & M0 & 0 & 0 & 2 & 1 \\
S75 & 55 & B & $1 b$ & Nx & M0 & 0 & 0 & 9 & 4 \\
S76 & 49 & C & T3 & Nx & M0 & 1 & 1 & 3 & 1 \\
S77 & 57 & D & T3 & N0 & M0 & 1 & 0 & 8 & 1 \\
S79 & 74 & B & T1a & Nx & M0 & 0 & 0 & 12 & 1 \\
S81 & 67 & C & T1b & Nx & M0 & 0 & 0 & 8 & 6 \\
\hline
\end{tabular}

Tabelle 3.4: Ausgewählte Daten von Patienten, die mindestens eine polarisierte Tumorzelle aufwiesen.

\subsubsection{Detektionsraten in Abhängigkeit von Tumorgröße und T-Stadium}

Elf von fünfzehn Tumorpräparaten konnten hinsichtlich ihrer Tumorgröße gemäß der TNMKlassifikation ${ }^{38}$ histopathologisch einem T-Stadium zugeordnet werden. Bei drei Patienten war der Tumor nicht mehr lokal begrenzt, sondern verteilte sich diffus über das gesamte Leberparenchym. Bei einem weiteren Patienten erfolgte die Größenbestimmung mittels CT-Diagnostik.

\section{Tumorstadium}

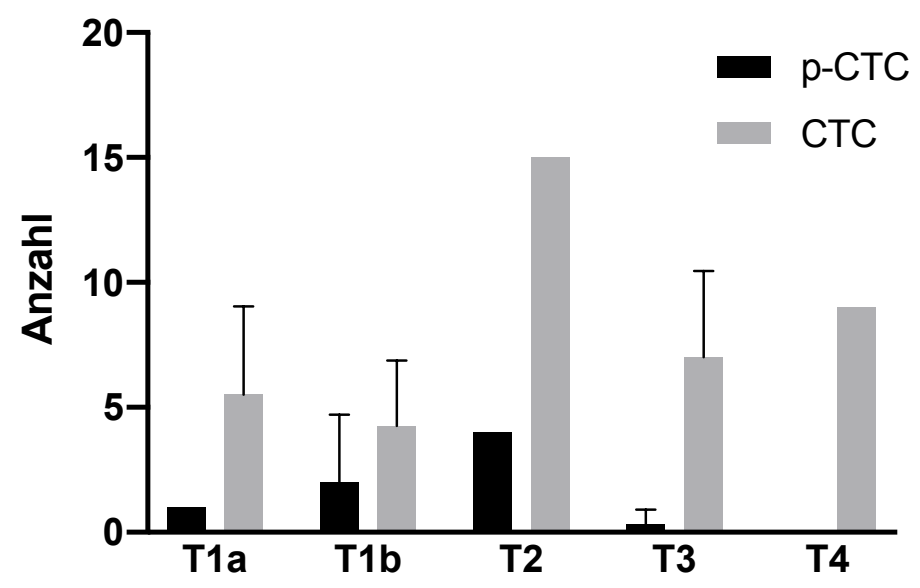

Abbildung 3.11: Detektionsraten der CTCs vs. p-CTCs geordnet in Tumorstadien. 


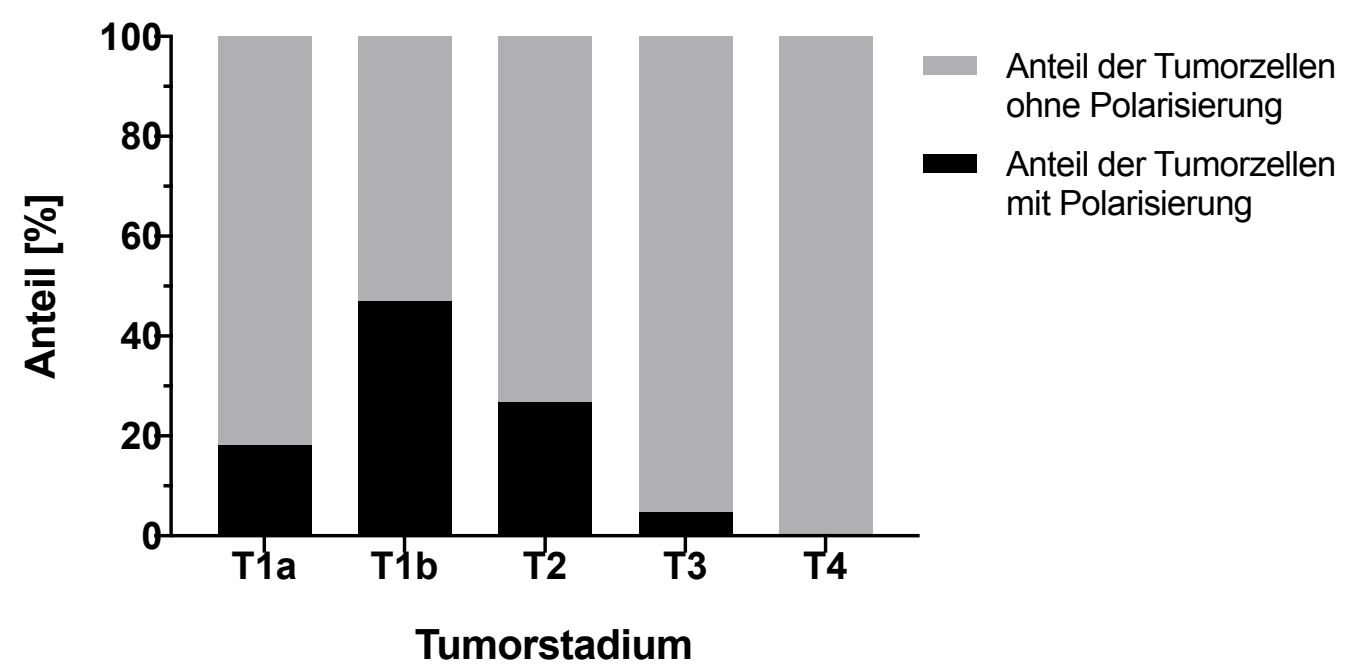

Abbildung 3.12: Verteilung der polarisierten CTCs nach Tumorstadium

In neun der elf (81\%) Proben konnten polarisierte CTC detektiert werden. In beiden Proben, die in einem relativ frühen Stadium (T1a) des diagnostizierten HCC waren (100\%), wurden polarisierte CTC detektiert.

Das größte Kollektiv in Bezug auf das Tumorstadium bildete die Gruppe mit Tumorstadium T1b $(\mathrm{n}=4)$. In diesem Stadium waren drei von vier (75\%) Proben positiv.

\section{Tumorgröße}

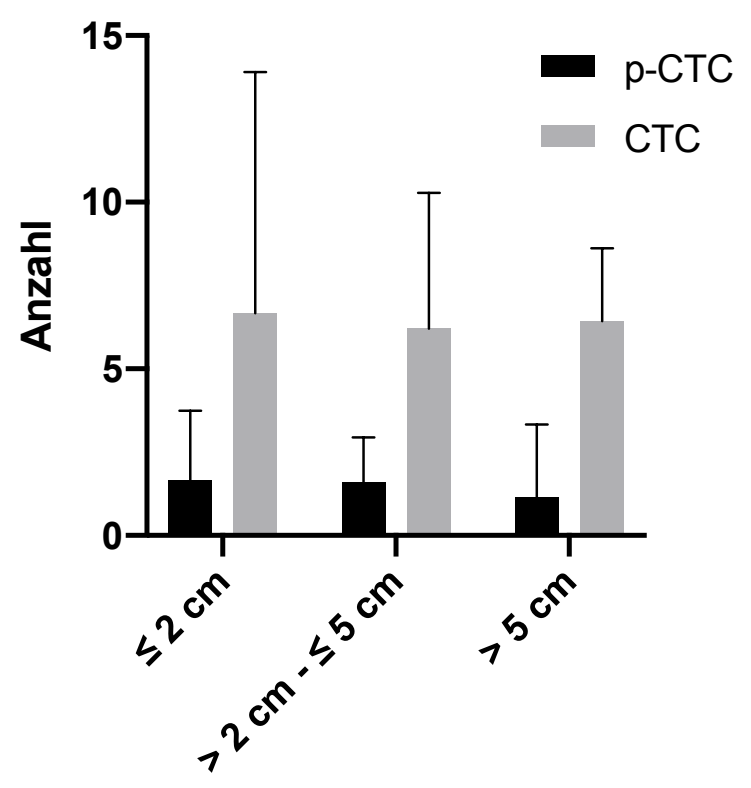

Abbildung 3.13: Detektionsraten der CTCs vs. p-CTCs geordnet nach aufsteigender Größe des Tumors.Eine genaue Angabe der Anzahl detektierter CTCs und p-CTCs kann Tab. 3.5 entnommen werden 


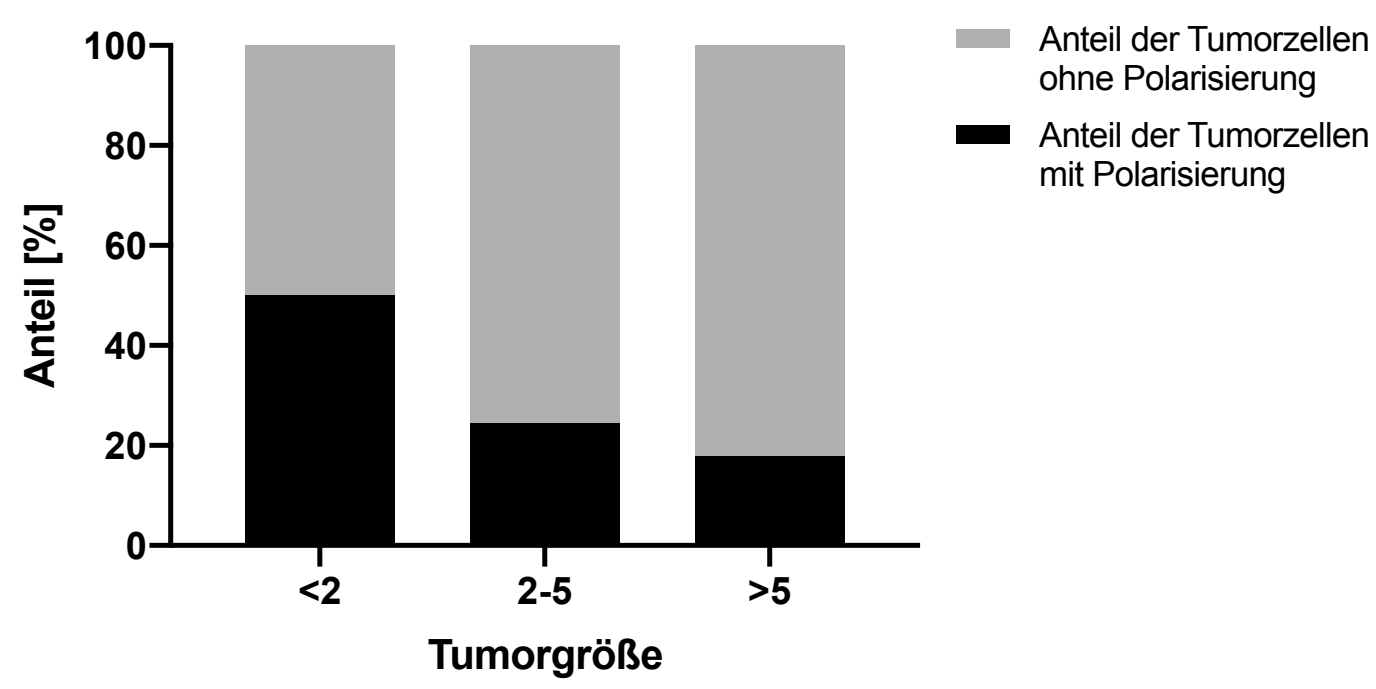

Abbildung 3.14: Verteilung der polarisierten CTCs nach Tumorgröße [cm]

Die Korrelationsanalyse ergab mit $r=0,130$ und $p=0,685$ keinen signifikanten Zusammenhang zwischen Tumorgröße und der Anzahl and CTC ohne Polarisierung. Eine negative Korrelation fand sich mit der Tumorgröße und der Anzahl polarisierter CTC ( $r=-0,029, p=0,93)$.

\begin{tabular}{|c|c|c|c|c|c|c|c|}
\hline Patienten \# & Tumorgröße $[\mathrm{cm}]$ & BCLC & CTC total & polar CTC & Ezrin + & Ezrin ++ & Ezrin +++ \\
\hline S74 & 0,70 & 0 & 2 & 1 & 0 & 1 & 1 \\
\hline S65 & 2,00 & B & 15 & 4 & 8 & 5 & 2 \\
\hline OA1 & 2,00 & $\mathrm{C}$ & 3 & 0 & 0 & 3 & 0 \\
\hline S71 & 2,50 & B & 4 & 1 & 1 & 3 & 0 \\
\hline S79 & 3 & B & 12 & 1 & 0 & 3 & 9 \\
\hline S75 & 3,8 & B & 9 & 4 & 0 & 1 & 8 \\
\hline S76 & 3,80 & $\mathrm{C}$ & 3 & 1 & 0 & 0 & 1 \\
\hline S73 & 4 & $\mathrm{C}$ & 3 & 1 & 1 & 0 & 2 \\
\hline $\mathrm{OA} 2$ & 8,00 & $\mathrm{C}$ & 2 & 1 & 0 & 1 & 1 \\
\hline S81 & 10 & C & 8 & 6 & 0 & 0 & 8 \\
\hline S77 & 13 & $\mathrm{D}$ & 8 & 1 & 0 & 2 & 6 \\
\hline S72 & 14 & $\mathrm{D}$ & 9 & 0 & 1 & 7 & 1 \\
\hline E1 & diffus & $\mathrm{C}$ & 9 & 0 & 1 & 3 & 5 \\
\hline OA3 & diffus & $\mathrm{D}$ & 0 & 0 & 0 & 0 & 0 \\
\hline S83 & diffus & $\mathrm{C}$ & 9 & 0 & 8 & 1 & 0 \\
\hline
\end{tabular}

Tabelle 3.5: Anzahl detektierter CTC mit und ohne Polarisierung in Bezug auf die Tumorgröße. 


\subsubsection{Detektionsraten bei Patienten mit Fernmetastasen}

Hinsichtlich Fernmetastasierung wurden bei drei der fünfzehn (20\%) HCC-Patienten vor Blutentnahme im Rahmen des klinischen Metastasenscreenings Metastasen nachgewiesen. In dieser Patientengruppe konnten lediglich in einer Probe polarisierte CTCs detektiert werden. Absolute Zahlenangaben finden sich zur Übersicht in Tab. 3.6.

\begin{tabular}{lcccccc}
\hline Patienten \# & CTC total & polar CTCs & total Ezrin & Ezrin + & Ezrin ++ & Ezrin +++ \\
\hline S72 & 9 & 0 & 9 & 1 & 7 & 1 \\
S73 & 3 & 1 & 3 & 1 & 0 & 2 \\
OA3 & 0 & 0 & 0 & 0 & 0 & 0 \\
\hline
\end{tabular}

Tabelle 3.6: Anzahl detektierter CTCs mit und ohne Polarisierung in Bezug auf den M1-Status

\section{V-Status}

Drei der fünfzehn (20 \%) Patienten mit HCC wiesen eine tumoröse Infiltration der Portalvene auf. Diese Patientengruppe wird hinsichtlich des signifikanten Einflusses dieses Faktors auf die Prognose in Tab. 3.7 in Bezug auf die Anzahl vorhandener Tumorzellen mit und ohne Polarisierung genauer beleuchtet. Es wurden in zwei von drei $(66,6 \%)$ Patienten polarisierte CTC nachgewiesen. In allen drei Proben (100\%) wurden CTCs detektiert.

\begin{tabular}{lcccccc}
\hline Patienten \# & CTC total & polar CTCs & total Ezrin & Ezrin + & Ezrin ++ & Ezrin +++ \\
\hline S72 & 9 & 0 & 9 & 1 & 7 & 1 \\
OA2 & 2 & 1 & 2 & 0 & 1 & 1 \\
S77 & 8 & 1 & 8 & 0 & 2 & 6 \\
\hline
\end{tabular}

Tabelle 3.7: Anzahl detektierter CTCs mit und ohne Polarisierung in Bezug auf den V-Status 


\subsubsection{Detektionsraten in Abhängigkeit vom BCLC-Stadium}

Es konnten insgesamt 15 Proben auf ihr BCLC-Stadium zurückgeführt werden. Dabei waren im

- Stadium 0: eine von einer (100 \%) Probe

- Stadium B: vier von vier (100 \%) Proben

- Stadium C: vier von sieben Proben (57,1 \%)

- Stadium D: eine von drei (33,3\%) Proben

positiv im Sinne von gefundenen polarisierten CTC.

\section{BCLC Stadium}

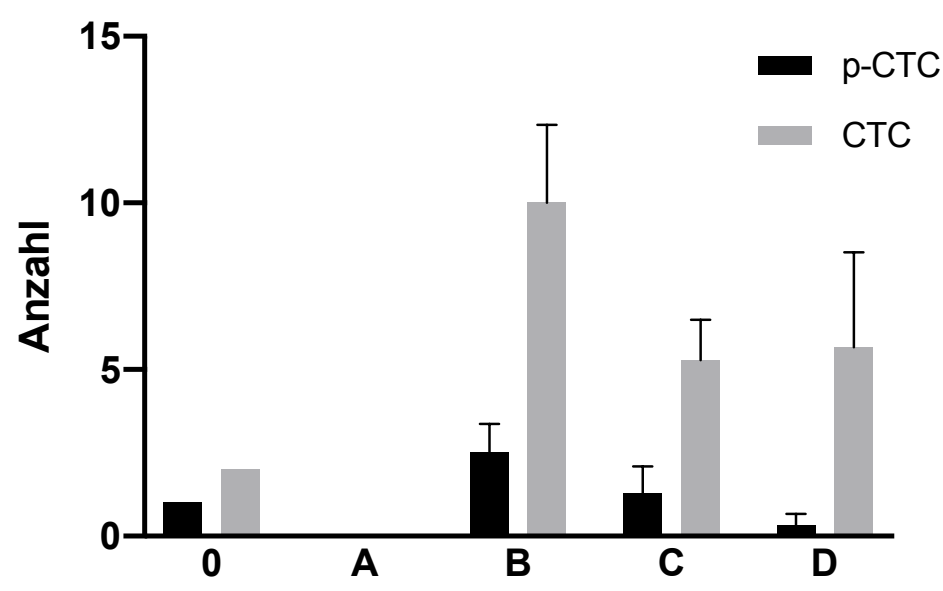

Abbildung 3.15: Detektionsraten der CTCs vs. p-CTCs geordnet nach BCLC-Stadien.

Die Abb. 3.16 stellt den prozentualen Anteil der Tumorzellen mit und ohne Polarisierung an der Gesamtmenge aller detektieren Tumorzellen dar. Es gab in der Untersuchung keinen Patienten mit dem BCLC-Stadium A. Daher liegen für diese Gruppe auch keine Zahlen vor. Auffällig ist, dass der prozentuale Anteil der polarisierten CTCs mit steigendem BCLC-Stadium abnimmt. 


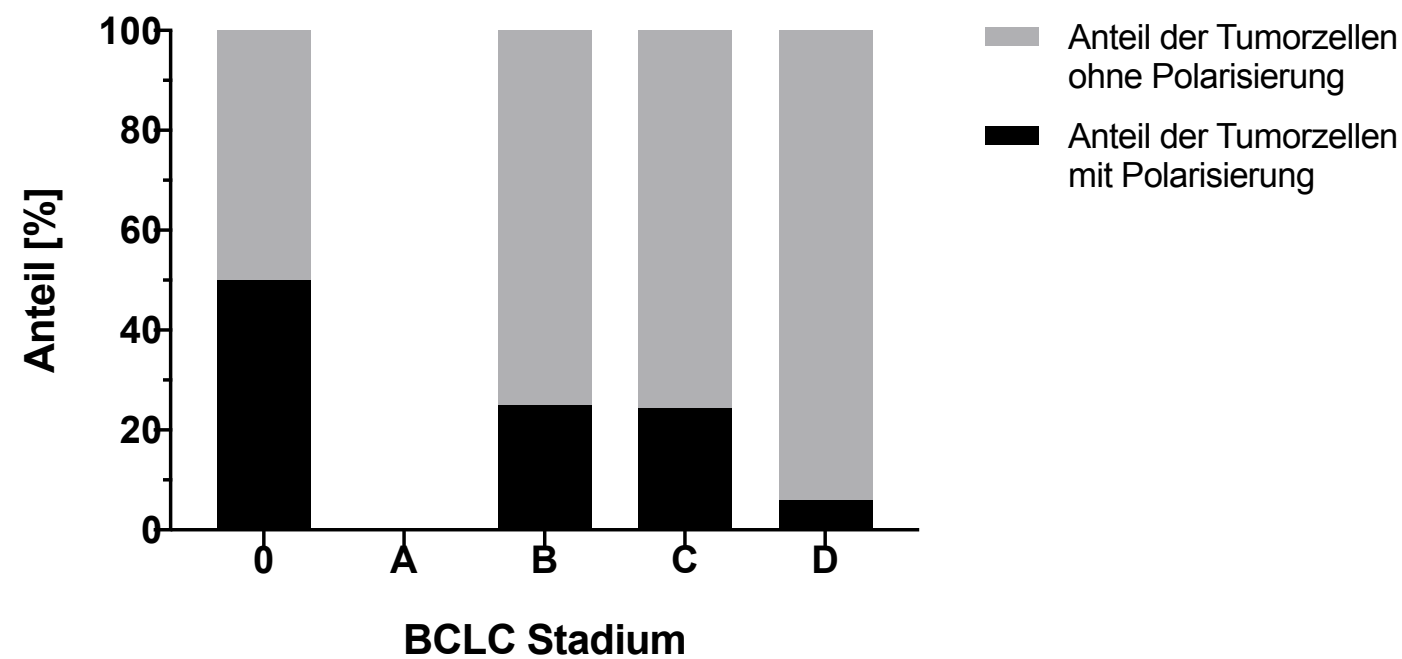

Abbildung 3.16: Prozentualer Anteil der Tumorzellen mit und ohne Polarisierung in Bezug auf alle detektieren Tumorzellen bei unterschiedlichen BCLC-Stadien

Eine statistische Überprüfung der Ergebnisse, insbesondere der Korrelationsanalyse zwischen BCLC-Stadium und Anzahl der CTCs mit Polarisierung, ließ keine signifikante Aussage zu ( $\mathrm{r}=-$ 0,511; $\mathrm{p}=0,067)$. BCLC-Stadium und die Anzahl der CTCs ohne Polarisierung ergab ebenfalls eine negative Korrelation $(\mathrm{r}=-0,219, \mathrm{p}=0,449)$. 


\begin{tabular}{lcccccc}
\hline Patienten\# & BCLC & CTC total & polar CTC & Ezrin + & Ezrin ++ & Ezrin +++ \\
\hline S74 & 0 & 2 & 1 & 0 & 1 & 1 \\
S65 & B & 15 & 4 & 8 & 5 & 2 \\
S71 & B & 4 & 1 & 1 & 3 & 0 \\
S75 & B & 9 & 4 & 0 & 1 & 8 \\
S79 & B & 12 & 1 & 0 & 3 & 9 \\
E1 & C & 9 & 0 & 1 & 3 & 5 \\
S73 & C & 3 & 1 & 1 & 0 & 2 \\
OA1 & C & 3 & 0 & 0 & 3 & 0 \\
OA2 & C & 2 & 1 & 0 & 1 & 1 \\
S76 & C & 3 & 1 & 0 & 0 & 1 \\
S81 & C & 8 & 6 & 0 & 0 & 8 \\
S83 & C & 9 & 0 & 8 & 1 & 0 \\
S72 & D & 9 & 0 & 1 & 7 & 1 \\
OA3 & D & 0 & 0 & 0 & 0 & 0 \\
S77 & D & 8 & 1 & 0 & 2 & 6 \\
\hline
\end{tabular}

Tabelle 3.8: Anzahl detektierter CTCs mit und ohne Polarisierung in Bezug auf das BCLC-Stadium

\subsubsection{Detektionsraten in Abhängigkeit vom Differenzierungsgrad}

Die zahlenmäßig am stärksten vertretene Gruppe waren G2 mit 73,3\% aller Patienten. Patienten mit dem Differenzierungsgrad G1 gab es nicht. Daten für diese Gruppe liegen entsprechend nicht vor. Auffällig ist, dass die zahlenmäßig kleinere Patientengruppe mit G3 einen prozentual höheren Anteil an polarisierten Tumorzellen aufweist als die Gruppe G2 (Abb. 3.18).

Ein möglicher Zusammenhang zwischen der Anzahl detektierter polarisierter CTCs und dem Differenzierungsgrad G3 ließ sich jedoch statistisch nicht verifizieren ( $r=0,061 ; p=0,897)$. 


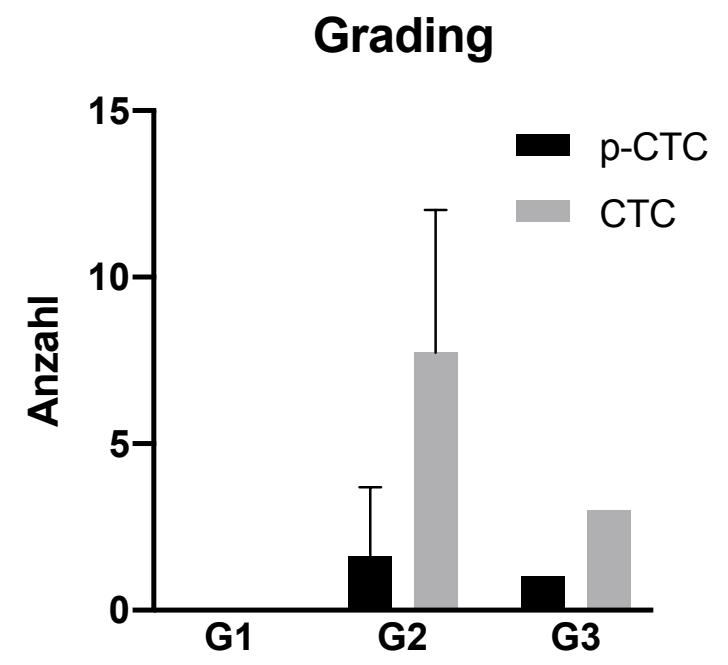

Abbildung 3.17: Detektionsraten der CTCs vs. p-CTCs in Bezug auf den pathologisch gesicherten Differenzierungsgrad des Primärtumors.

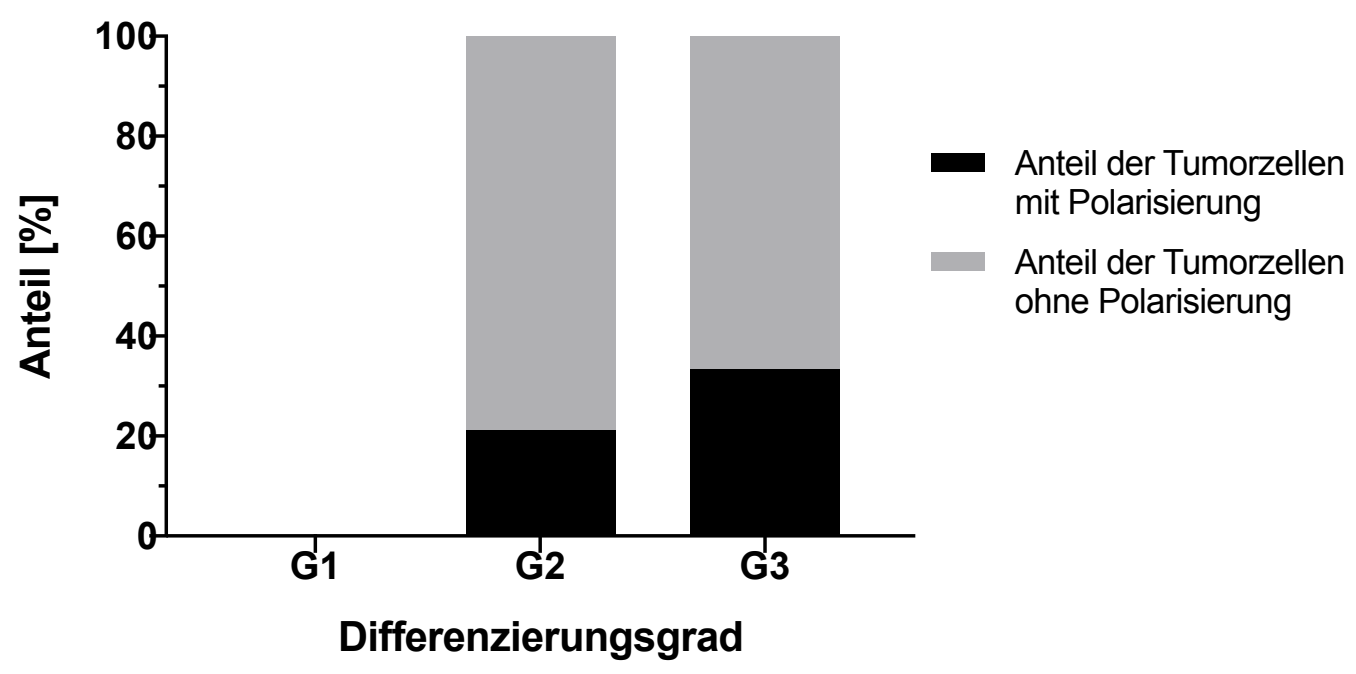

Abbildung 3.18: Anzahl detektierter CTCs mit und ohne Polarisierung in Bezug auf den Differenzierungsgrad 


\begin{tabular}{lllllll}
\hline Patienten \# & Grading & CTC total & polar CTC & Ezrin + & Ezrin ++ & Ezrin +++ \\
\hline S65 & G2 & 15 & 4 & 8 & 5 & 2 \\
E1 & G2 & 9 & 0 & 1 & 3 & 5 \\
S71 & G2 & 4 & 1 & 1 & 3 & 0 \\
S72 & G2 & 9 & 0 & 1 & 7 & 1 \\
S74 & G2 & 2 & 1 & 0 & 1 & 1 \\
OA3 & G2 & 0 & 0 & 0 & 0 & 0 \\
S75 & G2 & 9 & 4 & 0 & 1 & 8 \\
S77 & G2 & 8 & 1 & 0 & 2 & 6 \\
S79 & G2 & 12 & 1 & 0 & 3 & 9 \\
S81 & G2 & 8 & 6 & 0 & 0 & 8 \\
S83 & G2 & 9 & 0 & 8 & 1 & 0 \\
S73 & G3 & 3 & 1 & 1 & 0 & 2 \\
S76 & G3 & 3 & 1 & 0 & 0 & 1 \\
\hline
\end{tabular}

Tabelle 3.9: Anzahl detektierter CTCs mit und ohne Polarisierung in Bezug auf den Differenzierungsgrad.

\subsubsection{Assoziation der Detektionsraten mit der AFP-Serumkonzentration}

\section{AFP}

Die AFP-Werte wurden am Tag der Blutentnahme im Rahmen der Laborroutineuntersuchung bestimmt. Sie wurden für alle HCC-Patienten und Patienten der NMLD-Gruppe erhoben. Die Werte der HCC-Gruppe zeigte eine Spanne von minimal 2,6 ng/ml bis maximal $60.500 \mathrm{ng} / \mathrm{ml}$. Der Mittelwert beträgt 8484 ng/ml (Stabw. $\pm 21147 \mu \mathrm{g} / \mathrm{l}$ ). Dabei wurden bei zwei Proben mit > $60.500 \mathrm{ng} / \mathrm{ml}$ Wiederholungsuntersuchungen zur Bestätigung der Messergebnisse durchgeführt.

Die Werte der NMLD-Gruppe variieren von $1,3 \mathrm{ng} / \mathrm{ml}$ bis maximal 4,1 ng/ml. Der Mittelwert beträgt 2,26 ng/ml (Stabw. $\pm 0,8859 \mathrm{ng} / \mathrm{ml}$ ).

Die statistische Überprüfung mittels Mann-Whitney-U Test ergab einen signifikanten Unterschied zwischen den Gruppen ( $\mathrm{p}<0,0001)$.

Die Korrelationsanalyse ergaben weder für den Zusammenhang mit polarisierten CTC ( $\mathrm{r}=-$ 0,286; $p=0,300)$ noch für die Gesamtzahl aller CTC $(r=-0,338 ; p=0,217)$ ein signifikantes Ergebnis. 


\begin{tabular}{|c|c|c|}
\hline Patienten \# & Gruppe & $\begin{array}{c}\text { AFP } \\
{[\mathrm{ng} / \mathrm{ml}]}\end{array}$ \\
\hline S65 & 1 & 4,3 \\
\hline E1 & 1 & 39,5 \\
\hline S71 & 1 & 147,6 \\
\hline S72 & 1 & 60.500 \\
\hline S73 & 1 & 5,9 \\
\hline OA1 & 1 & 935,6 \\
\hline OA2 & 1 & 60.500 \\
\hline S74 & 1 & 2,6 \\
\hline OA3 & 1 & 4.329 \\
\hline S75 & 1 & 6,3 \\
\hline S76 & 1 & 9,7 \\
\hline S77 & 1 & 22,6 \\
\hline S79 & 1 & 4,3 \\
\hline S81 & 1 & 753,9 \\
\hline S83 & 1 & 3,4 \\
\hline S66 & 2 & 2,5 \\
\hline S67 & 2 & 1,5 \\
\hline S68 & 2 & 2,2 \\
\hline S78 & 2 & 1,3 \\
\hline S80 & 2 & 1,4 \\
\hline S82 & 2 & 3,2 \\
\hline OA4 & 2 & 1,9 \\
\hline OA5 & 2 & 4,1 \\
\hline OA6 & 2 & 1,3 \\
\hline OA7 & 2 & 2,6 \\
\hline
\end{tabular}

Tabelle 3.10: Erhobenen Serumkonzentrationen des AFP. Gruppe 1 entspricht der HCC-Gruppe und Gruppe 2 der NMLD-Gruppe. 


\begin{tabular}{cccccc}
\hline \multicolumn{7}{c}{ Minimum } & Maximum & Spannweite & Mittelwert & Stabw. \\
\hline AFP $[\mathrm{ng} / \mathrm{ml}]$ & 2,6 & 4329 & 4326 & 481,9 & 1197 \\
\hline \multicolumn{5}{c}{ Tabelle 3.11: AFP-Werte HCC-Patienten } \\
\hline Minimum & Maximum & Spannweite & Mittelwert & Stabw. \\
\hline AFP $[\mathrm{ng} / \mathrm{ml}]$ & 1,3 & 4,1 & 2,8 & 2,2 & 0,925 \\
\hline
\end{tabular}

Tabelle 3.12: AFP-Werte NMLD-Gruppe

\subsubsection{NMLD-Gruppe: Sensitivität und Spezifität der Methode}

Zur Kontrolle der Leistungsfähigkeit der in der Arbeitsgruppe etablierten Methode wurde der NMLD-Gruppe, bestehend aus 10 Patienten, jeweils $5 \mathrm{ml}$ Blut entnommen. Die Patienten waren an einer nicht malignen Veränderung der Leber erkrankt (NMLD) (z.B. Leberzirrhose, Leberzyste, Caroli-Syndrom, Hepatolithiasis, Regeneratknoten, zystische Echinokokkose). Die Proben wurde nach genau denselben Protokollen bearbeitet wie die Blutproben der Patienten mit gesichertem HCC.

Bei keinem der 10 Patienten aus der NMLD-Gruppe konnten p-CTC nachgewiesen werden.

Die Falsch-Positiv Rate lag bei 0,2 isolierter Zellen /ml in der NMLD-Gruppe ( $\mathrm{p}=0,0006)$.

In 10/14 (71\%) der HCC Patienten konnten p-CTCs identifiziert werden. Damit wies die HCCGruppe mit 0,42 p-CTCs/ml signifikant mehr p-CTCs als die NMLD-Gruppe auf (0 p-CTCs/ml; $\mathrm{p}=0,002$ ) 


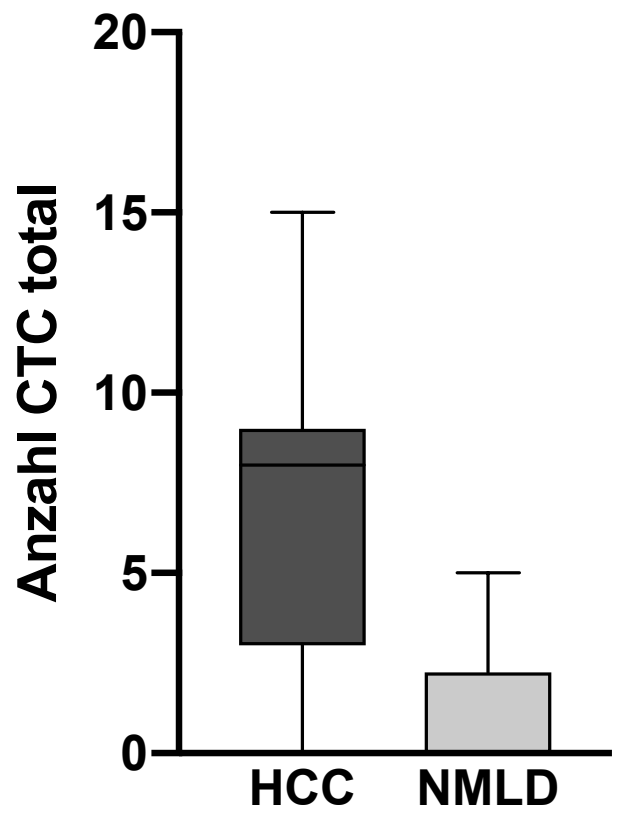

Abbildung 3.19: Vergleich aller detektierten CTCs. HCC=Hepatozelluläres Karzinom, NMLD= Non malignant liver disease

Die Abb. 3.19 zeigt die Anzahl aller detektierten CTC in der HCC Gruppe im Vergleich zur NMLD Gruppe.

In der HCC Gruppe wurden im Mittel 6,4 (min.0, max.15) CTCs detektiert mit einer Standardabweichung von 4,29 CTCs

Die NMLD Gruppe zeigte eine mittlere Wiederfindungsrate von 1,1 CTCs (Stabw. 1 1,73).

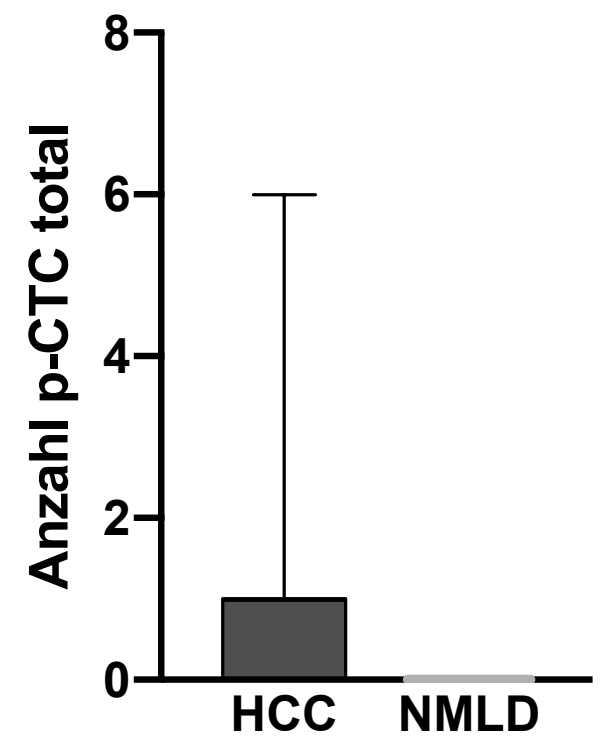

Abbildung 3.20: Vergleich der Anzahl p-CTCs total in der HCC-Gruppe vs NMLD-Gruppe. $\mathrm{HCC}=$ Hepatozelluläres Karzinom, $\mathrm{NMLD}=$ Non malignant liver disease 
Wie in Abb. 3.20 dargestellt konnten Zwischen 0 und max. 6 p-CTC in der HCC-Gruppe nachgewiesen werden. Im Mittelwert 1,4 CTC (Stabw. $\pm 1,85$ ).

In der NMLD-Gruppe wurden keine p-CTC detektiert. 


\section{Diskussion}

Trotz erfolgreicher Forschung in den letzten Jahren und der Weiterentwicklung laboranalytischer Verfahren zur Diagnosesicherung bleibt das HCC eine der Tumorerkrankungen mit der weltweit höchsten Sterblichkeitsrate. Es entwickelt sich rasch und zeichnet sich durch eine hohe Rezidivrate aus. Die Früherkennung stellt nach wie vor einen Schwerpunkt in der erfolgreichen Therapie dar, sodass sich die Untersuchungen der Tumorforschung weltweit auf eine Diagnosestellung in diesem Stadium konzentrieren.

Besonders relevant ist dabei die frühe Detektion zirkulierender Tumorzellen im Blut der betroffenen Patienten. Im Rahmen der „liquid biopsy“, der mehr und mehr Aufmerksamkeit zukommt, können disseminierte Tumorzellen, die sich vom Primärtumor lösen und zunächst im Blut des Patienten verbleiben, um sich anschließend in peripheren Organen anzusiedeln, detektiert werden. Bisher sind circa 40 Verfahren bekannt, die eine Isolation und Charakterisierung der CTCs ermöglichen.

Die weitere molekularbiologische Analyse der CTCs im Anschluss an deren Isolation trägt so dazu bei, dass nicht nur eine quantitative Datenerhebung sondern auch eine qualitativer Art erfolgen kann. Im Rahmen dessen können das Verhalten des Tumors und vor allen Dingen der Metastasierungsprozess in Zukunft besser verstanden und im Umkehrschluss individuelle Therapieformen daraus abgeleitet werden.

Neben der Validierung der in der Arbeitsgruppe entwickelten Methode zur Detektion von CTCs bei Patienten mit HCC war Ziel der vorliegenden Untersuchung, diese weiter zu charakterisieren. Dabei sollte die Expression des zytoskelettalen Membranproteins Ezrin in den detektierten CTCs qualitativ nachgewiesen werden. Im Mittelpunkt der Untersuchung stand dabei die Lokalisation dieses Proteins.

Aktuelle Untersuchungen ${ }^{77}$ legen nahe, dass ein Zusammenhang zwischen der Polarisierung, d.h. der Verschiebung und Akkumulation des Ezrins zu einem Pol der Tumorzelle und dem Metastasierungspotential der CTCs besteht. Zwar gibt es Untersuchungen, die einen Zusammenhang zwischen der Expression von Ezrin und dem klinischen Verlauf des HCC darstellen konnten, jedoch beziehen sich diese Arbeiten größtenteils auf Gewebeuntersuchungen oder Gensequenzanalysen.

Im Rahmen dieser Promotionsarbeit konnte eine Methode etabliert werden, die nach Detektion der CTCs bei Patienten mit HCC einen Nachweis der Polarisierung dieser Zellen ermöglicht. Dies gelang sowohl in der Zelllinie als auch in 10 von 15 Patientenproben. Ein direkter statisti- 
scher Zusammenhang der Anzahl polarisierter CTCs mit Prognosefaktoren wie der Tumorgröße, dem Differenzierungsgrad des Tumors oder dem Tumormarker AFP konnte nicht bestätigt werden. Bestätigt werden konnte, dass die Polarisierung der CTCs spezifisch für Tumorerkrankungen ist. Offen bleibt, welchen Einfluss dies auf den Krankheitsverlauf oder die Prognose des Patienten hat.

\subsection{Begrenzungen der Methode}

Die Detektion der CTCs erfolgte aus dem venösem Vollblut von insgesamt 25 Patienten. Davon waren 10 Patienten an einer nicht-malignen Erkrankung der Leber (NMLD) erkrankt und bei 15 Patienten war die HCC-Erkrankung histopathologisch gesichert. Den Patienten wurden jeweils $5 \mathrm{ml}$ Blut entnommen, wobei die Probenentnahme entweder aus dem ZVK erfolgte oder peripher über einen Butterfly. In beiden Fällen erfolgte die Lagerung der Proben zunächst in EDTA-Röhrchen, in denen der Transport ins nahe gelegene Labor erfolgte.

Verschiedene Faktoren tragen dazu bei, dass die Anzahl der CTCs im peripheren Vollblut der Patienten relativ gering ist. Ein effektives Einschreiten des Immunsystems bei der Elimination der CTCs führt zu einer niedrigen Anzahl von CTCs. CTCs, die sich zunächst im geschützten Umfeld des Tumorgewebes befinden, ${ }^{79}$ werden nach Austritt in die Blutbahn einem normal funktionierenden Immunsystem ausgesetzt und durch natürliche Killerzellen zerstört. Auf diese Weise überleben nur wenige Tumorzellen.

Fidler konnte in einem Mausmodell nachweisen, dass weniger als 0,1 \% der injizierten Tumorzellen im Anschluss überhaupt überlebten und dazu in der Lage waren, Metastasen auszubilden. ${ }^{80}$ Basierend auf den Erkenntnissen von Wong et al. gingen die meisten CTCs bereits nach 1-2 Tagen zugrunde. Zurückzuführen ist dies auf die Apoptose der CTCs. ${ }^{81}$

Auch der mechanische Stress, dem die CTCs auf ihrem Weg durch das Gefäßsystem im Rahmen von Scherkräften an den Endothelwänden oder durch das Hängenbleiben in schmalen Kapillaren ausgesetzt sind, begünstigt den intravaskulären Untergang der CTCs. ${ }^{82}$ Eine Besonderheit bei der Isolation von Tumorzellen des HCC stellt dabei die Filterung des Blutes durch die Portalzirkulation der Leber dar, auf Grund dessen die Anzahl von CTCs sich weiter erniedrigt.

Durch die Probenentnahme aus dem ZVK, der in unmittelbarer Nähe zum rechten Herzen liegt, kann das Blut abgefangen werden, bevor es den Lungenkreislauf passiert.

Fraglich ist, ob die abgenommene Blutmenge von $5 \mathrm{ml}$ ausreichend ist. Die Menge des benötigten Blutes hängt dabei auch von der angewandten Analysemethode ab. So variieren Angaben in der Literatur zwischen 1-30 ml Blut. Dichtegradient-abhängige Verfahren wie das in der Studie angewandte Oncoquick ${ }^{\oplus}$-Verfahren fordern demnach ein Blutmenge von mind. 10-30 ml. ${ }^{83}$ In der hiesigen Untersuchung war eine höhere Blutentnahmemenge nach Ethikantrag nicht möglich. Die Patienten leiden auf Grund der Tumorerkrankung bereits an einer Anämie. 
Festzuhalten ist, dass die Anzahl der detektierbaren CTCs eine Frage des richtigen Zeitpunkts, des Orts und der Blutmenge ist.

Der Verlust weiterer CTCs ist im Verlauf der Probenbearbeitung unvermeidbar. Dabei stellen vor allem die Waschgänge im Rahmen der CTC-Isolation und die notwendige Erythrozytenlyse ein Problem dar. So wurde in der vorliegenden Arbeit darauf geachtet, eine Erythrozytenlyse schonend anzuwenden und nur in bestimmten vorgegeben Fällen zu verwenden.

Zur besseren Übersichtlichkeit im IF-Mikroskop wurde eine Lyse durchgeführt und dabei in Kauf genommen, dass CTCs zusätzlich zu Grunde gingen. ${ }^{84}$ In Folge der individuellen Abwägung, ob eine Lyse notwendig war oder nicht, variierte jedoch auch die Sensitivität der Untersuchung.

Ebenfalls an dieser Stelle zu diskutieren ist die angewendete Methode zur CTC-Isolation, das dichtegradienten-abhängige Verfahren Oncoquick ${ }^{\oplus}$. In diesem Verfahren werden die sich im Blut befindlichen Tumorzellen nach ihrer Größe und Dichte aufgetrennt, sodass die CTCs in einer bestimmten Phase, der Interphase, zu liegen kommen und für weitere Immunfluoreszenzuntersuchungen entnommen werden können.

Der Vorteil dieser Methode besteht in der einfachen Umsetzbarkeit und dem geringen Zeitaufwand für Wasch-und Isolationsschritte und der damit verbundenen schonenden Probenverarbeitung. Die Effektivität des Anreicherungsverfahrens wird in der Literatur mit einer Wiederfindungsrate in Spiking-Experimenten von 87 \% beschrieben. Rosenberg et al. untersuchte hier Blutproben von Patienten mit gastrointestinalen Tumoren. Darüber hinaus bestätigte diese Untersuchung, dass es mit diesem Verfahren möglich ist, die gleichzeitig stattfindende Anreicherung der Leukozyten signifikant zu reduzieren. ${ }^{85}$

Dem gegenüber steht das Cell Search Verfahren, welches momentan als "Goldstandard"von der FDA zur Detektion und Anreicherung von CTCs zugelassen ist. Die Arbeit von Balic et al. vergleicht die genannten Methoden und kommt zu dem Schluss, dass die Detektionsrate von CTCs im peripheren Blut von Patienten verschiedener Tumorentitäten stark abweichen ( $25 \%$ Oncoquick, $60 \%$ CellSearch). ${ }^{86}$ Dabei ist zu beachten, dass diese Untersuchungen nicht ausschließlich das Isolationsverfahren der CTCs berücksichtigen, sondern immer eine Kombination aus Isolations- und Anreicherungsverfahren darstellen. Eine reine Bewertung der Isolationsmethodik von CTCs ist daher schwer möglich.

Ein größere Bedeutung sollte daher dem Vergleich der Anreicherungsmethoden zukommen. Die CTCs weisen Geno-/Phänotypen unterschiedlichster Art auf und exprimieren in Abhängigkeit von ihrer Herkunft ein großes Spektrum verschiedener Antigene auf ihrer Zelloberfläche. Unabhängig von den Oberflächenantigenen galt es in der vorliegenden Untersuchung, das sich intrazellulär befindliche Protein Ezrin anzufärben. 
Das Cell-Search System stellt ein Epithelial Cell Adhesion Molecule (EpCAM)-basiertes Verfahren zur Detektion und Anreicherung von CTCs dar. EpCAM ist jedoch in CTCs von HCC Patienten nicht immer nachweisbar, da das HCC das niedrigste Expressionslevel an EpCAM im Vergleich $\mathrm{zu}$ anderen epithelialen Tumoren zeigt. ${ }^{87}$

Im Laufe der EMT verändern die CTCs die Eigenschaften ihrer Oberflächenmoleküle bis hin zu deren Verlust. ${ }^{52}$ Daher wurde in der vorliegenden Arbeit ein Antikörpergemisch aus CD146, CD45, DAPI und Anti-Ezrin-Alexa Fluor $488^{\circledR}$ genutzt, um die Sensitivitäts- bzw. Spezifitätsrate durch Doppelpositivität möglichst hoch zu halten. Hervorzuheben ist dabei der Nutzen von CD146, welches die Möglichkeit zu einem nicht EpCAM-basierten Anreicherungsverfahren bietet und so Subpopulationen der CTCs berücksichtigt, die mesenchymale Eigenschaften aufweisen. Ein weiterer Grund für die Verwendung von CD146 ist der in verschiedenen Arbeiten nachgewiesene Zusammenhang zwischen der Expression von CD146 und der daraus resultierenden höheren Sterblichkeitsraten bei Tumorpatienten. ${ }^{88-90}$

CTCs sind CD45-Negative, nicht hämatopoetische Zellen. Das Antigen CD45, welches auf der Oberfläche von Leukozyten exprimiert wird, wurde in der Untersuchung dazu genutzt, CTCs von Leukozyten differenzieren zu können und somit über Negativselektion eine CTC auf Grund ihrer CD146-Positivität und CD45-Negativität eindeutig als eine Tumorzelle identifizieren zu können. ${ }^{91,} 92$

Darüber hinaus wurde im Rahmen der Spiking-Experimente die Oberflächenfärbung der Leukozyten optimiert, indem die Reihenfolge, in der die Antikörper auf die Objektträger aufgebracht wurden, so geändert wurde, dass eine Färbung der Oberflächenantigene CD45 und CD146 vor dem Permeabilisierungsprozess erfolgte. Dadurch war es möglich, die Oberfläche der Leukozyten deutlich und scharf zu färben. Eine anschließende visuelle Unterscheidung zu den umliegenden CTCs war so vereinfacht und reduzierte das Risiko der Falsch-Positivität.

Zelllinien sind nur bedingt mit frischen, aus dem Blut von Patienten isolierten Tumorzellen zu vergleichen. Sie bieten den Vorteil homogener Oberflächenmarkerexpression und unterscheiden sich dadurch deutlich von den Leukozyten. Umgebungsbedingungen sowie Reaktionen der CTCs auf Angriffe des Immunsystems können die Expressiosnmuster der Oberflächenmarker verändern. Daher ist es möglich, dass die Validität einer Methode in vitro höher eingestuft wird. ${ }^{93}$ Neben der Unterscheidung der CTCs von ebenfalls in der Probe vorhandenen Leukozyten wird die visuelle Untersuchung unter dem IF-Mikrsokop zusätzlich durch die Bildung von Tumorzellverbänden (Zellcluster) erschwert. Die Zellcluster können als Ganzes aus dem Primärtumor herausgelöst werden oder sich im Laufe der Zeit im Blut aus einzelnen CTCs zusammensetzen. ${ }^{94}$ Dabei können diese Zellcluster bis zu 100 Tumorzellen pro Verband enthalten. ${ }^{95}$

Die CTCs neigen dazu gemeinsam mit den Leukozyten derartige Zellcluster auszubilden, um sich vor den Angriffen des Immunsystem zu schützen. Das führt dazu, dass eine Untersuchung der einzelnen CTCs in diesen Clustern auf bestimmte Merkmale hin wie z.B. deren Polarisierung 
praktisch nicht möglich ist. Bedauerlich ist dies vor dem Hintergrund, dass nach aktuellen Untersuchungen vor allem die Ausbildung von Zellclustern im Verdacht steht, das Risikopotential für die Metastasierung von Primärtumoren um ein 50-100 faches zu erhöhen. ${ }^{95,96}$

Eine Berücksichtigung dieser bestimmten CTCs war in der Untersuchung leider nicht möglich. Der Einsatz eines PCR-basierten Verfahrens könnte hier weitere Detektionsmöglichkeiten eröffnen. Eine unspezifische Bindung der genutzten Antikörper an die CTCs kann ebenfalls nie vollständig ausgeschlossen werden.

Zusammenfassend steht die Forschung und damit auch diese Untersuchung vor verschiedenen Herausforderungen bei der CTC-Isolation, Anreicherung und Detektion. Dazu kommt, dass die vorhandenen Untersuchungsverfahren validiert werden müssen und eine Reproduzierbarkeit der Ergebnisse nur bedingt möglich ist. Im Falle der vorliegenden Promotionsarbeit konnte auch nur eine indirekte Standardisierung erfolgen, indem die Auswertung aller Proben durch ein und denselben Untersucher erfolgte. Die Subjektivität des Untersuchers kann dabei nicht vernachlässigt werden.

\subsection{Diskussion der Ergebnisse}

Das Hauptziel der Promotionsarbeit war, das zytoskelletale Membranprotein Ezrin und dessen Lokalisation innerhalb der CTCs nachzuweisen. Wie bereits beschrieben war die Grundvoraussetzung dafür, die CTCs entsprechend $\mathrm{zu}$ isolieren und $\mathrm{zu}$ detektieren. Bisher fanden EzrinNachweise bei Tumorpatienten ausschließlich in Gewebeproben statt. Die ersten spezifischen Nachweise von Ezrin in CTCs gelangen Zhong et al. im Jahr 2017 bei Patienten, die an einem Osteosarkom erkrankt waren. Jedoch erfolgte der Nachweis in dieser Studie ausschließlich auf Gen-Ebene. ${ }^{78}$

Die Arbeitsgruppe um Lorentzen et al. berichtete 2018 das erste mal über den erfolgreichen Nachweis der Polarisierung des Ezrin in CTCs. Untersuchungen erfolgten im Zellmodell und in Blutproben von an Brustkrebs, Pankreaskrebs sowie an Lungenkrebs erkrankten Patienten. Zur Isolation der CTCs wurde das Cell-Search ${ }^{\circledR}$ System genutzt. ${ }^{77}$

Lorentzen et al. berichten ebenso wie in der vorliegenden Studie von auftretenden Zellclustern und darin enthaltenen polarisierten CTCs. Angelehnt an diese Untersuchung war es möglich, die polarisierende Eigenschaft von CTCs bei Patienten mit HCC erstmals erfolgreich nachzuweisen. ${ }^{77}$

Um Störvariable zu vermeiden und eine homogene Patientengruppe zu generieren, erfolgte der Einschluss der Patienten nach den in 2.1.2 aufgeführten strengen Kriterien. Folglich konnten nur 15 Patienten, die an HCC erkrankt waren und die Kriterien erfüllten, in die Studie aufgenommen werden. 
Der Ausschluss HBV-, HCV-und HIV-infizierter Probanden, auf Grund der Sicherheitsregulatorien im Labor, führte zusätzlich zu einer reduzierten Probandenanzahl. Deshalb ist bei der Betrachtung der Ergebnisse zu berücksichtigen, dass diese Hochrisikogruppe, die immerhin zu 90 \% ursächlich für die spätere Erkrankung an einem HCC ist, aus der Untersuchung ausgeschlossen werden musste. Weiterhin ist zu berücksichtigen, dass die ausgewählten Patienten sich bereits in einem fortgeschrittenen Stadium ihrer Erkrankung befanden und ein Selektionsbias nicht auszuschließen ist.

Eine statistische Signifikanz der Ergebnisse ist auf Grund der geringen Probandenzahl daher nicht eindeutig nachweisbar. Für eine erste vorläufige Bewertung und die Erfassung eines klinisch relevanten Unterschieds zwischen den beiden Gruppen (HCC vs. NMLD) sind die vorliegenden Daten jedoch ausreichend und können im Sinne einer Pilotstudie die Basis für weitere Untersuchungen der Arbeitsgruppe bilden.

Im Mittel wurden in der Untersuchung 2,1 polarisierte CTCs pro $5 \mathrm{ml}$ Blut nachgewiesen. In der Literatur liegen momentan ausschließlich Werte für CTCs als solche vor, ohne weitere Charakterisierung in Hinblick auf ihre Ezrin-Expression. Ou et al. beschreibt Detektionsraten von CTCs von ebenfalls 2 CTCs $/ 5 \mathrm{ml}$ Blut. ${ }^{97}$ Man hat sich zwar indirekt darauf geeinigt, die CTCZahl pro ml Blut anzugeben, in der Auswertung der verschiedenen Untersuchungen fehlt jedoch eine einheitliche Definition, wann eine Blutprobe als CTC-positiv zu werten ist.

Die Cut-off-Werte variieren bei Untersuchungen, die der hiesigen Studie in Isolations- und Detektionsmethode ähneln, zwischen 1 CTC/5 ml Blut bis zu 3,5 CTCs/5 ml Blut. ${ }^{98}$ Ein Vergleich dieser Zahlen mit den vorliegenden Ergebnissen ist auf Grund der vielen unterschiedlichen Analyseverfahren somit allenfalls mit Einschränkungen möglich.

Postuliert wird, dass eine erhöhte Anzahl an CTCs im Blut die Prognose eines Patienten verschlechtert und ein Therapieversagen vorhersagen kann. ${ }^{99}$ Eine Metaanalyse von Fan et al. bestätigt einen direkten Zusammenhang mit dem Vorhandensein von CTCs im Blut der HCCPatienten mit einer schlechteren Prognose, einem erhöhten Risiko an einem Rezidiv zu erkranken und dem Tod der Patienten. ${ }^{100}$ Dem gegenüber steht eine aktuelle Metaanalyse von Sun $e t$ al., die nach Einschluss von 20 Studien und damit 998 HCC-Patienten zu dem Schluss kommt, dass die rein nummerische Erhebung der CTCs keinen diagnostischen Vorteil bringt. ${ }^{98}$

Die Reduktion der Tumorgröße oder das gänzliche Vernichten des Tumors wird in der Krebstherapie momentan als das einzig wirksames Mittel gesehen, den Kampf gegen die Krankheit zu gewinnen. ${ }^{101} \mathrm{Zu}$ erwarten wäre daher, dass eine Vergrößerung des Tumors gleichzeitig mit einem Anstieg der CTCs einhergeht, und somit als abhängige Faktoren eine prognostische Aussagekraft über den weiteren Krankheitsverlauf des Patienten haben.

Die eigenen Daten sind mit den Ergebnissen von Oklu et al. aus dem Jahr 2018 vergleichbar. Er sieht keinen direkten Zusammenhang zwischen der Tumorgröße beim HCC und der Anzahl 
der CTCs. ${ }^{102}$ Ein Erklärungsansatz für dieses Phänomen wäre, dass der Eintritt der CTCs in die Blutzirkulation zu einem relativ frühen Zeitpunkt, nämlich zu Beginn der Tumorgenese, erfolgt.

Das Modell der Parallelen Progression beschreibt das gleichzeitige Fortschreiten des Tumorwachstums mit der Ausbildung von Metastasen. Demnach muss der Metastasierungsprozess der Tumorausbildung nicht zeitlich nachstehen. ${ }^{103}$ Der Aktivitätszustand kleinerer Tumore in Hinblick auf ihre Freisetzung von CTCs scheint höher zu sein. Kleinere Tumore könnten auf Grund ihrer überdurchschnittlich guten Durchblutung einen besseren Zugang zum vaskulären System besitzen und so die Freisetzung der CTCs erleichtern. An Hand der hier vorliegenden Daten scheint es ebenfalls so, dass ein früheres Tumorstadium, das mit einem kleineren Tumor gleichzusetzen ist, mit einer erhöhten Anzahl an polarisierten CTCs einhergeht.

In Abhängigkeit von ihrem histopathologischen Differenzierungsgrad zeigten die Patienten mit einem gering differenzierten (G3) Tumor eine prozentual höhere Anzahl polarisierter CTCs als die mittelgradig differenzierte (G2) Patientengruppe. In wie weit der zelluläre Differenzierungsgrad überhaupt eine prognostische, klinisch relevante Bedeutung zukommt, steht offen. Er sollte in erster Linie der Differentialdiagnostik dienen. ${ }^{104}$

Als ein weiteres diagnostisches Mittel wird der AFP-Wert herangezogen. Dieser stellt allerdings mit einer sehr geringen Sensitivität nur einen suboptimalen Biomarker für die Diagnostik des HCC dar. Die eigenen Daten bekräftigten jedoch das Vorliegen eines signifikanten Unterschiedes zwischen den Gruppen (HCC vs. NMLD). Ein Zusammenhang zwischen erhöhten Detektionsraten polarisierter CTCs und einem Anstieg der AFP-Werte konnte statistisch nicht bestätigt werden.

Schulze et al. stellten zwar eine Korrelation zwischen erhöhten AFP-Werten (>400ng/ml) und einer CTC-Positivität her, merkten jedoch an, dass einige Patienten der Studie trotz erhöhter CTC-Zahlen normale AFP-Werte aufzeigten. ${ }^{105}$ Die Frage nach der Sensitivität des AFP-Wert in der Tumordiagnostik stellt sich nach wie vor.

Es gilt weiterhin zwischen der diagnostischen und prognostischen Aussagekraft zu unterscheiden. Von größerer Bedeutung könnte die Qualität der p-CTCs sein.

Die Rolle des ERM-Proteins Ezrin in den detektierten CTCs steht in der vorliegenden Untersuchung im Mittelpunkt. Eine Überexpression an Ezrin wird mit verschiedene Tumorentitäten in Verbindung gebracht. ${ }^{76}$ Chen et al. konnten in einem Mausmodell feststellen, dass eine Phosphorylisierung von Ezrin an einem Thr567-Rest die Invasivität des HCC und seine Tendenz, Metastasen auszubilden, maßgeblich erhöhte. ${ }^{106}$

Eine aktuelle Metaanalyse von Liang et al. untersuchte den prognostischen Nutzen von Ezrin in gastrointestinalen und kolorektalen Karzinomen und kam zu dem Schluss, dass die Expression von Ezrin signifikant mit dem Tumorstadium und Lymphknotenstatus zusammenhängt. ${ }^{107}$ Die Studie von Yeh et al. mit 104 HCC-Patienten kam zu dem Ergebnis, dass eine Überexpression an 
Ezrin mit einer kleineren Tumorgröße, einer schlechteren Differenzierung und einer erhöhten vaskulären Invasion einhergeht. ${ }^{108}$ Die eigenen Daten stützen diese Ergebnisse.

Die genannten Untersuchungen beziehen sich wie bereits erwähnt ausschließlich auf Gewebeuntersuchungen. Die Anwendbarkeit dieser Erkenntnisse auf die Expression von Ezrin in CTCs, insbesondere dessen Lokalisation, lässt sich nur eingeschränkt übertragen. Lorentzen et al. konnte in Zellmigrationsassays nachweisen, dass ein Zusammenhang mit der Expression des ERMProteins Ezrin in den Zellen und deren Tendenz besteht, in fremdes Gewebe einzuwandern.

Beobachtet werden konnte ebenfalls, dass diese Zellen eine Polarität entwickelten, durch die es erst ermöglicht wurde, den Metastasierungsprozess zu durchlaufen. An welcher Stelle des Prozesses die Polarisierung der Zellen eine entscheidende Funktion einnimmt, konnte jedoch nicht abschließend geklärt werden. Fest steht, dass die Polarität der Zelle einen positiven Effekt auf das Adhäsionsverhalten hat und eine Anheftung der CTCs an das Endothel der Blutgefäße und folglich deren Transmigration erleichtert.

Die Befunde der vorliegenden Untersuchung stimmen mit der Erstbeschreibung von Lorentzen et al. größtenteils überein. So war es möglich, in den Blutproben von HCC-Patienten eine Polarisierung der CTCs nachzuweisen. Dies unterschied sich wesentlich vom Bild, dass die NMLDGruppe zeigte. Die Befunde weisen darauf hin, dass eine Polarisierung vor allem in Patienten mit einem aktiven Tumorgeschehen nachweisbar ist.

Die Verlust der Zell-Zell-Kontakte und die erhöhte Zellmotilität sind Schlüsselereignisse bei der Metastasierung. Ezrin reguliert diesen Prozess, indem es direkten Einfluss auf die Regulation der Zellform, das Adhäsionsverhalten und die Zellmotilität nimmt. Es beeinflusst also das sogenannte „actin cytoskeleton remodeling“ ${ }^{109}$ Auch Peng et al. beschreiben diesen durch Ezrin ausgelösten Umbauprozess im Mausmodell. ${ }^{110}$

Weiterführend zu untersuchen gilt es, welchen Einfluss die Polarisierung der CTCs auf den weiteren Krankheitsverlauf hat und in welcher Verbindung sie mit der Expression von Ezrin steht. Die Untersuchungen von Manneville et al. legen einen molekularen Zusammenhang zwischen der Zellpolarität und dem Migrationsverhalten nahe. Nach ihren Erkenntnissen basiert die stabile Verbindung benachbarter Zellen auf deren zunächst baso-apikaler Ausrichtung. Nach Verlust der Zell-Zell-Adhäsion kommt es automatisch zu einer Verschiebung der Zellpolarität. ${ }^{111}$

Meng et al. konnten in einer Pankreas-Tumorzellinie beobachten, dass die Überexpression an Ezrin die Zellmotilität beeinflusst und es zu Veränderungen im Zytoskelett („actin-cytoskeleton remodeling“) der Zellen kommt. Gleichzeitig folgte aus der Ezrin-Überexpression eine erhöhte Anzahl metastatischer Foci im Mausmodell. ${ }^{112}$

Die verschiedenen Untersuchungen führen, gestützt auf den neuesten Ergebnisse von Lorentzen et al., zu dem Schluss, dass die Lokalisation des Ezrin eine wichtigere Rolle spielt, als dessen Ex- 
pressionslevel. ${ }^{77}$ So hatte auch die in der vorliegenden Untersuchung vorgenommene Einstufung der Färbeintensität des Ezrin in den CTCs keine signifikante Aussagekraft.

Eine weitere Beobachtung konnte im Rahmen der vorliegenden Untersuchung gemacht werden. Die Zellpolarisierung ist nicht nur in der Ezrin-Färbung sichtbar zu machen, sondern parallel auch in der CD146-Färbung. Zunächst könnte eine unspezifische Antikörperbindung dafür verantwortlich gemacht werden. Jedoch konnten auch Luo et al. davon berichten, dass es ein Zusammenspiel der ERM-Proteine mit CD146 geben muss. Genauer vermuteten sie, dass die ERM-Proteine es im Sinne eines Adaptors ermöglichen, CD146 an die Aktinfilamentstruktur der Zelle zu binden und es so zu einer Anhebung des Zytoskeletts an dieser Stelle kommt. Diese Konformationsveränderung („,actin-cytoskeleton-remodeling“) befähigt die Zelle im Anschluss dazu sich fortzubewegen. ${ }^{113}$

Witze et al. konnten dieselbe Beobachtung machen und benennen diese als "CD146-ActinMyosin-Polarity Structure“. ${ }^{114}$ Es erscheint plausibel, dass ein Zusammenwirken aus ERMProteinen, zu denen auch das Ezrin gehört, und CD146 eine gerichtete Zellbewegung zur Folge hat, die den Metastasierungsprozess begünstigen kann.

Es stellt sich nach wie vor die Frage, welche prognostische Aussagekraft die Polarisierung der CTCs hat. Festzustellen ist, dass in der vorliegenden Untersuchung lediglich in der Gruppe der HCC-Patienten polarisierte CTCs detektiert werden konnten. Dagegen wurden in der NMLDGruppe keine polarisierten CTCs gefunden.

Im Gegensatz dazu konnten jedoch in 4 der 10 Patienten der NMLD-Gruppe nicht polarisierte, normale CTCs nachgewiesen werden. Bei diesen detektierten CTCs könnte es sich um zirkulierende epitheliale Zellen handeln, die sich in Folge eines physiologischen EMT-Prozesses im Blut befinden. Diese könnten auf Grund eines inflammatorischen Prozesses der Leber freigesetzt worden sein. Tatsächlich lagen die IL-6 Werte der NMLD-Gruppe im Mittelwert höher als die der HCC-Patienten. Das Ergebnis passt zu der Vermutung, dass die Polarisierung der CTCs einen direkten Zusammenhang mit der Aggressivität und dem Invasionsverhalten dieser Zellen hat und hochspezifisch für die Diagnostik des HCC ist.

Alles in allem kann man darauf schließen, dass die Ausbildung wie auch die Veränderung der Zellpolarität eine Auswirkung auf das Migrationsverhalten der CTCs haben muss. Die vorliegende Promotionsarbeit konnte diesen direkten Zusammenhang zwar nicht abschließend bestätigen. Jedoch war es möglich, die Polarisierung in den CTCs der HCC-Patienten eindeutig nachzuweisen. Dies kann die Grundlage für weitergehende klinische Untersuchungen bilden. Parallel dazu erscheint die weitere Forschung in Zelllinien für ein besseres Verständnis der Vorgänge unabdingbar. 


\subsection{Schlussfolgerungen und Perspektiven}

Diese Promotionsarbeit ist nur ein Schritt zur abschließenden Klärung, welchen Effekt die Polarisierung der CTCs auf den weiteren Krankheitsverlauf hat. Durch eine Verlängerung des Untersuchungszeitraums mit einer Nachbeobachtungszeit über mindestens 5 Jahre wäre es möglich, Zusammenhänge mit dem Voranschreiten der Krankheit aufzudecken.

Ebenfalls wäre es wünschenswert, das Studienkollektiv zu erweitern und dann auch HBV- und HCV-Patienten in die Untersuchung mit aufzunehmen. So wäre sichergestellt, dass die Studie einen Durchschnitt der Grundgesamtheit der HCC-Patienten darstellt und statistische Signifikanzen würden sich deutlicher abzeichnen. Wünschenswert wäre eine regional übergreifende Zusammenarbeit der Forschungszentren bei der Probensammlung, um die Ergebnisse im Rahmen einer Multicenterstudie zu erweitern.

Die „liquid biopsy“ bildet die Grundlage dieser Untersuchung und ist aktuell die große Hoffnung der Tumorforschung. Dabei spielt nicht nur die Isolation der CTCs eine Rolle, sondern im Mittelpunkt steht deren molekulare Charakterisierung. In der vorliegenden Arbeit konnten aus methodischen Gründen ausschließlich CTCs berücksichtigt werden, die eine intakte Zellform vorweisen konnten. Beobachtet werden konnte aber mindestens genau so häufig, dass die CTCs zu Zellfragmenten zerfallen waren und keinen Zellkern mehr besaßen.

Genau diese Zellfragmente, die in Folge apoptotischer Vorgänge im Blut zirkulieren, gilt es mittels geeigneter Methoden zusätzlich zu erfassen. Dafür stehen momentan drei Möglichkeiten zur Verfügung: Die Analyse der cell-free DNA (cfDNA), ${ }^{115}$ die Analyse exosomaler DNA ${ }^{116}$ sowie die Analyse der miRNA. ${ }^{117}$

Die Arbeitsgruppe fokussiert sich momentan auf die funktionelle Rolle der Exosomen. Bei der Vielzahl an vorhandenen Untersuchungsmethoden stellt sich nicht zuletzt die Frage nach der Effektivität.

Der Versuchsablauf der vorliegenden Promotionsarbeit nimmt nach Blutentnahme mehrere Tage in Anspruch und erfordert eine hochkonzentrierte Auswertung am Mikroskop. Eine solche Auswertung ist zwangsläufig abhängig vom Untersucher. Der Einsatz von Cell-ImagingSoftware könnte die Subjektivität des Verfahrens in Zukunft minimieren.

Dem gegenüber stehen die Vorteile der bereits angeführten Verfahren auf DNA-Basis, welche keine mühsamen Anreicherungs-und Identifizierungsverfahren benötigen, da eine Extraktion direkt aus Plasma oder Serum erfolgen kann. Jedoch wäre eine molekulare Charakterisierung bzw. der Ezrin-Nachweis bei dieser Methode ebenfalls nur auf Genebene möglich gewesen. Für die Verbesserung der hier beschriebenen Versuchsdurchführung sollte der Fokus daher auf die Optimierung der Isolationsmethoden gelegt werden, um möglichst viele CTCs zu erfassen. 
Auch wenn die Probengewinnung zunächst einfach erscheint und eine Durchführung der Analyse wiederholt werden kann, stellt die entnommene Blutprobe von $5 \mathrm{ml}$ nur einen minimalen Anteil des Gesamtblutvolumens dar. Vor diesem Hintergrund wäre es interessant, das gesamte Blutvolumen auf CTCs hin filtern zu können und diese im Anschluss auf ihre molekularen Eigenschaften hin untersuchen zu können. Ein geeignetes Verfahren hierfür würde eine Austauschtranfusion vorsehen. Dies scheint jedoch weder ethisch vertretbar noch durchführbar zu sein.

Galanzha et al. etablierten eine solche in vivo Methode und führte mittels Photoakustik eine Art Flow Cytometry intravasal durch. Jedoch stößt auch diese Methode bei der Untersuchung tiefer liegender Gefäße und auf Grund der vielen unterschiedlichen Bestandteile des Bluts an ihre Grenzen. ${ }^{118}$ Davon abgesehen ist eine Isolation der erfassten CTCs zur weiteren Untersuchung so nicht möglich.

Die klinische Signifikanz der Ezrin-Expression der CTCs und deren Auswirkung auf die Zellformation wird kontrovers diskutiert. Während Meng et al. in einer Pankreas-Zelllinie beobachten konnten, dass eine Überexpression an Ezrin zu einer erhöhten Zellbeweglichkeit führt, berichten Lin et al., dass niedrige Ezrin-Expressionsraten bei Patienten mit großen Tumoren und Lymphknotenmetastasen gemessen wurden. ${ }^{112,119}$

Weiterhin bestätigten Lin et al., dass die 5-Jahres Überlebensrate der Patienten mit einem niedrigen Ezrin-Expressionslevel signifikant niedriger lag und kamen zu dem Schluss, dass das Fehlen von Ezrin mit einer schlechten Prognose einhergeht. Zu diesem Schluss kamen auch Hiscox und Jiang bei Untersuchungen in Colon-Zelllinien. ${ }^{120}$ Es gilt also in zukünftigen Untersuchungen, einen Publikationsbias zu berücksichtigen und daran zu denken, dass die Ezrin-Expression nicht unweigerlich mit einem erhöhten Metastasierungspotential einhergeht.

Die klinische Relevanz der CTC-Forschung begründet sich vor allem in einem möglichen Nutzen für die personalisierte Therapie bestimmter Tumore in der Zukunft. Die aktuelle Tumortherapie konzentriert sich vornehmlich auf bestimmte mutierte Onkogene oder aber auf einzelne Signalwege, die eine Schlüsselrolle in der Onkogenese einnehmen.

Diese herkömmlichen Therapieansätze entziehen sich jedoch CTCs, indem sie genetische und epigenetische Veränderung in ihrer DNA vornehmen. Einzelne von den CTCs exprimierte Gene könnten so als ein weiteres Therapietarget dienen. Folglich könnte auch das gezielte Ausschalten des Ezrin-Gens in den CTCs eine Schlüsselrolle in der Tumortherapie einnehmen.

Die Untersuchung von He et al. bestätigt, dass eine Herabregulation von Ezrin in einer BrustkrebsZelllinie einen negativen Effekt auf die Expression von EMT-Markern und einzelnen Transkriptionsfaktoren zeigt. ${ }^{121}$ Da EMT-Marker wie CD44, welches direkt mit Ezrin interagiert, im Rahmen des EMT-Prozesses von großer Bedeutung für die Ausbildung von Metastasen und die Freisetzung von CTCs sind, könnte dies einen möglichen Angriffspunkt darstellen. So steht CD44 schon seit längerem als molekulares Target der Krebstherapie im Focus. ${ }^{122}$ 
Abschließend lässt sich zusammenfassen, dass in Zukunft genauere Analysemethoden für den Nachweis von Ezrin-Expression in CTCs benötigt werden. Die vorgelegte Arbeit bereitet dafür bereits den Weg und stellt eine Ergänzung zur etablierten Methode der „liquid biopsy“ dar. Weiterhin steht die Frage offen, welch ein Zusammenhang in der Polarisierung der CTCs, gekennzeichnet durch die Akkumulation des Ezrin an einem Pol der Zelle, zum klinischen Verlauf des HCC besteht.

In einem weiteren Schritt gilt es daher zu evaluieren, in wie Weit es möglich ist, diese Erkenntnisse dem klinischen Zwecke zu zuführen und dadurch der Ausbildung von Metastasen vorzubeugen. 


\section{Literaturverzeichnis}

1. American Cancer Society Cancer Facts and Statistics 2019 https://www.cancer.org/research/cancer-facts-statistics/global.html. Accessed March 11, 2020.

2. Bray F, Ferlay J, Soerjomataram I, Siegel R. L, Torre L. A, Jemal A. Global cancer statistics 2018: GLOBOCAN estimates of incidence and mortality worldwide for 36 cancers in 185 countries Cancer J Clin. 2018;68:394-424

3. Llovet J. M, Zucman-Rossi J, Pikarsky E, et al. Hepatocellular carcinoma Nat Rev Dis Primers. 2016;2(16018)

4. Barnes B, Kraywinkel K, Nowossadeck E, et al. Bericht zum Krebsgeschehen in Deutschland 20162016 https://edoc.rki.de/handle/176904/3264. Accessed March 11, 2020.

5. Hiddeman W B. C. Die Onkologie 2 ed. Berlin: Springer Medizin Verlag; 2010:973-981.

6. O'Shea R. S, Dasarathy S, McCullough A. J. Alcoholic liver disease Hepatology J. 2010;51:307-328

7. Chang M.-H, Chen C.-J, Lai M.-S, et al. Universal hepatitis B vaccination in Taiwan and the incidence of hepatocellular carcinoma in children N Engl J Med. 1997;336(26):1855-1859

8. Wong M. C, Jiang J. Y, Goggins W. B, et al. International incidence and mortality trends of liver cancer: a global profile Sci Rep. 2017;7(45846)

9. Mittal S, El-Serag H. B. Epidemiology of HCC: consider the population J Clin Gastroenterol. 2013;47:S2-6

10. Degos F, Christidis C, Ganne-Carrie N, et al. Hepatitis C virus related cirrhosis: time to occurrence of hepatocellular carcinoma and death Gut. 2000;47(1):131-136

11. Bruix J, Sherman M. Management of hepatocellular carcinoma: An update. Hepatology J. 2011;53:1020-1022

12. El-Serag H. B, Rudolph K. L. Hepatocellular carcinoma: epidemiology and molecular carcinogenesis Gastroenterology. 2007;132(7):2557-2576

13. Hassan M. Risk factors for hepatocellular carcinoma: Synergism of alcohol with viral hepatitis and diabetes mellitus Hepatology J. 2002;36(5):1206-1213 
14. Younossi Z. M, Koenig A. B, Abdelatif D, Fazel Y, Henry L, Wymer M. Global epidemiology of nonalcoholic fatty liver disease-Meta-analytic assessment of prevalence, incidence, and outcomes Hepatology J. 2016;64(1):73-84

15. Younossi Z, Anstee Q. M, Marietti M, et al. Global burden of NAFLD and NASH: trends, predictions, risk factors and prevention Nat Rev Gastro Hepat. 2017;15(1):11-20

16. Estes C, Razavi H, Loomba R, Younossi Z, Sanyal A. J. Modeling the epidemic of nonalcoholic fatty liver disease demonstrates an exponential increase in burden of disease Hepatology J. 2017;67(1):123-133

17. Younossi Z. M, Marchesini G, Pinto-Cortez H, Petta S. Epidemiology of Nonalcoholic Fatty Liver Disease and Nonalcoholic Steatohepatitis: Implications for Liver Transplantation. 2019;103(1):22-27

18. Williams C. D, Stengel J, Asike M. I, et al. Prevalence of Nonalcoholic Fatty Liver Disease and Nonalcoholic Steatohepatitis Among a Largely Middle-Aged Population Utilizing Ultrasound and Liver Biopsy: A Prospective Study Gastroenterology. 2011;140(1):124 - 131

19. Reeves H, Villa E, Bellentani S, et al. The Emerging Impact of the Hepatocellular Carcinoma arising on a background of NAFLD J Hepatol. 2012;56:S3

20. Toyoda H, Kumada T, Nakano S, et al. Impact of diabetes mellitus on the prognosis of patients with hepatocellular carcinoma Cancer. 2001;91:957-963

21. Shau W.-Y, Shao Y.-Y, Yeh Y.-C, et al. Diabetes Mellitus Is Associated with Increased Mortality in Patients Receiving Curative Therapy for Hepatocellular Carcinoma Oncologist. 2012;17(6):856-862

22. Schattenberg J, Nelles C, Wörns M, et al. Hepatozelluläres Karzinom (HCC) bei NASH Trend zur Metastasierung? Z Gastroenterol. 2012;50(01):P5-49

23. Kew M. C. Aflatoxins as a cause of hepatocellular carcinoma. J Gastrointestin Liver Dis. 2013;22(3):305-310

24. Bressac B, Kew M, Wands J, Ozturk M. Selective G to T mutations of p53 gene in hepatocellular carcinoma from southern Africa Nature. 1991;350(6317):429

25. Liu Y, Wu F. Global burden of aflatoxin-induced hepatocellular carcinoma: a risk assessment Environ Health Perspect. 2010;118(6):818-824

26. Groopman J. D, Kensler T. W, Wild C. P. Protective interventions to prevent aflatoxininduced carcinogenesis in developing countries Annu Rev Public Health. 2008;29:187-203

27. Bruix J, Bru C, Llovet J. M. Hepatocellular Carcinoma 5 ed. Elsevier; 2006:1109-1131. 
28. Llovet J. M, Bruix J. Novel advancements in the management of hepatocellular carcinoma in $2008 \mathrm{~J} \mathrm{Hepatol.} \mathrm{2008;48:S20-37}$

29. Burrel M, Llovet J. M, Ayuso C, et al. MRI angiography is superior to helical CT for detection of HCC prior to liver transplantation: an explant correlation Hepatology J. 2003;38(4):10341042

30. Greten T, Malek N, Schmidt S, et al. Diagnostik und Therapie des hepatozellulären Karzinoms Z Gastroenterol. 2013;51(11):1269-1326

31. Di Bisceglie A. M, Sterling R. K, Chung R. T, et al. Serum alpha-fetoprotein levels in patients with advanced hepatitis C: Results from the HALT-C Trial J Hepatol. 2005;43(3):434-441

32. Kobayashi M, Hosaka T, Ikeda K, et al. Highly sensitive AFP-L3\% assay is useful for predicting recurrence of hepatocellular carcinoma after curative treatment pre- and postoperatively Hepatology Res. 2011;41(11):1036-1045

33. Giannitrapani L, Cervello M, Soresi M, et al. Circulating IL-6 and sIL-6R in Patients with Hepatocellular Carcinoma Ann Ny Acad Scie. 2006;963(1):46-52

34. Elsharkawy A. M, Mann D. A. Nuclear factor- $\kappa \mathrm{B}$ and the hepatic inflammation-fibrosiscancer axis Hepatology J. 2007;46(2):590-597

35. Lu H, Ouyang W, Huang C. Inflammation, a Key Event in Cancer Development Mol Cancer Res. 2006;4(4):221-233

36. Shakiba E, Ramezani M, Sadeghi M. Evaluation of serum interleukin-6 levels in hepatocellular carcinoma patients: a systematic review and meta-analysis Clin Exp Hepatol. 2018;4(3):182-190

37. Wong V. W.-S, Yu J, Cheng A. S.-L, et al. High serum interleukin-6 level predicts future hepatocellular carcinoma development in patients with chronic hepatitis B Int J Cancer. 2009;124(12):2766-2770

38. James D.Brierley C. W. TNM-Classification of Malignant Tumors 8th Edition. WileyBlackwell; 2017:80-83.

39. Kolligs R.-T. o. d. W. M. B. C. J. H. K. J. T. F. L. R. T. C. Z. C. J. W. R. Diagnose und multimodale Therapie des hepatozellulären Karzinoms Z Gastroenterol. 2010;48(02):274-288

40. Edmondson H. A, Steiner P. E. Primary carcinoma of the liver. A study of 100 cases among 48,900 necropsies Cancer. 1954;7(3):462-503

41. Solaß W, Tannapfel A. Histopathologie und Leberbiopsie des hepatozellulären Karzinoms Visc Med. 2013;29(2):78-83 
42. N. Martins-Filho S, Paiva C, Azevedo R, Avancini Ferreira Alves V. Histological Grading of Hepatocellular Carcinoma-A Systematic Review of Literature Front Med. 2017;4:193

43. Greenburg G, Hay E. Cytodifferentiation and tissue phenotype change during transformation of embryonic lens epithelium to mesenchyme-like cells in vitro Dev Biol. 1986;115(2):363 - 379

44. Kalluri R, Neilson E. G. Epithelial-mesenchymal transition and its implications for fibrosis J Clin Invest. 2003;112(12):1776-1784

45. Olmeda D, Montes A, Moreno-Bueno G, Flores J. M, Portillo F, Cano A. Snai1 and Snai2 collaborate on tumor growth and metastasis properties of mouse skin carcinoma cell lines Oncogene. 2008;27:4690-4701

46. Nam E.-H, Lee Y, Zhao X.-F, Park Y.-K, Lee J. W, Kim S. ZEB2-Sp1 cooperation induces invasion by upregulating cadherin-11 and integrin a 5 expression Carcinogenesis. 2014;35(2):302-314

47. Pérez-Moreno M. A, Locascio A, Rodrigo I, et al. A new role for E12/E47 in the repression of E-cadherin expression and epithelial-mesenchymal transitions J Biol Chem. 2001;276(29):27424-27431

48. Peinado H, Olmeda D, Cano A. Snail, Zeb and bHLH factors in tumour progression: an alliance against the epithelial phenotype? Nat Rev Cancer. 2007;7:415-428

49. Yap A. S, Brieher W. M, Gumbiner B. M. Molecular and functional analysis of cadherinbased adherens junctions Annu Rev Cell Dev Biol. 1997;13(1):119-146

50. Imamura H, Matsuyama Y, Tanaka E, et al. Risk factors contributing to early and late phase intrahepatic recurrence of hepatocellular carcinoma after hepatectomy J Hepatol. 2003;38(2):200-207

51. Katyal S, Oliver J. H, Peterson M. S, Ferris J. V, Carr B. S, Baron R. L. Extrahepatic Metastases of Hepatocellular Carcinoma Radiology. 2000;216(3):698-703

52. Kalluri R, Weinberg R. A. The basics of epithelial-mesenchymal transition J Clin Invest. 2009;119(6):1420-1428

53. Camara O, Rengsberger M, Egbe A, et al. The relevance of circulating epithelial tumor cells (CETC) for therapy monitoring during neoadjuvant (primary systemic) chemotherapy in breast cancer Ann Oncol. 2007;18(9):1484-1492

54. Dhakal H. P, Naume B, Synnestvedt M, et al. Vascularization in primary breast carcinomas: its prognostic significance and relationship with tumor cell dissemination Clin Cancer Res. 2008;14(8):2341-2350 
55. Schlange T, Pantel K. Potential of circulating tumor cells as blood-based biomarkers in cancer liquid biopsy Pharmacogenomics J. 2016;17(3):183-186

56. Ashworth T. A case of cancer in which cells similar to those in the tumours were seen in the blood after death Aust Med Rec J. 1869;14:146

57. Salgado I, Hopkirk J. F, Long R. C, Ritchie A. C, Ritchie S, Webster D. R. Tumour cells in the blood Can Med Assoc J. 1959;81(8):619-622

58. Alexander R, Spriggs A. The differential diagnosis of tumour cells in circulating blood $J$ Clin Pathol. 1960;13(5):414-424

59. Racila E, Euhus D, Weiss A. J, et al. Detection and characterization of carcinoma cells in the blood Proc Natl Acad Sci USA. 1998;95(8):4589-4594

60. Alix-Panabières C, Pantel K. Circulating tumor cells: liquid biopsy of cancer Clin Chim Acta. 2013;59(1):110-118

61. Dawood S, Cristofanilli M. Using circulating tumor cells to guide therapy in breast cancer: could this replace biopsies? Pharmacogenomics J. 2015;16(7):669-672

62. Crowley E, Di Nicolantonio F, Loupakis F, Bardelli A. Liquid biopsy: monitoring cancergenetics in the blood Nat Rev Clin Oncol. 2013;10(8):472

63. Krebs M. G, Metcalf R. L, Carter L, Brady G, Blackhall F. H, Dive C. Molecular analysis of circulating tumour cells-biology and biomarkers Nat Rev Clin Oncol. 2014;11(3):129-144

64. Cohen S. J, Punt C, Iannotti N, et al. Relationship of circulating tumor cells to tumor response, progression-free survival, and overall survival in patients with metastatic colorectal cancer Clin Oncology. 2008;26(11):3213-3221

65. De Bono J. S, Scher H. I, Montgomery R. B, et al. Circulating tumor cells predict survival benefit from treatment in metastatic castration-resistant prostate cancer Clin Cancer Res. 2008;14(19):6302-6309

66. Ferreira M. M, Ramani V. C, Jeffrey S. S. Circulating tumor cell technologies Mol Oncol. 2016;10(3):374-394

67. Jung A, Kirchner T. Liquid Biopsy in der tumorgenetischen Diagnostik Dtsch Arztebl Int. 2018;115(10):169-174

68. Vaheri A, Carpen O, Heiska L, et al. The ezrin protein family: membrane-cytoskeleton interactions and disease associations Curr Opin Cell Biol. 1997;9(5):659-666

69. Martin T. A, Harrison G, Mansel R. E, Jiang W. G. The role of the CD44/ezrin complex in cancer metastasis Crit Rev Oncol Hemat. 2003;46(2):165-186 
70. Xu H, Tian Y, Yuan X, et al. The role of CD44 in epithelial-mesenchymal transition and cancer development Onco Targets Ther. 2015;8:3783-3792

71. Kang Y. K, Hong S. W, Lee H, Kim W. H. Prognostic implications of ezrin expression in human hepatocellular carcinoma Mol Carcinog. 2010;49(9):798-804

72. Elliott B. E, Meens J. A, SenGupta S. K, Louvard D, Arpin M. The membrane cytoskeletal crosslinker ezrin is required for metastasis of breast carcinoma cells Breast Cancer Res. 2005;7:R365-R373

73. Madan R, Brandwein-Gensler M, Schlecht N. F, et al. Differential tissue and subcellular expressionof ERM proteins in normal and malignant tissues: Cytoplasmic ezrin expression has prognostic signficance for head and neck squamous cell carcinoma Head Neck. 2006;28(11):1018-1027

74. Akisawa N, Nishimori I, Iwamura T, Onishi S, Hollingsworth M. A. High Levels of Ezrin Expressed by Human Pancreatic Adenocarcinoma Cell Lines with High Metastatic Potential Biochem Biophys Res Commun. 1999;258(2):395-400

75. Elzagheid A, Korkeila E, Bendardaf R, et al. Intense cytoplasmic ezrin immunoreactivity predicts poor survival in colorectal cancer Hum Pathol. 2008;39(12):1737-1743

76. Hunter K. W. Ezrin, a key component in tumor metastasis Trends Mol Med. 2004;10(5):201204

77. Lorentzen A, Becker P. F, Kosla J, et al. Single cell polarity in liquid phase facilitates tumour metastasis Nat Commun. 2018;9(887)

78. Zhong G. X, Feng S. D, Shen R, Wu Z. Y, Chen F, Zhu X. The clinical significance of the Ezrin gene and circulating tumor cells in osteosarcoma Oncotargets Ther. 2017;10:527-533

79. Munn D. H, Bronte V. Immune suppressive mechanisms in the tumor microenvironment Curr Opin Immunol. 2016;39:1-6

80. Fidler I. J. Metastasis: quantitative analysis of distribution and fate of tumor emboli labeled with 125I-5-iodo-2区-deoxyuridine J Natl Cancer Inst. 1970;45(4):773-782

81. Wong C. W, Lee A, Shientag L, et al. Apoptosis: An Early Event in Metastatic Inefficiency Cancer Res. 2001;61(1):333-338

82. Weiss L. Biomechanical interactions of cancer cells with the microvasculature during hematogenous metastasis Cancer Metastasis Rev. 1992;11(3-4):227-235

83. Kowalik A, Kowalewska M, Góźdź S. Current approaches for avoiding the limitations of circulating tumor cells detection methods-implications for diagnosis and treatment of patients with solid tumors Transl Res. 2017;185:58 - 84.e15 
84. Yang L, Lang J. C, Balasubramanian P, et al. Optimization of an enrichment process for circulating tumor cells from the blood of head and neck cancer patients through depletion of normal cells Biotechnol Bioeng. 2009;102(2):521-534

85. Rosenberg R, Gertler R, Friederichs J, et al. Comparison of two density gradient centrifugation systems for the enrichment of disseminated tumor cells in blood Cytom. 2002;49(4):150-158

86. Balic M, Dandachi N, Hofmann G, et al. Comparison of two methods for enumerating circulating tumor cells in carcinoma patients Cytometry B Clin Cytom. 2005;68(1):25-30

87. Barretina J, Caponigro G, Stransky N, et al. The Cancer Cell Line Encyclopedia enables predictive modelling of anticancer drug sensitivity Nature. 2012;492(290):603-607

88. Jiang G, Zhang L, Zhu Q, Bai D, Zhang C, Wang X. CD146 promotes metastasis and predicts poor prognosis of hepatocellular carcinoma J Exp Clin Cancer Res. 2016;35:38

89. Yang X, Zhang D, Chong T, Li Y, Wang Z, Zhang P. Expression of CK19, CD105 and CD146 are associated with early metastasis in patients with renal cell carcinoma Oncol Lett. 2018;15(4):4229-4234

90. Rapanotti M. C, Campione E, Spallone G, Orlandi A, Bernardini S, Bianchi L. Minimal residual disease in melanoma: circulating melanoma cells and predictive role of MCAM/MUC18/MelCAM/CD146 Cell Death Discov. 2017;3:17005-17005

91. Ning N, Zhan T, Zhang Y, et al. Improvement of specific detection of circulating tumor cells using combined CD45 staining and fluorescence in situ hybridization Clinica Chimica Acta. 2014;433:69 - 75

92. Liu H.-Y, Qian H.-H, Zhang X.-F, et al. Improved method increases sensitivity for circulating hepatocellular carcinoma cells World J of Gastroenterol. 2015;21(10):2918-2915

93. Yang M.-H, Imrali A, Heeschen C. Circulating cancer stem cells: the importance to select Chin J Cancer Res. 2015;27(5):437-449

94. Williams S. C. P. Circulating tumor cells Proc Natl Acad Sci USA. 2013;110(13):4861-4861

95. Yu M, Bardia A, Wittner B. S, et al. Circulating Breast Tumor Cells Exhibit Dynamic Changes in Epithelial and Mesenchymal Composition Science. 2013;339(6119):580-584

96. Aceto N, Bardia A, Miyamoto D. T, et al. Circulating tumor cell clusters are oligoclonal precursors of breast cancer metastasis Cell. 2014;158(5):1110-1122

97. Ou H, Huang Y, Xiang L, et al. Circulating Tumor Cell Phenotype Indicates Poor Survival and Recurrence After Surgery for Hepatocellular Carcinoma Dig Dis Sci. 2018;63(9):2373 
98. Sun C, Liao W, Deng Z, et al. The diagnostic value of assays for circulating tumor cells in hepatocellular carcinoma: A meta-analysis Medicine (Baltimore). 2017;96(29):e7513

99. Ye X, Li G, Han C, et al. Circulating tumor cells as a potential biomarker for postoperative clinical outcome in HBV-related hepatocellular carcinoma Cancer Manag Res. $2018 ; 10: 5639-5647$

100. Fan J. L, Yang Y. F, Yuan C. H, Chen H, Wang F. B. Circulating Tumor Cells for Predicting the Prognostic of Patients with Hepatocellular Carcinoma: A Meta Analysis Cell Physiol Biochem. 2015;37(2):629-640

101. Dai C.-Y, Lin C.-Y, Tsai P.-C, et al. Impact of tumor size on the prognosis of hepatocellular carcinoma in patients who underwent liver resection J Chin Med Assoc. 2018;81(2):155 163

102. Oklu R, Sheth R, Albadawi H, et al. Relationship between hepatocellular carcinoma circulating tumor cells and tumor volume Cancer Converg. 2018;2(1):2

103. Klein C. A. Parallel progression of primary tumours and metastases Nat Rev Cancer. 2009;9:302-312

104. Herfarth C, Schlag P. M. , eds.Neue Entwicklung in der Therapie von Lebertumoren. Berlin: Springer- Verlag; 1991:3-21.

105. Schulze K, Gasch C, Staufer K, et al. Presence of EpCAM-positive circulating tumor cells as biomarker for systemic disease strongly correlates to survival in patients with hepatocellular carcinoma Int J Cancer. 2013;133(9):2165-2171

106. Chen Y, Wang D, Guo Z, et al. Rho Kinase Phosphorylation Promotes Ezrin-Mediated Metastasis in Hepatocellular Carcinoma Cancer Res. 2011;71(5):1721-1729

107. Liang F, Wang Y, Shi L, Zhang J. Association of Ezrin expression with the progression and prognosis of gastrointestinal cancer: a meta-analysis Oncotarget. 2017;8(54):93186-93195

108. Yeh C.-N, Pang S.-T, Chen T.-W, Wu R.-C, Weng W.-H, Chen M.-F. Expression of ezrin is associated with invasion and dedifferentiation of hepatitis B related hepatocellular carcinoma BMC cancer. 2009;9:233

109. Saito S, Yamamoto H, Mukaisho K.-i, et al. Mechanisms underlying cancer progression caused by ezrin overexpression in tongue squamous cell carcinoma PloS one. 2013;8(1):e54881

110. Peng J.-M, Bera R, Chiou C.-Y, et al. Actin cytoskeleton remodeling drives epithelialmesenchymal transition for hepatoma invasion and metastasis in mice Hepatology J. 2018;67(6):2226-2243 
111. Etienne-Manneville S. Polarity proteins in migration and invasion Oncogene. 2008;27(55):6970-6980

112. Meng Y, Lu Z, Yu S, Zhang Q, Ma Y, Chen J. Ezrin promotes invasion and metastasis of pancreatic cancer cells J Transl Med. 2010;8:61

113. Luo Y, Zheng C, Zhang J, et al. Recognition of CD146 as an ERM-binding protein offers novel mechanisms for melanoma cell migration Oncogene. 2012;31(3):306

114. Witze E. S, Litman E. S, Argast G. M, Moon R. T, Ahn N. G. Wnt5a Control of Cell Polarity and Directional Movement by Polarized Redistribution of Adhesion Receptors Science. 2008;320(5874):365-369

115. Ulz P, Auer M, Heitzer E. Detection of Circulating Tumor DNA in the Blood of Cancer Patients: An Important Tool in Cancer Chemoprevention . In: Strano S. , ed.Cancer Chemoprevention: Methods and Protocols. New York, NY: Springer New York; 2016:45-68

116. Chen R, Xu X, Tao Y, Qian Z, Yu Y. Exosomes in hepatocellular carcinoma: a new horizon Cell Commun Signal. 2019;17(1):1

117. Izzotti A, Carozzo S, Pulliero A, Zhabayeva D, Ravetti J. L, Bersimbaev R. Extracellular MicroRNA in liquid biopsy: applicability in cancer diagnosis and prevention Am J Cancer Res. 2016;6(7):1461-1493

https://www.ncbi.nlm.nih.gov/pubmed/27508091. Accessed February 27, 2019.

118. Galanzha E. I, Viegas M. G, Malinsky T. I, et al. In vivo acoustic and photoacoustic focusing of circulating cells Sci Rep. 2016;6(21531)

119. Lin L. L. Association between ezrin protein expression and the prognosis of colorectal adenocarcinoma Mol Med Rep. 2013;8(1):61-66

120. Hiscox S, Jiang W. G. Ezrin regulates cell-cell and cell-matrix adhesion, a possible role with E-cadherin/beta-catenin J Cell Sci. 1999;112(18):3081-3090

121. He J, Ma G, Qian J, et al. Interaction Between Ezrin and Cortactin in Promoting Epithelial to Mesenchymal Transition in Breast Cancer Cells Med Sci Monit. 2017;23:1583-1596

122. Li L, Hao X, Qin J, et al. Antibody against CD44s inhibits pancreatic tumor initiation and postradiation recurrence in mice Gastroenterology. 2014;146(4):1108-1118 


\title{
Abkürzungsverzeichnis
}

\author{
AFB1 Aflatoxin B1 \\ AFP Alpha-Feto Protein \\ BCLC Barcelona-Clinic Liver Cancer Klassifikation \\ BMI Body Mass Index \\ BSA Bovines Serum Albumin \\ CD Cluster of differentiation \\ cfDNA cell-free DNA \\ CLIP Cancer of the Liver Italian Program \\ CT Computertomographie \\ CTC zirkulierende Tumorzelle \\ DAPI 4',6-Diamidin-2phenylindol
}

DM Typ 2 Diabetes Mellitus Typ 2

EASL European Association of the Study of the Liver

EDTA Ethylendiamintetraessigsäure

EMA European Medicines Agency

EMT Epitheliale mesenchymale Transition

EpCAM Epithelial Cell Adhesion Molecule

ERM Ezrin-Radixin-Moesin

FACS Fluorescence-activated cell sorting

FCS fetal calf serum

FDA US Food and Drug Administration

FITC Fluoreszeinisothiocyanat 
HBV Hepatitis B Virus

HCC Hepatozelluläres Karzinom

HCV Hepatitis C Virus

HIV Humane Immundefizienz Virus

IL-6 Interleukin-6

INR International Normalized Ratio

LTX Lebertransplantation

MACS Magnetic-activated cell sorting

MCAM Melanoma cell adhesion molecule

MET Mesenchymale-Epitheliale-Transition

MRT Magnetresonanztomographie

MWA Mikrowellen-Ablation

NAFLD Nichtalkoholische Fettlebererkrankung

NASH Nichtalkoholische Steatohepatitis

NMLD Non malignant liver disease

PBS Phosphate Buffered Saline

PCR Polymerase chain reaction

PIP2 Phosphatidylinositol-4,5-bisphosphat

RT-PCR Reverse transcriptase polymerase chain reaction

Stabw. Standardabweichung

TACE Transarterielle Chemo-Embolisation

WHO World Health Organization 


\section{Danksagung}

An erster Stelle gilt mein Dank meinem Doktorvater Prof. Dr. W.O. Bechstein, Direktor der Klinik für Allgemein- und Viszeralchirurgie der Uniklinik Frankfurt. Durch die Überlassung des Themas war es mir möglich, einen Einblick in die klinisch-experimentelle Arbeitsweise zu bekommen.

Für die inhaltliche Ausrichtung sowie die thematische Eingrenzung sei Dr. Mazen Juratli gedankt. Er hat durch sein großes persönliches Engagement zum Gelingen und erfolgreichen Abschluss dieser Arbeit beigetragen. Ich bin ihm für die fachliche Unterstützung während der gesamten Bearbeitungsphase meiner Dissertation sehr dankbar.

Besonderer Dank geht an dieser Stelle auch an Frau Elsie Oppermann (Bsc), die mich an manchen Tagen davor bewahrt hat, das Mikroskop in die Luft zu sprengen. Ohne ihre geduldige und professionelle Einführung in die verschiedensten Labormethodiken wäre eine Dissertation in dieser Arbeitsgruppe nicht möglich gewesen. Danke Elsie!

Danken möchte ich außerdem meinen Laborgirls: Joséphine Fetzner, Larissa Laufer, Linda Riegelbauer, Scarlett Bather, Natascha Kohl, Roxana Zokai sowie Lena Fleckenstein. Die Stimmung im Labor habt ihr an so einigen Tagen gerettet. Vor allem bedanken möchte ich mich bei Larissa und Josi für die tatkräftige Unterstützung bei der Sammlung der Proben.

Zuletzt möchte ich auch meinen Eltern Bärbel Friedrich und Prof. Dr. Jörg Friedrich PhD (Purdue University) und meinen Geschwistern Kathrin Friedrich und Christoph Friedrich für die liebevolle uneingeschränkte und vielseitige Unterstützung danken. Ihr habt zu einem nicht unwesentlichen Teil zum erfolgreichen Abschluss meines Studiums und damit auch dieser Arbeit beigetragen.

Großer Dank geht auch an meinen Verlobten Dr. jur. Artur Swierczok LLM (UCL), MSt. (Oxford). Ohne seine unerlässliche Motivation, sein Verständnis und seinen Beistand wäre es nicht möglich gewesen, diese Dissertation zu einem Abschluss zu bringen. 


\section{Schriftliche Erklärung}

Ich erkläre ehrenwörtlich, dass ich die dem Fachbereich Medizin der Johann Wolfgang GoetheUniversität Frankfurt am Main zur Promotionsprüfung eingereichte Dissertation mit dem Titel „Ex-vivo Nachweis der Polarität zirkulierender Tumorzellen bei Patienten mit Hepatozellulärem Karzinom“

im Zentrum der Chirurgie, Institut für Allgemein-und Viszeralchirurgie unter Betreuung und Anleitung von Prof. Dr. med. W.O. Bechstein mit Unterstützung durch Dr. Mazen Juratli ohne sonstige Hilfe selbst durchgeführt und bei der Abfassung der Arbeit keine anderen als die in der Dissertation angeführten Hilfsmittel benutzt habe. Darüber hinaus versichere ich, nicht die Hilfe einer kommerziellen Promotionsvermittlung in Anspruch genommen zu haben.

Ich habe bisher an keiner in- oder ausländischen Universität ein Gesuch um Zulassung zur Promotion eingereicht. Die vorliegende Arbeit wurde bisher nicht als Dissertation eingereicht. 


\section{Lebenslauf}

\section{Persönliche Daten}

Name:

Babette Margarete Friedrich

Geburtsdatum:

11.5.1993

Geburtsort:

Schorndorf

Staatsangehörigkeit:

deutsch

\section{Bildungsweg}

$06 / 2018-01 / 2019$

Promotion an der Klinik für Allgemein-und Viszeralchirur-

gie Universitätsklinikum Frankfurt a.M

$06 / 2018$

Approbation zur Zahnärztin

Frankfurt a.M.

$10 / 2012-06 / 2018$

Studium der Zahnmedizin

J.W.G.-Universität, Frankfurt a.M.

$09 / 2015$

Zahnärztliche Vorprüfung

J.W.G.-Universität, Frankfurt a.M.

$09 / 2013$

Naturwissenschaftliche Vorprüfung,

J.W.G.-Universität, Frankfurt a.M.

$07 / 2012$

Abitur, Salier-Gymnasium, Waiblingen

07/2009-03/2010

Auslandssemester, High-School Aufenthalt

Lafayette, IN (USA)

\section{Beruflicher Werdegang und Erfahrungen}

10/2019- Heute

03/2019-10/2019

$02 / 2016-07 / 2018$

$12 / 2016-10 / 2017$
Vorbereitungsassistentin

Gabriele Bernhard \&Kollegen, Weiterstadt

Vorbereitungsassistentin

Dr. Anke Dittrich \& Kollegen, Frankfurt a.M.

Assistenz im zahnärztlichen Notdienst

AllDent Zahnzentrum, Frankfurt a.M.

Studentische Hilfskraft im Notdienst

Carolinum, Frankfurt a.M. 
05/2015-07/2015

07/2014-09/2014

$12 / 2013$

07/2012-09/2012

\section{Sprachen}

Englisch

Französisch

Spanisch
Hilfswissenschaftliche Mitarbeiterin

Institut für Biochemie

J.W.G.-Universität, Frankfurt a.M.

Pflegehilfe in der Gerontopsychatrie

Krankenhaus Stuttgart Bad-Cannstatt

Hilfswissenschaftliche Mitarbeiterin

Anatomisches Institut

J.W.G.-Universität, Frankfurt a.M.

Krankenpflegepraktikum

Katharinenhospital, Stuttgart

Fließend in Wort und Schrift

Gute Kenntnisse in Wort und Schrift

Grundkenntnisse 